\title{
4 Die Materialität spätantiker Inschriften zwischen Tradition und Innovation
}

\subsection{Was ist ,Materialität' und wozu nach ihr fragen?}

Der Begriff bzw. das Konzept der ,Materialität‘ ist untrennbar verbunden mit den Begriffen der ,Materie‘ und des ,Materials‘. Er setzt diese gleichermaßen als definitorische Parameter voraus, ist in seinem Sinngehalt aber wesentlich komplexer und beziehungsreicher. Mit dem Lateinischen materia oder materies wurde grundsätzlich der Stoff bezeichnet, aus welchem etwas hervorgeht, verfertigt oder unterhalten wird. Im Besonderen meinte es das Holz seiner Nutzbarkeit nach, entsprechend dem griechischen Äquivalent $\check{\nu} \lambda \eta$ mit der Bedeutung von Nutz- oder Bauholz, das in der Metaphysik des Aristoteles den formbaren Stoff bezeichnete und dort im Gegensatz zur Form, dem $\varepsilon \tilde{\varepsilon} \delta o \varsigma$, stand. ${ }^{332}$ So zeigen bereits die etymologischen Bedeutungen, dass den Begriffen $\check{\nu} \lambda \eta$ und materia immer schon eine Zweckmäßigkeit innewohnte, und dass man sich darunter einen bestimmten Stoff im Hinblick auf seine Nützlichkeit und den Gebrauch durch den Menschen vorstellte. Auch unser heutiges ,Material bezeichnet in diesem Sinne eine Substanz, welche zur Schaffung oder Herstellung eines Artefakts erforderlich ist, sei es ein natürlich vorkommender Stoff in unverarbeitetem Zustand, wie Stein oder Holz, oder ein schon verarbeiteter, verbundener oder vermischter Stoff, etwa Bronze, Wachs oder Ton.

Wenn wir von einem Material reden, beziehen wir uns zumeist auf seine physische und chemische Beschaffenheit, auf seine sinnlich wahrnehmbaren Eigenschaften, wie beispielsweise Farbe, Konsistenz, Oberflächenstruktur, Haptik oder Geruch. Das Material Marmor ließe sich in diesem Sinne etwa in seiner optischen Erscheinung als weißlich und grau oder blau geädert, in seiner Ausformung als hart und massiv und auf seiner bearbeiteten Oberfläche als glatt und kühl beschreiben. Wachs hingegen ist zumeist farblich nahezu durchscheinend oder opak, kann sowohl von flüssiger, knetbarer oder fester Konsistenz sein, fühlt sich je nachdem kristallin oder fest, warm oder kalt an und kann in seiner Form vielfach und immer wieder verändert werden. Sprechen wir hingegen von ,Materialität‘, so meist nicht im Zusammenhang mit einem Roh- oder Werkstoff, sondern mit einem Artefakt, also von einem durch den Menschen absichtsvoll erschaffenen Objekt. Wir beschreiben nicht seine natürlichen und wesenseigenen Merkmale, sondern richten den Blick gezielt auf seine spezifische Bearbeitung, Ausformung und Gestaltung durch die menschliche Hand - und dies im Hinblick auf die ihm angedachte Funktion, Verwendung und Bedeutung. Wir interessieren uns also für jene Merkmale und beobachtbaren Eigenschaften des Artefakts, aus deren genauerer Untersuchung wir Rückschlüsse auf seine Wirkung und Bedeu-

332 OLD 1083 s. v. materia; LSJ 1847f. s. v. Ü $\eta$.

Ә Open Access. () 2019 Katharina Bolle, publiziert von De Gruyter. (c) BY-NC-ND Dieses Werk ist lizenziert unter der Creative Commons Attribution-NonCommercial-NoDerivatives 4.0 Lizenz. 
tung sowie mögliche Handlungszusammenhänge ziehen können. Fragen wir also nicht nur nach den materiellen, sondern auch nach den materialen Charakteristika eines Artefakts - in unserem Fall ganz konkret: eines mit einer Inschrift versehenen Artefakts - so tun wir dies, um einerseits die Wechselwirkungen zwischen formhaftem Gegenstand und textlichem Inhalt, andererseits das reziproke Verhältnis zwischen Objekt und seinem Urheber oder Rezipienten besser zu verstehen. Inwiefern, so die eine zentrale Frage, beeinflussen die materiale Beschaffenheit eines Textträgers und die spezifische Ausgestaltung der darauf angebrachten Schrift die inhaltliche Aussage des Texts? Und in welcher Hinsicht, so die andere grundlegende Frage, bestimmt die spezifische Materialität eines inschriftlichen Denkmals dessen zugedachte Botschaft und die Rezeption durch den menschlichen Betrachter?

In der Tat spielte die Wahl eines bestimmten Materials und dessen absichtsvolle Bearbeitung zu einem Artefakt eine entscheidende Rolle für dessen Wirkkraft. Die verschiedenen in der Antike zur Verfügung stehenden Materialien hatten je nach Verwendungszweck Vor- und Nachteile, und nicht jeder Stoff eignete sich gleichermaßen für die Ausführung eines bestimmten Monuments oder Denkmals - und dies nicht nur aus rein technischen und handwerklichen Gründen, sondern auch aufgrund ideeller Normvorstellungen und Assoziationen, nach welchen einzelne Materialien bestimmte Wertigkeiten besaßen, die sich nur bedingt von ihren physischen und chemischen Eigenheiten als viel eher von kulturellen Bedeutungszuschreibungen ableiteten. Wie stark dies der Fall war, lehrt ein Blick in die antiken Schriftquellen, in denen der materielle und ideelle Wert verschiedener Roh- und Werkstoffe zum Thema gemacht wird. Vor allem Metalle wurden immer wieder als Vergleichsgegenstand herangezogen, insbesondere dann, wenn von den verschiedenen Weltaltern die Rede war und diese in eine hierarchische Rangfolge eingeordnet wurden. So ist bereits in Hesiods Érga kai hemérai von einem goldenen Zeitalter des Glücks und Reichtums zu lesen, von einem silbernen der Unvernunft und Maßlosigkeit, von einem ehernen der Gewalt und Grausamkeit und von einem eisernen des Dunkels und des Tods. ${ }^{333}$ Ähnliche Schilderungen, wonach Gold besser als Silber, Silber besser als Erz und Erz besser als Eisen sei, finden sich ebenso in den Phainómena des Aratos von Soloi ${ }^{334}$ sowie in Ovids Metamorphosen. ${ }^{335}$ Und auch in der Bibel begegnen bestimmte Materialen als Sinnbilder, etwa wenn der Prophet Daniel das Traumbild des babylonischen Königs Nebukadnezar als Verkörperung der vier aufeinander folgenden Weltreiche deutet, angefangen vom golden glänzenden über das silberne und kupferne bis hin zum harten eisernen, das alles zerschlägt und zermalmt, und dem brüchigen tönernen, das auf schwachen Füßen steht. ${ }^{336}$

333 Hesiod, erga 106-155. Die verschiedenen Wertigkeiten von Metall bei Herodot hat untersucht Kurke 1995.

334 Arat. 105-136 (ed. Erren 2009).

335 Ov. met. I 89-151.

336 Dan 2,31. 
Dass Materialien auch in direkte Rivalität miteinander treten konnten und nicht überall die gleiche Wertschätzung genossen, zeigt die Gegenüberstellung der beiden Werkstoffe Marmor und Ton. Bekanntermaßen soll sich Kaiser Augustus gerühmt haben, Rom einst in Ziegeln vorgefunden, aber in Marmor hinterlassen zu haben. ${ }^{337}$ Der weiß glänzende Stein galt als Sinnbild des unter Augustus waltenden Wohlstands und der Prosperität und war Ausdruck der Würde und Reinheit seiner Herrschaft. Plinius wiederum mochte solcherlei Gebaren als „Marmorluxus“ verurteilt haben. Er schätzte hingegen den Ton als Werkstoff für die Herstellung öffentlicher Denkmäler und Bildwerke, da solcherlei doch den Glanz der Altehrwürdigkeit und tugendhafter virtus in sich trügen. Es seien nämlich die Standbilder und Giebelfiguren aus Ton, so Plinius, „die bewundernswert sind durch die erhabene Arbeit und Kunst und durch ihre Dauerhaftigkeit, heiliger als Gold, sicherlich unschuldiger“. ${ }^{338}$ Für den ideellen Wert der Denkmäler war der rein materielle Wert, das heißt der Kostenwert des verarbeiteten Materials, also vollkommen ohne Belang. Was den Ton aus der einen Perspektive in den Schatten des Marmors stellte - der vergleichsweise geringe Anschaffungspreis, das häufige Vorkommen, die einfache Bearbeitung, das schlichte Erscheinungsbild, ein Empfinden von Gestrigkeit - gereichte ihm von einem anderen Standpunkt aus betrachtet zum Vorteil: Zwar mochte er weniger teuer und luxuriös sein und dem aktuellen Zeitgeschmack nicht mehr entsprechen, doch war er Plinius gerade deswegen so wertvoll und galt ihm gleichsam als historische Metapher für eine Zeit vorbildhafter Bescheidenheit im Sinne altrömischer Tugendvorstellungen. ${ }^{339}$

Wenn es wie hier um das Spannungsverhältnis zwischen dem realen wirtschaftlichen Wert eines Materials, der künstlerischen Qualität eines Artefakts und der abstrakten Bedeutsamkeit eines Kunstwerks geht, so erweist sich auch die Lektüre Lukians und seines Jupiter tragoedus als aufschlussreich, eines satirischen Werks über eine von Zeus einberufene Versammlung, zu der neben den Göttern auch die berühmtesten von Menschen geschaffenen Bildwerke geladen sind. Als Hermes vom Göttervater aufgefordert wird, den ankommenden Standbildern den ihnen gebührenden Rang zuzuweisen, kommt er in Verlegenheit. Einerseits soll er das Material berücksichtigen und goldene Werke vor silberne und elfenbeinerne, und diese wiederum vor solche aus Bronze und Marmor reihen, andererseits muss er aber auch der ästhetischen Ausführung und dem Prestige des Künstlers Rechnung tragen, und zwar ungeachtet des verwendeten Metalls oder Gesteins. Und so klagt Hermes: „Es soll geschehen; sie werden

337 Suet. vita Augusti 28.

338 Plin. nat. 35, 158. Ähnlich: 36, 6, wo sich Plinius darüber empört, dass Unmengen an Marmor in die privaten Häuser reicher Römer geschleppt würden, und zwar „,vorbei an den tönernen Giebeln der Göttertempel!“. An anderer Stelle verweist er auf den höheren Wert des Wachses gegenüber Bronze für die Anfertigung von Ahnenbildern: 35, 6. Auch hier werden wieder die altrömischen Tugenden der Schlichtheit und Bescheidenheit dem zeittypischen Laster der luxuria gegenübergestellt.

339 Die übermäßige Verwendung von Marmor in privaten Wohnhäusern kritisierte auch Juvenal und warf den Eigentümern, zumeist Angehörige der reichen Oberschicht Roms, hemmungslose Verschwendungssucht vor: Iuv. 14, 86-95 (ed. Adamietz 1993). 
den ihnen gebührenden Platz erhalten. Aber über eins bin ich mir nicht recht klar: Wenn einer von ihnen aus Gold und viele Talente schwer, aber nicht sorgfältig gearbeitet ist, sondern nur ganz roh und unförmig, soll der vor den Ehernen des Myron, Polykleitos und Pheidias und vor den Marmornen des Alkamenes sitzen dürfen, oder hat die Kunst größeren Anspruch auf Ehrung?“340

Wie im Fall der figürlichen Bildwerke bei Plinius und Lukian waren auch die Wirkung und die Bedeutung eines inschriftlichen Monuments durch die natürlichen Eigenschaften des verwendeten Materials, den diesem zugeschriebenen realen und ideellen Werten und die spezifische Ausgestaltung seiner äußeren Form bestimmt. Dass für manche Typen von Inschriften oder einzelne Genres beinahe ausschließlich bestimmte Materialien Verwendung fanden, verwundert daher nicht. Ob man sich für ein gewisses Gestein oder ein Metall, für Ton oder Holz entschied und wie man die Inschrift darauf gestaltete, war ferner davon abhängig, welche Funktion das Objekt erfüllen, wie es der Betrachter wahrnehmen und welche Rolle es als Medium der Kommunikation und Kommemoration spielen sollte.

Diese unabdingbare Konvergenz von Form, Inhalt und Botschaft wird mit einem Blick auf konkrete Beispiele aus der antiken Welt deutlich. Für die Niederschrift orphischer Gebete etwa, die man den Verstorbenen mit auf ihre Reise in die Totenwelt gab, verwendete man vornehmlich kleine Goldtäfelchen. Das kostbare Metall unterstrich einerseits den hohen sakralen Wert der Worte und garantierte dem Toten in seiner Eigenschaft als Zahlungsmittel andererseits Einlass ins Jenseits. ${ }^{341}$ In ähnlicher Weise - allerdings mit gegensätzlicher Konnotation - funktionierten auch die defixiones, kleine Täfelchen mit darauf eingeschriebenen Verfluchungen und üblen Wünschen, mit denen man Unheil auf ungeliebte Zeitgenossen herab zu wünschen suchte. Diese waren ihrerseits zumeist aus Blei gefertigt, das vergleichsweise billig zu haben war, sich leicht verarbeiten und beschreiben ließ und aufgrund seiner Beständigkeit eine lange Lebensdauer versprach. Außerdem weckte es angesichts seiner schwarzen Färbung und der kühlen Oberfläche negative Assoziationen und wurde mit Dunkelheit, Kälte und Übel verbunden. ${ }^{342}$ Für die Bekanntmachung und Dokumentation offizieller Dekrete wiederum wählte man im griechischen Raum seit klassischer Zeit Stelen aus massivem Stein und untermauerte damit die unumstößliche und fortwährende Geltung der Beschlüsse für die Gemeinschaft. ${ }^{343}$ Noch stärker autoritativen Charakter hatten die öffentlich errichteten Bronzetafeln der Römer, auf welche bis in die Spätantike hinein Beschlüsse, Staatsverträge und wichtige Bekanntmachungen eingraviert wurden. ${ }^{344}$ Die golden glänzende Bronze wurde nicht nur aufgrund ihres

340 Lukian. Jup. trag., Übersetzung nach H. Gasse (Hg.), Lukian. Vergnügliche Gespräche und burleske Szenen, Sammlung Dietrich Bd. 219, Leipzig 1985, 305.

341 Bernabé Pajares/Jiménez San Cristóbal 2008; Edmonds 2011.

342 Gager 1992; Versnel 1999.

343 Thomas 1989; Sickinger 1999; Osborne 2012.

344 Williamson 1987; Corbier 2006, 62-64. 
vergleichsweise hohen Preises und ihrer optischen Wirkmacht als ein angemessenes Material für die Dokumentation offizieller Beschlüsse und Verfügungen seitens des Staats oder des Kaisers als angemessen empfunden. Die Römer sagten dem korrosionsfreiem Metall auch ewige Existenz nach und schätzten es in dieser Hinsicht noch mehr als Stein, weshalb Plinius die „beständige Dauer“ eherner Denkmäler und bronzener Inschriftentafeln pries. ${ }^{345}$

\subsection{Materialien und Techniken}

Über das für inschriftliche Monumente verwendete Material zu sprechen ist (nicht nur im Fall der Spätantike) nicht unproblematisch, da wir mit den erhaltenen Zeugnissen nur einen kleinen Ausschnitt, nicht aber das Gesamtbild der tatsächlichen Wirklichkeit zu fassen bekommen. Während langlebige Materialen wie Stein die Jahrhunderte fast unversehrt überdauert können, sind empfindlichere Beschreibstoffe wie Metall, Holz, Ton, Wachs, Papyrus und Textilien in weiten Teilen verloren, entweder aufgrund natürlichen Verfalls oder weil die Objekte für die Gewinnung von Rohstoffen zerstört wurden. Wie groß der Anteil solcherlei Inschriften aus kurzlebigen Materialen tatsächlich gewesen ist, lässt sich nur schwer abschätzen, zumal auch aus literarischen Quellen hierzu kaum belastbare Erkenntnisse zu gewinnen sind - eine forschungspraktische Aporie, aus der sich wohl kaum ein Ausweg finden lässt, der wir uns aber gerade deshalb bewusst sein müssen. Obgleich es also kaum möglich sein wird, die Materialität spätantiker Inschriftlichkeit in ihrem Gesamtbild nachzuzeichnen, lassen sich durchaus Tendenzen beschreiben und Entwicklungslinien nachvollziehen, die für das Wesen der Inschriftenkultur jener Zeit relevant und prägend gewesen sind. So zeigt sich beim Blick auf die erhaltenen Zeugnisse, dass einige Materialien und Techniken der Inschriftenkunst in der Spätantike immer seltener zum Einsatz kamen, andere nach wie vor und in großem Stil genutzt wurden und wiederum andere, die zuvor kaum eine Rolle für öffentlich dargebrachte Inschriftenmonumente spielten, zunehmend an Bedeutung gewannen.

Den weitaus größten Anteil spätantiker Inschriften des italischen Raums repräsentieren jene aus Stein, darunter vornehmlich lokal vorkommende Sorten wie der recht poröse, helle Travertin (lapis tiburtinus), der vulkanische Tuffstein (lapis tophaceus) oder der weiße lunensische Carrara-Marmor (marmor lunense), seltener auch importierte Ware aus Griechenland (hymettischer oder pentelischer Marmor). Für Statuenbasen, Postamente und Altäre gilt dies ohne Ausnahme. Die Gründe hierfür liegen auf der Hand: Stein war in ausreichender Menge vorhanden, er war vergleichsweise günstig in der Anschaffung und Bearbeitung, die hieraus hergestellten Monumente waren stabil, witterungsbeständig, langlebig, bei Bedarf zu überarbeiten, ein weite-

345 Plin. nat. 34, 99. 
res Mal zu verwenden und an einen anderen Standort zu bewegen. ${ }^{346}$ Inschriften auf Stein hatten eine lange Tradition in Rom, in ihrer Herstellung war man sehr erfahren und verfügte über die notwendigen Kenntnisse und Infrastrukturen. Sie waren gesellschaftlich akzeptiert und den Menschen in ihrer Lebenswelt hinlänglich vertraut. In Stein eingemeißelte Texte zu lesen war den meisten ohne größere Schwierigkeiten möglich. Als Inschriftenträger war Stein gleichsam konkurrenzlos, denn kein anderes Material verfügte über ähnliche Eigenschaften, die es für die Anfertigung eines der öffentlichen Kommunikation und Kommemoration angedachten Monuments besser qualifiziert hätten.

Doch auch aus künstlerischer Perspektive erweist sich Stein als vorteilhaft: Je nach geographischer Herkunft und mineralischer Zusammensetzung zeigen Gesteinsarten unterschiedliche Körnungen und Färbungen, was dazu führte, dass bestimmte Sorten für bestimmte Zwecke oder Themen bevorzugt wurden. Dies galt insbesondere für die Fertigung von Statuen, sei es aufgrund des Wunsches nach einer naturalistischen Darstellung oder um den Inhalt des Bildwerks und die Herkunft des Gesteins miteinander in Beziehung zu setzen. Für den geschundenen Marsyas etwa eignete sich der rotgefleckte Pavonazzetto aus Phrygien besonders gut. Menschen africanischer Herkunft waren oft in schwarzem Marmor (Nero antico) ausgeführt, der ihre dunkle Hautfarbe nachahmte. Um üppige Stoffpartien bei Porträtbüsten wiederzugeben, griff man auf den weichen, durchscheinenden orientalischen Alabaster zurück. Und Löwenstatuen waren nicht selten aus dem gelblichen Marmor Numidiens (marmor Numidicum) gehauen, wohl auch um der Heimat der Tiere auf diese Weise Rechnung zu tragen. ${ }^{347}$

Manches Mal spielten auch der symbolische Wert einer Farbe und die mit ihr verbundenen Assoziationen eine Rolle. Dionysische Bildwerke zum Beispiel wurden gerne in Rosso antico ausgeführt, da die Farbe Rot im Kult des Dionysos eine wichtige Rolle spielte. ${ }^{348}$ In der Herrschaftssymbolik war Rot bzw. Purpur ebenfalls von Bedeutung und stand hier für würdevolle Autorität und Herrschaftlichkeit, weshalb sich vor allem die tetrarchischen Kaiser mit Vorliebe in Statuen aus dem purpurfarbenen Porphyr abbilden ließen. Diese lediglich in den Steinbrüchen Ägyptens ausgebeutete Gesteinsart erlangte in der Spätantike große Bedeutung für die Fertigung kaiserlicher Porträtbilder und die Ausstattung höfischer Palastanlagen, und ihre Verwendung war spätestens seit konstantinischer Zeit dem Kaiserhaus vorbehalten. Mehr als jeder

$346 \mathrm{Zu}$ den verschiedenen in der Antike ausgebeuteten Marmorsorten und ihrer Verwendung s. Ward-Perkins 1992; Maniatis 1995; Jockey 2011 sowie Gutiérrez Garcia-Moreno et al. 2012 mit mehreren Beiträgen zu verschiedenen geographischen Regionen, Zeitrahmen und Aspekten; speziell zum Handel und Verarbeitung in Rom während der Kaiserzeit s. Maischberger 1997; s. außerdem Plin. nat. 36, 1-74 zu Marmor als geologisches Gestein und als Werkstoff, seinen Eigenschaften und den Verwendungsformen in der römischen Architektur und Bildkunst.

$347 \mathrm{Zu}$ direkten Bezügen zwischen dem Bildthema und der spezifischen Färbung des verwendeten Steins s. Schneider 1986.

348 Schneider 1986, 159f. mit Beispielen. 
andere Stein wurde Porphyr mit einer starken Symbolik aufgeladen und als ideologischer Bedeutungsträger in der Repräsentationskunst eingesetzt. ${ }^{349}$ Doch nicht nur die Farbgebung, auch die Herkunft eines Gesteins konnte für die symbolische Wirkkraft eines Denkmals eine Rolle spielen. Insbesondere solche Monumente, für die man exotische Steinsorten von den Rändern des Reichs verwendet, diese dort unter großem Aufwand abgebaut und dann mühevoll in die Zentren des Imperiums transportiert hatte, waren bedeutungsschwere Sinnbilder für das Ausgreifen Roms in die Gebiete an den Rändern der bekannten Welt, deren Einverleibung und Beherrschung sowie unmissverständliches Symbol römischen Machtanspruchs.

Ein derart absichtsvoller und konzeptueller Zugriff auf ein bestimmtes Material lässt sich bei Inschriften im Zusammenhang mit statuarischen Bildwerken indes selten beobachten. Dies mag nicht zuletzt daran liegen, dass der optische Reiz eines solchen Denkmals zuerst von der Statue selbst ausging, und daher war diese auch weit besser dazu geeignet, die Symbolsprache eines bestimmten Materials fruchtbar zu machen. In einigen Fällen scheint aber auch das für die Inschrift verwendete Trägermaterial nicht zufällig ausgewählt worden zu sein. So erhob sich etwa die Bronzestatue des Claudius Claudianus, welche die beiden Kaiser Arcadius und Honorius dem prominenten Dichter im Jahr 400 auf dem Trajansforum in Rom aufstellen ließen, auf einer stattlichen Basis aus rötlichem Marmor. ${ }^{350}$ Von den übrigen Ehrenbildnissen auf dem Platz, deren Postamente zumeist aus dem hellen lokalen Travertin oder weißlichem Marmor gehauen waren, muss sich die Basis aufgrund ihrer auffälligen Färbung deutlich abgehoben haben. Darüber hinaus vermochte der rötliche Stein aber auch auf die persönliche Herkunft des Geehrten Bezug genommen haben: Claudius Claudianus stammte ursprünglich aus Ägypten, dem seinerzeit einzigen Abbaugebiet rotfarbiger Marmorsorten.

Wie die meisten der erhaltenen spätantiken Inschriften des italischen Raums war auch die Ehreninschrift des Claudianus in den Stein eingemeißelt worden. Die Technik des Einmeißelns war für die verschiedenen Widmungstexte auf Statuenbasen, Ehrenoder Bauinschriften auf Tafeln, monumentale tituli an Architekturelementen sowie viele Grabinschriften das gebräuchliche Verfahren. Auch die Inschriften der Meilensteine waren zumeist gemeißelt, wobei sich im Fall von anepigraphischen miliaria auch an aufgemalte Texte denken lässt. Über den Herstellungsprozess von in Stein eingemeißelten Inschriften geben die epigraphischen Objekte selbst die anschaulichste und detailreichste Auskunft. Aus literarischen Quellen geht hingegen nur sehr

349 Insbesondere in konstantinischer Zeit spielte Porphyr als Werkstoff eine zentrale Rolle in der Symbolsprache der kaiserlichen Herrschaftsideologie. Mit Porphyr ausgelegte Bereiche im Fußboden der Empfangshallen durften lediglich von Konstantin I. selbst betreten werden, seine Söhne sollen in mit Porphyr vertäfelten Zimmern geboren worden sein und wurden nach ihrem Tod in Porphyr-Sarkophagen bestattet. Zur symbolischen Bedeutung des Porphyrs und seiner ideologischen Verwendung als Werkstoff in der Repräsentationskunst s. Del Bufalo 2012.

350 CIL VI 1710 = IG XIV 1074 = LSA 1355 mit Abbildungen. 
wenig darüber hervor, auf welche Art und Weise Inschriften gefertigt wurden, welche Personen daran beteiligt waren und welche einzelnen Fertigungsschritte notwendig waren. ${ }^{351}$ Immerhin sind einige der hierbei verwendeten Gerätschaften bekannt, zum einen durch archäologische Funde, zum anderen von bildlichen Darstellungen auf kaiserzeitlichen Grabreliefs und spätantiken Loculusplatten, wo sie den Handwerksberuf des Verstorbenen als kleine beigefügte Abbildungen illustrierten. ${ }^{352}$ Nach allem, was aus den verwertbaren Quellen und der Analyse der inschriftlichen Artefakte selbst zu gewinnen ist, gab es demnach wenigstens für Inschriften, die in einer steinverarbeitenden Werkstatt in Auftrag gegeben und dort hergestellt wurden, einen mehr oder minder festgelegten Arbeitsablauf, an dem verschiedene Handwerker mit unterschiedlichen Kompetenzen und Fähigkeiten beteiligt waren. In Absprache mit dem Auftraggeber wurde zunächst der gewünschte Text verfasst. Handelte es sich dabei beispielsweise um eine Ehreninschrift für eine öffentlich errichtete Porträtstatue, lag die Urheberschaft des Texts sicherlich alleine beim Auftraggeber, ${ }^{353}$ der ihn seinen Wünschen und dem Anlass entsprechend formulierte und damit an die Werkstatt herantrat. In anderen Fällen, insbesondere bei Grabinschriften, die über eine ganze Reihe standardisierter Elemente verfügten (einleitende Weiheformeln, Abschiedswidmungen, Zeichen- und Bildschmuck), boten einige Werkstätten wahrscheinlich auch schon vorgefertigte Stücke an, die dann nur noch mit den persönlichen Angaben des Käufers ergänzt werden mussten. ${ }^{354}$ Dass insbesondere figürliche Motive bereits vor dem Inschriftentext angebracht wurden und die so vorbereiteten Stücke dem Kunden gleichsam in Auswahl angeboten werden konnten, legen jedenfalls die oftmals aus Bild und Text kombinierten Epitaphe und Grabplatten aus Aquileia nahe. Bei diesen gruppiert sich der Inschriftentext in vielen Fällen um das in der Mitte des Steins platzierte Bildmotiv herum, sodass einzelne Wörter von diesem durchschnitten werden. So etwa bei den mit dem Motiv eines Betenden verzierten Grabinschriften des Caricus und des Didatus ${ }^{355}$ oder einer Grabtafel mit Taufszene im Zentrum (Abb. 28$){ }^{356}$

War der Auftrag angenommen und die passende Basis oder Tafel ausgesucht, glättete ein Steinmetz (in den Quellen zumeist als lapidarius, marmorarius oder quadratarius bezeichnet) in einem ersten Arbeitsschritt die Oberfläche des Beschreibfelds zunächst grob mit einem Zweispitz oder Zahneisen, hiernach noch einmal mit einem

351 Zum Herstellungsprozess römischer Inschriften s. insbesondere die Studie von J. Mallon und die diversen Arbeiten G. Susinis: Mallon 1952; Susini 1973; ders. 1989; ders. 1997; außerdem di Stefano Manzella 1987; Cooley 2012, 285-300.

$352 \mathrm{Zu}$ den Werkzeugen und ihrer Anwendung s. Susini 1973, 21-29. Für Abbildungen von Meißeln, Hämmern und anderer Gerätschaften der Steinbearbeitung auf Loculusplatten s. Ehler 2012, 244-255 III.3; III. 4 .

353 Wobei der Geehrte bei der textlichen Gestaltung aber Mitspracherecht haben konnte, s. hierzu Eck 1995.

354 Speziell zum Kauf und zur Produktion römischer Grabinschriften s. Carroll 2006, 86-125.

355 IAq 3006, 3022, jeweils mit Abbildungen.

356 IAq 3204. 


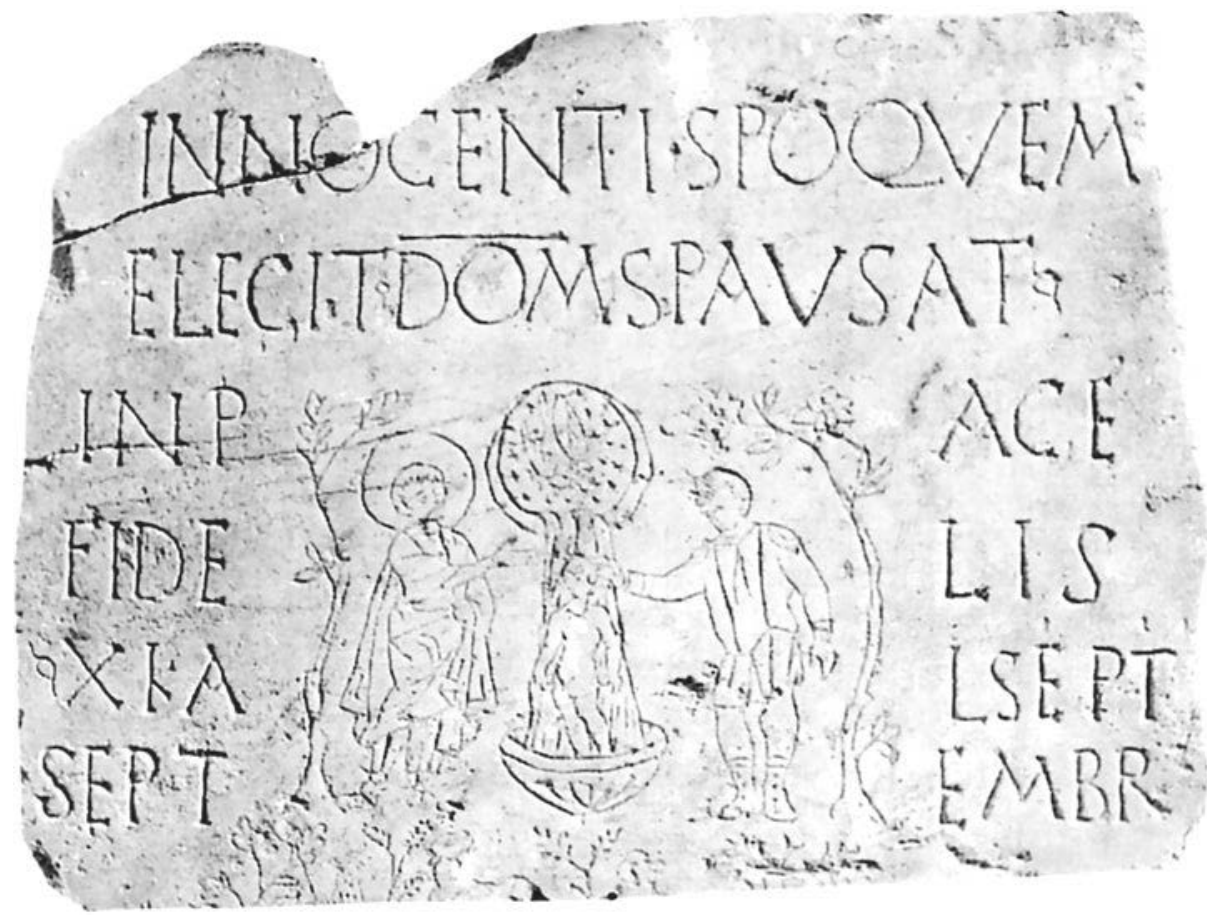

Abb. 28: Grabinschrift mit Taufszene, Aquileia.

feinen Meißel (scalprum) oder Breiteisen. Im Anschluss sorgte ein ordinator dafür, das Inschriftenfeld für die Beschriftung vorzubereiten und den Text der Vorlage auf den Stein zu übertragen. Dazu markierte er mit feinen Ritzlinien die äußeren Ränder des Textfelds, zog Hilfslinien und definierte die Höhe der einzelnen Zeilen. Bei einer ganzen Reihe von Steininschriften sind diese Hilfslinien bis heute sichtbar. Besonders deutlich treten sie im Fall einer Marmortafel aus Rom mit der Grabinschrift des 407 verstorbenen Basileon zu Tage, bei der neben den horizontal gezogenen Linien auch noch die vertikalen Begrenzungen des Textfeldes an den Rändern zu erkennen sind (Abb. 29). ${ }^{357}$

Danach transkribierte der ordinator die handschriftliche Vorlage des Texts mit Farbe auf den Stein, und zwar in der Regel genau so, wie die Inschrift dem Betrachter später erscheinen sollte. Dabei hatte er nicht nur auf die korrekte und vollständige Übertragung des Texts zu achten. Es galt auch, bestimmte gestalterische Vorgaben zu berücksichtigen, wie zum Beispiel die Hervorhebung bestimmter Textpassagen durch größere Buchstaben oder eine gezielte Anordnung in der Zeilenmitte, die Einhaltung kanonischer Abkürzungen oder die Aussparung von Freiflächen für die Anbrin-

357 ILCV 3504. Ein anderes Beispiel liefert die Marmortafel CIL X 6656 mit einer Restaurierungsinschrift einer Thermenanlage aus Antium, Abbildung bei Gordon/Gordon 1958-65, Bd. III, No. 336. 


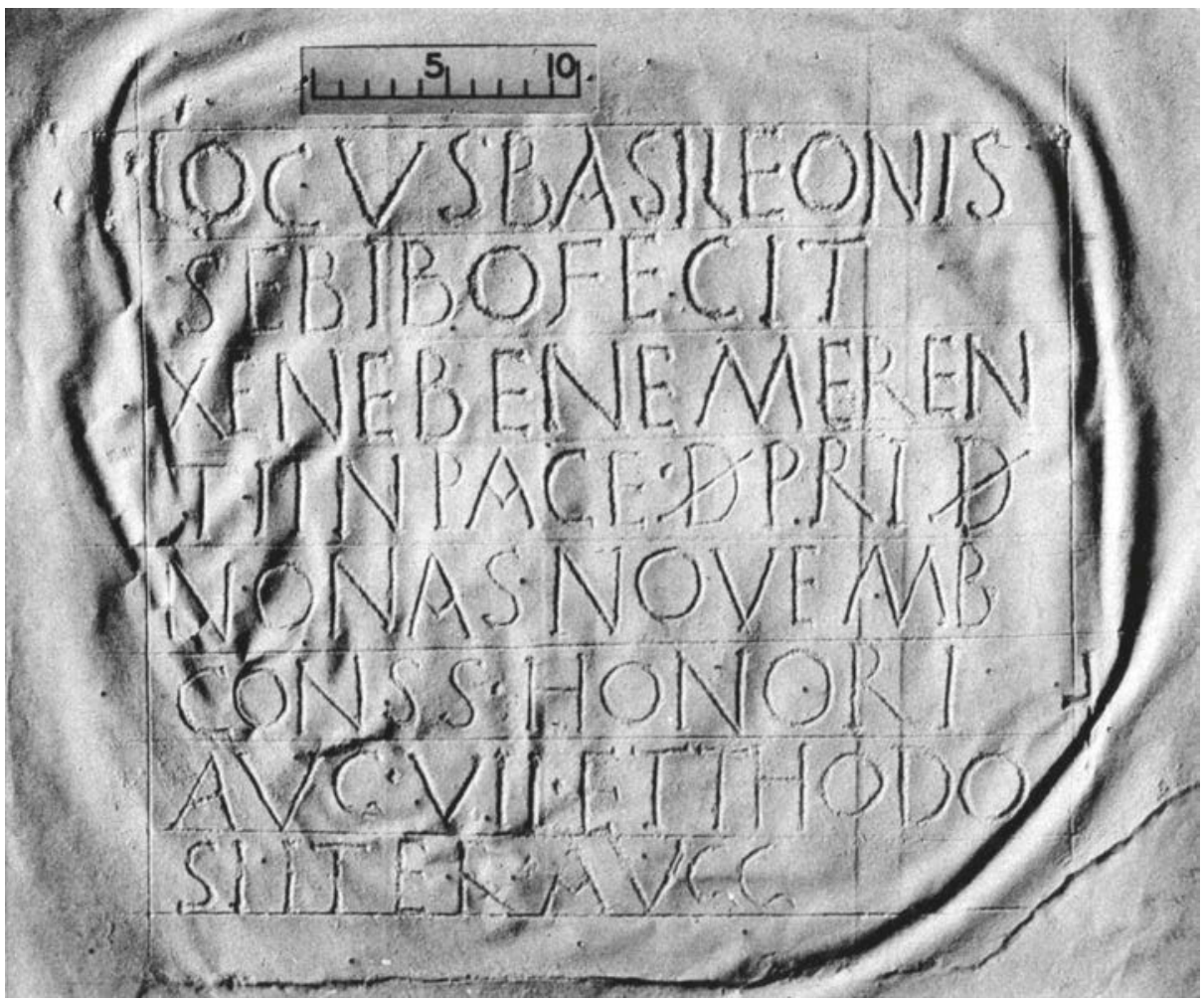

Abb. 29: Grabinschrift des Basileon mit deutlich sichtbaren Hilfslinien, Rom (Abklatsch).

gung bildlicher Motive. Das Fragment einer Marmortafel des beginnenden 5. Jhs. mit einer Namensliste der Zunftmitglieder der tabernarii Roms illustriert dies anschaulich (Abb. 30) ${ }^{358}$ Für den ersten Teil der Inschrift mit einem einleitenden Formular und einer Widmung an das Kaiserhaus wurden größere Buchstaben gewählt als für die danach folgenden Namen der in der Zunft organisierten Schenkwirte, die in drei Kolumnen untereinander im unteren Teil der Tafel angeordnet sind.

Für gewöhnlich malte der Schreiber die einzelnen Buchstaben sogleich in Form einer für Inschriften üblichen Schrifttype auf die Tafel, die in der Spätantike - wie wir später noch genauer sehen werden - der in der Kaiserzeit vorherrschenden capitalis quadrata mit ihren annährend quadratischen Großbuchstaben und dem gleichförmigen Modulus nur noch in Ansätzen entsprach. Ihre einzelne Lettern ${ }^{359}$ waren hingegen wesentlich schmaler und ihr Duktus wirkte weniger standardisiert. Unfertig gebliebene Stücke, anhand derer sich solche gemalten Vorlagen demonstrieren ließen,

358 CIL VI 9920.

359 Der Begriff ,Letter‘ wird hier wie im Folgenden nicht im Sinne von ,Druckbuchstabe‘ zur Herstellung eines typographischen Schriftstücks, sondern als Synonym zu ,Buchstabe‘ verwendet. 


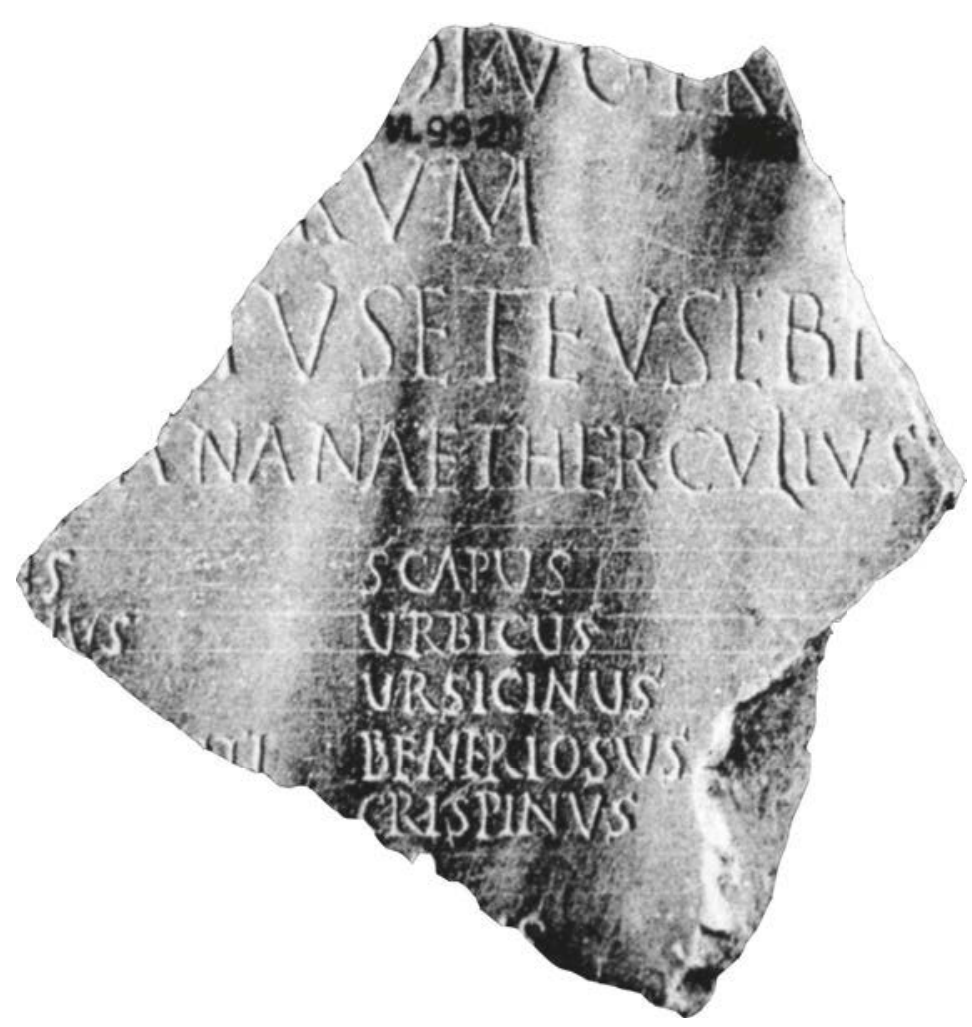

Abb. 30: Fragment einer Inschrift der tabernarii, Rom (Abklatsch).

haben sich zwar nicht erhalten. Das Beispiel einer teils gemeißelten, teils gemalten Ehreninschrift des späten 3. Jhs. aus dem norditalischen Ticinium (Pavia) vermittelt aber immerhin einen Eindruck davon, wie man sich eine Inschrift in diesem Stadium wird vorstellen dürfen. ${ }^{360}$ Manches Mal wird es auch vorgekommen sein, dass der verabredete Text handschriftlich auf den Stein übertragen wurde oder dass der Steinmetz, der die Inschrift den Vorzeichnungen entsprechend in einem dritten Arbeitsschritt schließlich ausarbeitete, sich an gar keiner Vorlage orientieren konnte, sondern sofort mit dem Einmeißeln der Buchstaben begann. Das Resultat einer solchen Vorgehensweise liegt offenbar in einer Marmortafel aus Rom vor, welche die Grabinschrift der

\footnotetext{
360 CIL V 6421 = AE 1973, 242, Abbildung bei HD010727. Ein anderes Exemplar vergleichbarer Art liefert ein Altar der Dii campestres aus Numidien, den der Reiterpräfekt M. Celerinius Augendus zwischen 222 und 235 in ihren Tempel in Gemellae (El-Kasbat) weihte. Wie auch bei der Ehreninschrift aus Ticinium ist nicht ganz klar, warum die Inschrift unfertig blieb und zum Teil ausgemeißelt, zum Teil aufgemalt worden war. In jedem Fall schien es die Stifter bzw. Auftraggeber nicht gestört zu haben, denn beide Stücke sind wohl tatsächlich zur Aufstellung gebracht worden. Zu dem Stück aus Gemellae s. Speidel 1991.
} 


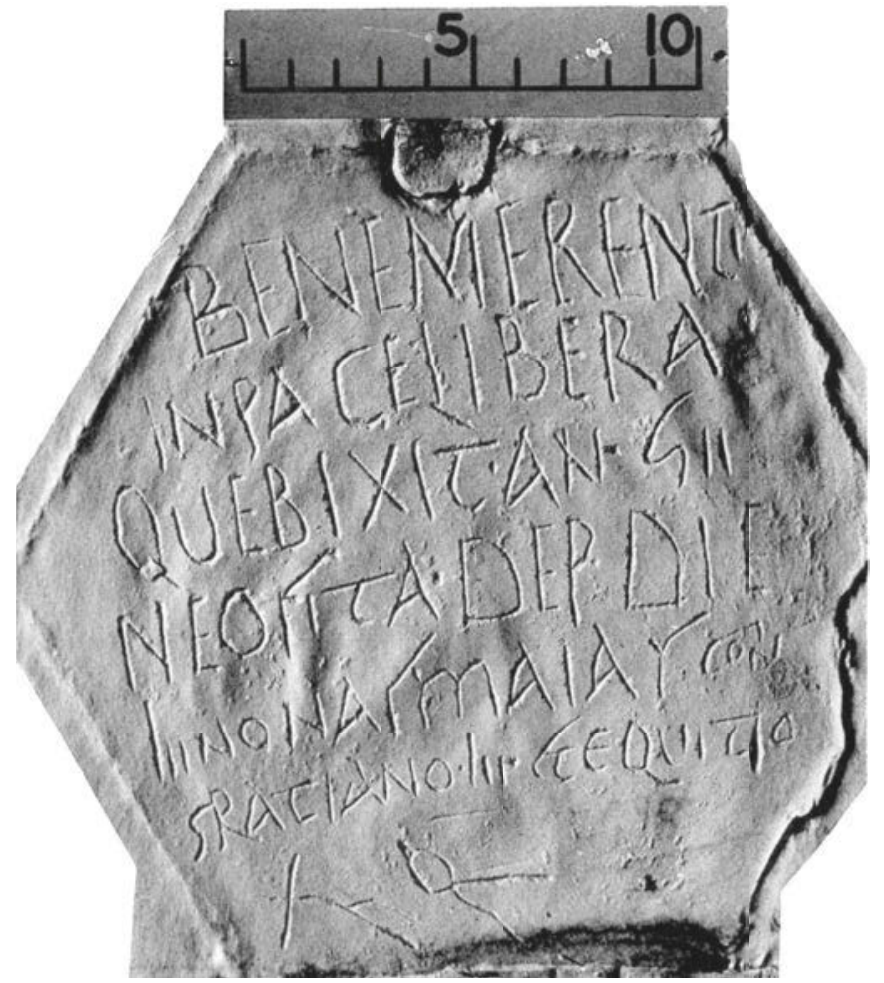

Abb.31: Grabinschrift der Libera, Rom (Abklatsch).

Neugetauften Libera trägt (Abb. 31). ${ }^{361}$ Die einzelnen Zeilen verlaufen nicht horizontal, sie werden nach unten immer kleiner und orientieren sich in ihrer Ausrichtung nur leidlich an der Form des sechseckigen Inschriftenfelds. Die einzelnen Buchstaben wurden eher eingeritzt denn eingemeißelt und folgen nicht immer der gleichen Formgebung. Am markantesten und als Hinweis auf das Fehlen einer zuvor angebrachten Vorlage am eindeutigsten ist die Tatsache, dass der Steinmetz ab und an handschriftliche Buchstabenformen verwendete, die gegen Ende der Inschrift immer häufiger werden. Hätte er den Text als gemalte Vorlage in großbuchstabigen Lettern vor sich gehabt, würde das Stück sicherlich anders ausgesehen haben.

Was die Lese- und Schreibfähigkeiten der beteiligten Handwerker angeht, so werden wir im Übrigen davon ausgehen dürfen, dass die allermeisten der ordinatores des Lesens und Schreibens fähig waren und sie die Buchstaben der Vorlage nicht bloß ,abmalten', sondern im Wissen um den Inhalt des Texts auf den Stein übertrugen. Ob dies allerdings auch für die Steinmetzen gilt, ist weniger gewiss. Womöglich verstanden sich einige von ihnen auch lediglich auf das Meißeln und konnten den Text in seiner Gesamtheit weder lesen noch verstehen.

361 ILCV 2007 = ICUR I 1937: Bene merenti / in pace Libera / qu(a)e bixit an(nos) VIII / qu(a)e bixit an(nos) VIII / neofita dep(osita) die / III Nonas Maias con(sulibus) / Gratiano III et Equitio. 
Neben der Technik des Einmeißelns bot der Schriftträger Stein auch noch andere Möglichkeiten der gestalterischen Ausfertigung einer Inschrift. Eine Alternative, die vor allem für monumentale Bauinschriften häufiger zum Einsatz kam, eröffneten eingelegte Buchstaben aus vergoldeter Bronze. Hierbei gab es zwei Varianten: Entweder wurden die Buchstaben zunächst aus Bronze gegossen, vergoldet und anschließend in eigens eingehauene Bettungen passgenau eingelegt und mit Hilfe kleiner Dübel befestigt. Oder man sägte die Buchstaben aus hauchdünnem Bronzeblech aus, vergoldete sie dann gleichermaßen und verdübelte sie ohne entsprechende Bettung direkt auf dem Stein. Insbesondere in augusteischer Zeit war diese Form der Inschriftenkunst sehr beliebt und auch in der hohen Kaiserzeit trugen noch einige öffentliche, vom Kaiserhaus gestiftete Gebäude tituli aus großen Bronzelettern. ${ }^{362}$ In der Spätantike sind vergleichbare Zeugnisse allerdings überaus rar. Wenigstens im Westen des Reichs scheint die Technik des Gießens und Einlegens seit dem späten 3. Jh. immer seltener und nur noch in Ausnahmefällen angewendet worden zu sein, wie etwa bei der Widmungsinschrift des Konstantinbogens in Rom aus dem Jahr 315, die an den historischen Sieg des Kaisers über seinen Widersacher Maxentius an der Milvischen Brücke erinnerte. ${ }^{363}$ Die Verwendung der vergoldeten Bronzebuchstaben war hier gleich in zweifacher Weise bedeutsam. Auf der einen Seite erwiesen sie sich der Relevanz und Würde des dem Kaiser zugeeigneten Denkmals als angemessen. Denn im Unterschied zu gemeißelten Inschriften waren solche aus eingelegten Metalllettern ungleich kostspieliger, ihre Herstellung war komplizierter und ihre Anbringung am Bogen erforderte wesentlich mehr Aufwand, Erfahrung und Wissen. Auf der anderen Seite ging von den golden glänzenden Buchstaben eine stärkere Anziehungskraft und ein einnehmenderes Erscheinungsbild aus als von eingehauenen Inschriften, selbst wenn diese durch eine spezielle Meißeltechnik ein differenziertes Licht- und Schattenspiel erzeugten oder mit leuchtender Farbe hervorgehoben wurden. Doch war die optische Wirkung wohl nicht alleine ausschlaggebend. Indem die Inschrift des Ehrenbogens mit Bronzebuchstaben auslegen wurde, griff man eine alte Tradition wieder auf, die untrennbar mit der Regierungszeit des Augustus verbunden und die zuletzt zunehmend in Vergessenheit geraten war. Wie einst die Bauwerke des ersten Princeps, sollten auch die Denkmäler Konstantins I. in würdevollem Glanz erstrahlten, und so wie einst Rom unter Augustus in einem neuen Zeitalter des Glücks und des Wohlstands erblühte, sollte auch das von Konstantin erneuerte Reich nach seinem Triumph über Maxentius gedeihen - die litterae aureae hier also gleichsam als Sinnbild einer goldenen Ära unter der Herrschaft Konstantins I.

Die Bronzeinschrift des konstantinischen Bogendenkmals ist im italischen Raum der Spätantike ohne Parallelen. Und obgleich in anderen Reichsteilen auch nach dem

$362 \mathrm{Zu}$ Inschriften aus Metallbuchstaben, ihrer Verbreitung und ideologischen Bedeutung in augusteischer Zeit s. Alföldy 1991, 297-299.

363 CIL VI 1139 = ILS 694. 
4. Jh. noch gelegentlich Inschriften in Metalllettern ausgeführt wurden - wie beispielswiese die prominente Inschrift des Theodosius I. an dem anlässlich seines Siegs über Magnus Maximus errichteten Bogenmonuments in Konstantinopel ${ }^{364}$-, waren Exemplare dieser Art Einzelfälle, die besonderer Anlässe und Botschaften bedurften. Und so kam auch jenseits monumentaler tituli an Bauwerken die Technik des Einlegens in der westlichen Inschriftenkunst der Spätantike nur selten zum Einsatz. Wenn man einmal von ihr Gebrauch machte, dann wiederum lediglich im Zusammenhang mit sehr teuren und ideell bedeutungsvollen Inschriften, welche sich durch ein außergewöhnliches Material von der Masse abzusetzen suchten. Das gilt in erster Linie für Tafeln aus Porphyr mit eingelegten Lettern aus Blei, Glaspaste oder Stuck, von denen sich einige wenige Fragmente in Rom erhalten haben. ${ }^{365}$ Welche Art von Texten sie einst wiedergaben und in welchen Kontexten sie zur Aufstellung kamen, lässt sich aufgrund des unvollständigen Erhaltungszustands und der unklaren Fundsituation allerdings nicht mehr zuverlässig rekonstruieren. Wenigstens im Fall eines auf dem Forum Romanum gefunden Fragments mit den erhaltenen Buchstaben [---LOR---] / [---ATUA---] ist es aber sehr wahrscheinlich, dass es sich um eine Ehreninschrift für das tetrarchischen Kaiserhaus gehandelt hat. ${ }^{366}$ In jedem Fall steht außer Frage, dass die jeweiligen Aufraggeber der Porphyr-Inschriften zu den Spitzen der damaligen römischen Gesellschaft gehört haben müssen, da derartige Stücke für eine andere Klientel schlichtweg zu kostspielig gewesen wären. Zur privilegierten Oberschicht jener Zeit gehörte wohl auch das im frühen 4. Jh. verstorbene Paar Taeofilius und Pontiana. Seine Grablege in der Katakombe S. Panfilo wurde mit einer Platte aus weißem lunensischen Marmor verschlossen, auf der die Inschrift mit Buchstaben aus hauchdünnen Porphyrblättchen aufgelegt war (Abb. 32). ${ }^{367}$

Vor dem Hintergrund dieser Befunde wird deutlich, in welch entscheidendem Maß in Stein eingemeißelte Inschriften das Gesamtbild der spätantiken Inschriftenkultur prägten. Wer sich durch eine römische Stadt des italischen Raums bewegte, wird sich insbesondere auf den öffentlichen Plätzen und entlang den Straßen nahezu ausschließlich steinernen Monumenten gegenübergesehen haben: Statuenpostamente mit Ehreninschriften, Basen und Altäre mit Weihinschriften, Tafeln mit Widmungsinschriften, Gebälkteile mit Bauinschriften. Jenseits des öffentlichen, freizugänglichen Stadtraums schuf sich allerdings seit dem 4. Jh. ein anderes Material und eine andere Schreibtechnik zunehmend Raum, und zwar das Mosaik bzw. das Ausarbeiten von Inschriften in der Technik des Mosaizierens. Es war dies ein Verfahren, das insbesondere für die inschriftliche Präsenz innerhalb der Kirchenanlagen des frühen

364 CIL III 735 = AE 1955, 102: Haec loca Theudosius decorat post fata tyranni / aurea saec(u)la gerit qui portam construit auro.

365 Del Bufalo 2012, 210 Nr. I6. I7. I8.

366 Eine denkbare Ergänzung wäre: [------?] / [--- f?]lor[entissim-? ---] / [--- st?]atua[---] / [------]; vgl. hierzu AE 1997, 149 und Gregori 1997, 163.

367 AE 1921, 80 = ICUR X 26460. 


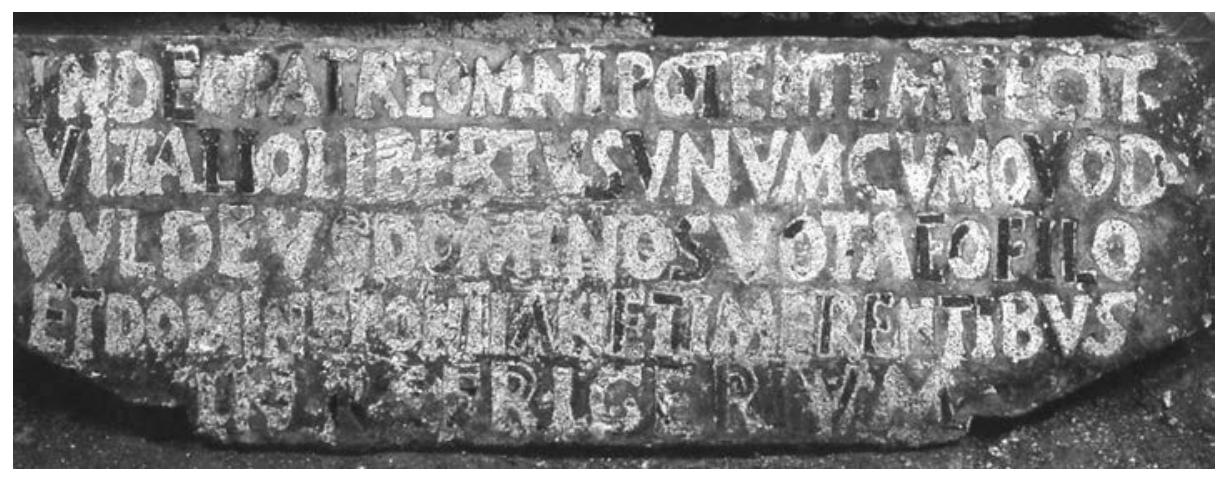

Abb. 32: Grabinschrift des Paares Taeofilius und Pontiana mit eingelegten Buchstaben aus Porphyr, Katakombe S. Panfilo in Rom.

Christentums große Bedeutung erlangte und das Gepräge des repräsentativen Stiftungswesen jener Zeit beeinflusste.

Die Technik des Mosaizierens unterscheidet sich von derjenigen des Meißelns fundamental. Im Unterschied zur Arbeit mit Hammer und Meißel entsteht die Schrift hier nicht dadurch, dass Material entfernt, sondern im Gegenteil hinzugefügt wird. In diesem Sinn lässt sich von Mosaiken auch nicht von tatsächlichen Textträgern sprechen, denn der Schriftzug wird darin nicht eingelassen oder darauf aufgetragen, sondern ist selbst Material und wird mit dem Untergrund zusammen in ein und demselben Akt geschaffen. Technisch und ikonographisch betrachtet, gelten Mosaiken mithin als eine spezielle Form der Malerei, bei der unterschiedlich farbige und/oder eigens zugeschnittene Steinchen (tesserae) zu einem Ornament, einem Bild oder eben $\mathrm{zu}$ einem Text zusammengesetzt werden. ${ }^{368}$ In der römischen Welt verwendete man dafür zumeist farbige Kiesel, Bruchstein oder Marmor, gelegentlich auch Glaspasten oder Perlmutt. Um besondere Farbeffekte zu erzielen, wurden einzelne Steinchen mitunter auch mit Gold überzogen und Glastesserae durch die Zugabe von Metalloxiden und mit Hilfe unterschiedlicher Brennverfahren eingefärbt. Für die Herstellung eines Mosaiks musste in einem ersten Arbeitsschritt der Untergrund planiert und mit einem aus mehreren Schichten bestehenden Estrich bedeckt werden, auf den man dann eine Vorzeichnung des gewünschten Musters oder Bilds mit Rötel auftrug. Dieser entsprechend wurden hiernach die benötigten Mosaiksteinchen zugeschnitten und gegebenenfalls gefärbt oder vergoldet. Zuletzt erfolgte schließlich das Ausfüllen der Vorlage, wobei sehr detailreiche und aufwendige Bildmotive (emblemata) zunächst separat auf

368 Zur Technik des Mosaizierens s. Knoepfli 1990. In Mosaiken eingefügte Texte bzw. Text-Mosaike hat es schon im hellenistischen Griechenland gegeben, darunter etwa Begrüßungsinschriften auf Türschwellen (s. Joyce 1979 mit Beispielen aus Delos und Pompeji; Muth 1998, passim für die römische Kaiserzeit) oder Künstlersignaturen (s. Donderer 2008). 
einer Ton- oder Marmorplatte in einer Werkstatt vorbereitet und erst vor Ort als Ganzes in das Mosaikwerk eingesetzt wurden.

Während Mosaiken zunächst vor allem für die künstlerische Ausgestaltung von Fußböden beliebt waren und hier vornehmlich im Kontext luxuriöser und repräsentativer Räume privater Wohnhäuser und Villen begegneten, gewannen sie in der Spätantike auch für die Auskleidung von Wänden, Decken und Gewölben an Bedeutung nun allerdings nicht mehr nur im privaten Wohnraum, sondern auch im religiösen Kontext von christlichen Kultstätten. Insbesondere die Kirchenanlagen des oströmischen Reichs und des stark durch Byzanz beeinflussten Ravennas waren überreich mit Mosaiken verziert. ${ }^{369}$ Im Westen des Reichs zeigten vor allem die frühchristlichen Anlagen Roms und Mailands, der beiden wichtigen Zentren des christlichen Glaubens, großformatige Mosaiken an Wänden, Apsiden und Decken. ${ }^{370}$ Mosaizierte Fußböden kamen vor allem im Raum des nördlichen Adriabogens vor. Eindrückliche Zeugnisse dieser Art haben sich in der Provinz Venetia et Histria erhalten: der Bischofskomplex und die sog. Monastero-Kirche von Aquileia, die Kathedrale von Grado, die Bischofskirche von Concordia, die Kirche Via Madonna del Mare von Tergeste oder die Basilika des Eufrasius von Parentium - um nur die wichtigsten zu nennen. Außerhalb der Grenzen Venetia et Histrias und der direkt benachbarten Regionen Flaminia, Noricum und Dalmatia sind Bodenmosaiken innerhalb von Kirchenräumen indes vergleichsweise selten und nur vereinzelt anzutreffen. In Mittelitalien sind die Basiliken von Florentia, Luna, Neapolis und Luceria zu nennen, im Süden die frühchristlichen Bauten von Barium und des sizilianischen Salemi. ${ }^{371}$

Neben geometrischen Dekorationsmustern, Ornamenten, figürlichen Motiven und szenischen Kompositionen zeigten die Mosaiken dieser Kirchen auch eine ganze Reihe von Inschriften. Darunter waren vor allem Stifter-, seltener auch Grabinschriften in den Fußböden, Bau- und Weihinschriften auf den Wänden und Beischriften in den Bildwerken der Apsiden und Kuppeln. Während öffentliche Profanbauten und pagane Tempel ihre tituli an der Außenfassade trugen, wo sie zumeist in eingemeißelten oder eingelegten Lettern an den Architraven prangten, präsentierten sich diejenigen der Kirchen dem Betrachter in der Regel erst im Inneren, manches Mal in Form

369 Zur Entwicklung des Mosaiks in der antiken Bildkunst s. Dunbabin 1999; Andreae 2003; RAC XXV 2013, Sp.1-58 (V. Blanc-Bijon/J.-M. Spieser); zum Mosaik als Ausstattungselement des privaten römischen Wohnens s. Becatti 1961; von Boeselager 1983; Donderer 1986; Isager 1997; Muth 1998; zum Beginn des Wandmosaiks s. Sear 1977; zu Bodenmosaiken, v. a. in religiösen Kontexten s. Hachlili 2009; zur Mosaikausstattung frühchristlicher Kirchenanlagen s. Demus 1964 für Byzanz; DonceelVoûte 1988; Piccirillo/Bikai 1993; Balty 1995; Baumann 1999 für Syrien und Palästina; AsemakopuluAtzaka 1998 für Griechenland; Rizzardi 2011 für Ravenna.

370 RAC XXV, 2013, Sp.41-45 (V.Blanc-Bijon/J.-M.Spieser) für die Befunde aus Rom; Sp.46f. (V. Blanc-Bijon/J.-M. Spieser) für Mailand. Dass Bodenmosaiken in Rom und Mailand kaum zu finden sind, könnte einer regionalen Vorliebe für Fußböden aus opus sectile geschuldet sein.

371 Zu den Befunden s. Caillet 1993; Zettler 2001; RAC XXV, 2013, Sp.31-56 passim (V. Blanc-Bijon/ J.-M.Spieser). 
eines Bodenmosaiks, wie etwa im Fall der frühchristlichen Kultanlage von Barium, ${ }^{372}$ häufiger aber als Wandmosaik, angebracht hoch oben über den Köpfen der Besucher. Ein solches Exemplar hat sich etwa in der Inschrift des Bischofs Eufrasius in der nach ihm benannten Basilika in Parentium aus dem 6. Jh. erhalten. Sie erstreckte sich direkt unterhalb des Apsismosaiks in hellen Buchstaben auf leuchtend blauem Hintergrund (Taf. 38 Abb. 17)..$^{373}$

In den Farben Gold und Blau war auch die Bauinschrift der Kirche S. Sabina in Rom gehalten (Abb.16, s. o. S. 85), für deren Anbringung man bemerkenswerterweise die Innenseite über dem Eingangsportal wählte, sodass sie der Besucher erst wahrnahm, nachdem er den Bau betreten und sich wieder dem Ausgang zugewandt hatte. Eingerahmt zwischen den beiden Personifikationen der Judenkirche und der Heidenkirche erinnerte sie an die Gründung der Basilika unter Papst Coelestin (422432) durch den Presbyter Peter. ${ }^{374}$

Wurde die Errichtung einer Kirche unter Beteiligung mehrerer Mitglieder aus der Kirchengemeinde finanziert, so ließen sich diese in Form individueller Inschriften ebenfalls im Inneren verewigen. Angebracht wurden diese auf dem mit Mosaiken ausgelegten Fußboden, dessen Finanzierung ihr Engagement gegolten hatte. Zeugnisse dieser Art haben sich in der Provinz Venetia et Histria zu Dutzenden erhalten. Es sind in der Regel kurze Inschriften mit dem Namen des Stifters sowie einer Angabe der von ihm gespendeten Summe in römischen Fuß (pedes) oder einer standardisierten Votum-Formel. Im Gegensatz zu den musivischen Bauinschriften der Apsiden und Innenwände waren die Inschriften der Laien bescheidener gestaltet, sowohl was die Ausmaße als auch die farbliche Gestaltung anging. Die meisten von ihnen wurden in kleine rechteckige Rahmen eingesetzt. Die Texte waren oft nur wenige Zeilen lang und als Farben dominierten Sandfarben für den Hintergrund und Schwarz oder Rot für die Schrift. Verbindungen zu figürlichen Motiven, wie beispielsweise im Fall der Stifterinschrift des Obsequentius aus Florentia (Florenz) mit der Darstellung eines farbenprächtigen Pfaus (Taf. 29 Abb. 154), ${ }^{375}$ waren selten. Anders als im Osten des Reichs, wo szenische oder narrative Bilder die Mosaikböden vieler Kirchen schmückten, ${ }^{376}$ zeichneten sich die Pavimente der frühchristlichen Kirchen des Westens ohnehin durch vornehmlich mit geometrischen und ornamentalen Motiven gestaltete Dekorsysteme aus, in welche die Inschriftenfelder mehr oder minder regelmäßig und bestimmten

372 Caillet 1993, 12-17.

373 InscrIt X 2, 81; zu den Mosaiken der Apsis s. Terry/Maguire 2007.

374 ILCV 1778a; zur Kirche s. Brandenburg 2004, 167-176.

375 Caillet 1993, 28.

376 S. zum Beispiel das Bodenmosaik im Mittelschiff der Nordkirche von Huarte in Syrien aus dem späten 5. Jh., das den zwischen verschiedenen Tieren thronenden Adam zeigt (Wisskirchen 2002). Für weitere Beispiele s. RAC XXV, 2013, Sp.37-40 (V. Blanc-Bijon/J.-M. Spieser) und die in Anm.370 angegebenen Literaturhinweise. 
Ordnungsprinzipien folgend integriert wurden. ${ }^{377}$ Mitunter bemühte man sich auch um eine auffälligere Gestaltung der eigenen Inschrift, indem man ihr eine besonders raffinierte, polygonale Rahmung aus Flechtbändern oder Mäandern verlieh. In gesteigerter Form lässt sich dies bei Inschriften von Stiftern aus klerikalen Kreisen beobachten, beispielsweise in der Basilika Sant'Eufemia in Grado, wo der Boden auch Inschriften hoher kirchlicher Würdenträger zeigte (Taf. 14-21). ${ }^{378}$

Jenseits von Bau- und Stifterinschriften bot das Kircheninnere auch Raum für andere Formen musivischer Inschriften. Begräbnisstätten unter dem Boden der Gotteshäuser etwa konnten ebenfalls durch Mosaikinschriften markiert werden, auch wenn dies im italischen Raum der Spätantike vergleichsweise selten vorkam und häufiger in Hispanien und Nordafrica belegt ist. ${ }^{379}$ Zahlreicher waren die in die Bildwerke der Gewölbe- und Kuppelmosaiken integrierten Inschriften, die hier auf ungemein vielfältige, mitunter sehr komplexe Art und Weise in Beziehung zu den dargestellten Personen und Szenerien gesetzt werden konnten: Als Beischriften identifizierten sie Personen, als Schriftzitate in aufgeschlagenen Büchern schufen sie subtile Bezüge zur Vita der dargestellten Heiligenfigur und als Schrift- oder Spruchbänder benannten sie das ikonographische Bildthema. ${ }^{380}$

Dass Mosaiken und mithin auch Mosaikinschriften ausgerechnet im frühchristlichen Kirchenraum eine so starke Präsenz entwickelten, hängt wohl vor allem mit dem Phänomen der ,Interiorisierung، des christlichen Kults im Gebäudeinneren und der Verlagerung des ästhetischen Fokus von der Außenfassade auf das Interieur zusammen. ${ }^{381}$ Im Unterschied zur römisch-polytheistischen Religion spielte sich die christliche Kultpraxis nicht an einem Opferaltar vor dem Tempel, sondern im Inneren des Gotteshauses ab. Fluchtpunkt jeder Kirche war der im Osten gelegene Altarbereich, das liturgische und symbolische Zentrum, wo Reliquien zur Schau gestellt und die Eucharistie gefeiert wurde. Römische Tempel waren in ihrer Architektur auf das vor ihnen gelegene Tempelareal hin ausgerichtet, wo sich die Kultteilnehmer unter freiem Himmel versammelten. Ihre Fassaden und Giebel waren dementsprechend aufwendig mit Skulpturen und feiner Ornamentik gestaltet, während sich das Innere vergleichsweise schmucklos und schlicht präsentierte. Anders hingegen die frühen Kirchenanlagen: Bei ihnen handelte es sich in der Regel um untektonische, zum Teil unverputzt gelassene Ziegel- oder Quaderbauten ohne nennenswerte Schmuckelemente an ihren äußeren Mauerwänden und Fassaden. Der architektonische und künstlerische Gestaltungswille konzentrierte sich auf das Innere, das angesichts seiner aufwendigen Ausgestaltung in fast diametralem Gegensatz zur kargen Außenansicht stand.

$377 \mathrm{Zu}$ der planvollen Anordnung der Inschriften im Boden s. die Ausführungen in Kap. 5.3.

$378 \mathrm{Zu}$ den Inschriften der Basilika Sant'Eufemia s. Carlini 1980; Caillet 1993, 218-257; Zettler 2001, 194-206.

$379 \mathrm{Zu}$ den musivischen Grabinschriften in Kirchen s. o. Kap. 2.2.6.

380 S. hierzu auch o. Kap.2.2.7.

$381 \mathrm{Zu}$ diesem Phänomen s. Fabricius Hansen 2001. 
Große Fenster sorgten dafür, dass ausreichend Licht in das Innere einfiel und Bauteile und Bildwerke gleichermaßen beleuchtete. Basen, Säulen, Kapitelle und Gebälkteile strahlten häufig in weißem Marmor. Farbige Malereien und Inkrustationen bedeckten die Wände, Apsiden und Deckengewölbe. Besondere Bedeutung kam den Mosaiken zu, denn sie erwiesen sich in vielerlei Hinsicht als optimale Dekorationsmedien. Mit ihrer Hilfe ließen sich auch große Flächen einheitlich auskleiden und mit Bildern kunstvoll verzieren. Insbesondere im Vergleich zu Malereien waren sie sehr widerstandsfähig und langlebig und eigneten sich auch für die Ausschmückung des immer wieder betretenen Fußbodens. ${ }^{382}$ Die Technik der zu Ornamenten und Bildern zusammengesetzten Steinchen bot ferner eine reichhaltige Vielfalt an verschiedenen Formen und Farben. Geübten Mosaizisten waren kaum technische Grenzen gesetzt, Vorlagen der Malerei in das Medium des Mosaiks zu übertragen. Besondere visuelle Effekte ließen sich mit gläsernen und goldüberzogenen tesserae erzielen, die das von außen einfallende Licht reflektierten und multiplizierten, sodass der Raum heller wirkte was Mosaiken wohl nicht zuletzt angesichts der engen Verbindung von Licht und Göttlichkeit im christlichen Glauben für den Kirchenraum so beliebt machte. ${ }^{383}$ Dessen ungeachtet waren zumindest Mosaiken einfacheren Typs, mit tesserae aus gebräuchlichen Materialien und in schlichten geometrischen Dekorationsschemata ausgeführt, durchaus erschwinglich, sodass sich auch kleinere Kirchengemeinden eine Mosaikausstattung leisten konnten. ${ }^{384}$ Mit Blick auf die Auftraggeber und Initiatoren der Inschriften waren Mosaiken auch deshalb interessant, weil man ihnen besser als in Stein gemeißelte Inschriften ein individuelles Erscheinungsbild verleihen konnte, indem man zum Beispiel mit verschiedenen Materialien und Farben arbeitete. Auch die Kombination mit figürlichen und szenischen Bildwerken eignete sich hierfür gut, denn diese besaßen eine starke visuelle Anziehungskraft und waren ihrerseits nicht selten von zeichenhafter oder sinnbildlicher Bedeutung. Besonders deutlich zeigt sich dies an den Inschriften der Apsismosaiken: Die in die Bilder integrierten Namensbeischriften der hier im Beisein der Gottesmutter, Heiliger und Christus selbst abgebildeten Stifter versicherten deren unmittelbare Nahbeziehung zum Göttlichen, und dies auch jenseits aller ikonographischer Symbolsprache.

382 Dass Malereien für die Ausstattung von frühchristlichen Kirchen selten waren, legt auch eine Passage bei Paulinus von Nola nahe: carm. 27, 543f.

383 Vgl. James 1996; RAC XXIII, 2010, bes. Sp. 114-117; 125-130 (M. Wallraff).

384 Wie viel man für ein Mosaik zu zahlen hatte, variierte je nach Region und Arbeitsaufwand. Konkrete Zahlen sind kaum zu benennen. Zumindest für Palästina und Griechenland lassen sich aber vorsichtige Berechnungen anstellen. Demnach kosteten $3 \mathrm{~m}^{2}$ Mosaikboden mit geometrischem Dekor ca. einen Solidus, was dem Monatslohn eines Facharbeiters in Konstantinopel des 6. Jhs. entspricht. Mosaiken mit figürlichen Motiven waren etwa doppelt so teuer; vgl. hierzu RAC XXV, 2013, Sp. 36f. (V. Blanc-Bijon/J.-M. Spieser). 


\subsection{Schriftbild und Schriftgestaltung}

Ebenso deutlich wie auf dem Feld der verwendeten Materialien und Techniken schlug sich der Wandel der Inschriftenkultur in der Spätantike im Schriftbild und in der Schriftgestaltung nieder. Es ist nicht viel Erfahrung nötig, um eine römische Inschrift des 2. Jhs. von einer des 4. oder 5. Jhs. zu unterscheiden, denn sowohl was die Ausformung der einzelnen Buchstaben als auch den visuellen Gesamteindruck angeht, sind die Unterschiede oftmals kaum zu übersehen. Eine aus den Thermen des umbrischen Spoletiums stammende opistographe Marmortafel illustriert dies besonders anschaulich (Inschrift Nr. B.III.4). ${ }^{385}$ Auf der einen Seite erinnert eine Inschrift des 2. Jhs. an die Stiftung des Badehauses durch den Magistraten C. Torasius Severus (Abb. 33a), auf der anderen Seite eine zweite Inschrift an die Restaurierung der Anlage durch Constantius II. und Julian (als Caesar) im Jahr 355 (Abb. 33b).

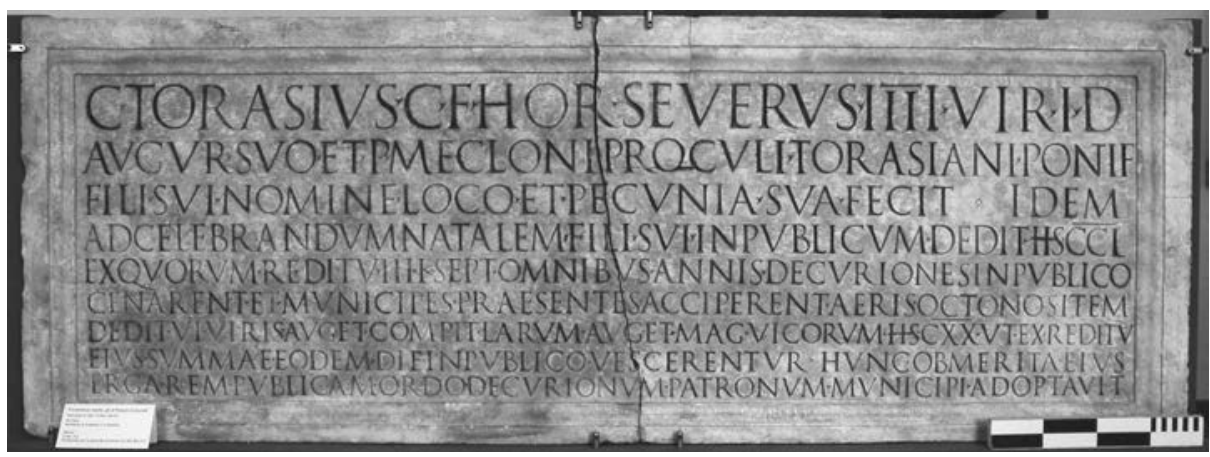

Abb. 33a: Opistographe Marmortafel aus den Thermen von Spoletium mit der Bauschinschrift des 2. Jhs. (CIL XI 4815).

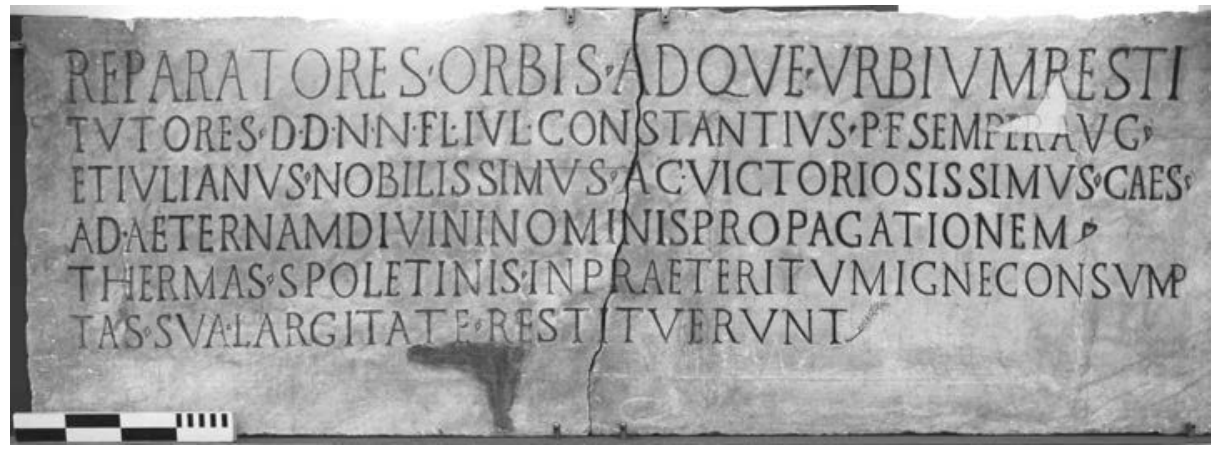

Abb.33b: Bauinschrift des 4. Jhs. auf der ehemaligen Rückseite (CIL XI 4781).

385 CIL XI 4781 bzw. 4815. 
Vergleicht man die beiden Inschriften miteinander, so wird ihre jeweilige Andersartigkeit schnell offenkundig. Ein erster Unterschied lässt sich bei dem Arrangement des Texts auf der Tafel erkennen: Während die kaiserzeitliche Inschrift durch einen profilierten Rahmen begrenzt wird, fehlt eine solche Einfassung bei der spätantiken. Erstere füllt das komplette Inschriftenfeld aus, wobei die Zeilen nach unten hin gleichmäßig kleiner werden. Bei letzteren enden einige Zeilen hingegen früher als andere, der rechte Rand flattert aus, und lediglich die erste Zeile beansprucht mehr Raum als die übrigen, untereinander gleichhohen Zeilen. Hier dienen kleine Dreiecke als Interpunktionszeichen, dort haben sie die Form kleiner Punkte und stilisierter hederae. Auch im Hinblick auf die Ausarbeitung und Gestaltung der einzelnen Buchstaben sind Abweichungen auszumachen. Die Inschrift des C. Torasius Severus wurde in einer ansehnlichen scriptura capitalis quadrata umgesetzt, die für monumentale und repräsentative Inschriften übliche Schrifttype der Kaiserzeit. Diese zeichnet sich durch annähernd quadratisch proportionierte Großbuchstaben, einen einheitlichen Duktus sowie eine kontrastierende Meißelführung mit verschieden starken Strichstärken und einem tiefen Keilschnitt aus, wodurch ein visuell interessantes Licht-Schatten-Spiel entsteht. Die einzelnen Lettern der Inschrift zeigen an ihren Ansätzen feine Serifen, die Abstriche des R und die Cauda des Q schwingen sanft aus und die Querhasten des E sitzen gleichmäßig verteilt an der Vertikalen. Die Abstände zwischen den einzelnen Buchstaben sind absolut regelmäßig, wodurch der Eindruck eines harmonischen Gesamtbilds entsteht. Bei der Inschrift des Constantius II. und des Julian dagegen wurde der quadratische Modulus der Buchstaben weitgehend aufgegeben. Er folgt hier eher der Form eines schmalen hohen Rechtecks. Die vertikalen Hasten einzelner Buchstaben verlaufen nicht exakt senkrecht, sondern neigen sich hier und da zur Seite. Die mittlere Querhaste des E sitzt oberhalb der Stammmitte, ebenso wie die Taillen des B und des R. Die Serifen sind ausgeprägt und finden sich nicht nur an den Hastenenden, sondern auch sehr prominent an den Scheiteln des A, des M und des N. Auf verschiedene Strichstärken wurde bei der Meißelführung verzichtet, alle Linien weisen stattdessen den gleichen rundförmigen Querschnitt auf. Sowohl die Breite der einzelnen Buchstaben als auch ihr Abstand untereinander variieren stark, und einzelne Lettern, wie etwa das M oder das S, zeigen unterschiedliche Formgebungen. Sie sind das eine Mal schmaler, dann wieder breiter ausgearbeitet, sind hier schwächer, dort stärker geschwungen. Im Vergleich zu der Inschrift des 2. Jhs. wirkt das spätantike Exemplar insgesamt weniger ausgewogen proportioniert, inhomogener und unruhiger - wenigstens für moderne Augen, die an die Abbildung typographischer, digital produzierter Texte gewöhnt und von der Ästhetik normierter Schrifttypen geprägt sind. Vor diesem Hintergrund wäre es daher falsch, das Erscheinungsbild der spätantiken Inschrift im Sinne einer normativen Beurteilung als Ausdruck ästhetischer Nachlässigkeit oder gar Symptom eines kulturellen Niedergangs in der Spätantike $\mathrm{zu}$ bewerten. Auch wenn derartige Urteile zuweilen auch heute noch zu lesen sind, gehört die Vorstellung vom künstlerischen Unvermögen am Ende der Antike spätes- 
tens seit Alois Riegl und seinem Begriff des „Kunstwollens“ der Vergangenheit an. ${ }^{386}$ Stattdessen sollten die so deutlich hervortretenden Veränderungen des Schriftbilds als Symptom eines umfassenderen Wandlungsprozesses verstanden werden, anhand dessen sich abzeichnet, in welche Richtung sich das visuelle Erscheinungsbild öffentlicher Inschriften zwischen Kaiserzeit und Spätantike entwickelte und inwiefern sich die Sehgewohnheiten der Zeitgenossen veränderten. So ließe sich das Schriftbild der Spätantike ebenso gut als weniger standardisiert und individueller als das des kaiserzeitlichen Gegenstücks und sein Gesamteindruck als komplexer und kreativer bezeichnen. Beide Lesarten haben ihre Berechtigung, und auch wenn jeweils unterschiedliche Bewertungen - hier eher pejorativ, dort eher meliorativ - mitzuschwingen scheinen, so beschreiben doch beide ein und dasselbe Phänomen: Das Spektrum, innerhalb dessen Schrift und Text visuell gestaltet werden konnten, weitete sich in der Spätantike erheblich aus. Gleichzeitig verwässerten zuvor herrschende Konventionen und Direktive auf diesem Gebiet oder wurden ignoriert.

Seit der Prinzipatszeit wurden insbesondere für staatliche bzw. kaiserliche Monumentalinschriften an Gebäuden und Baudenkmälern Majuskelschriften verwendet, vor allem die scriptura capitalis quadrata. Sie war ursprünglich wohl eine Schöpfung der augusteischen Zeit und fand in der Inschrift der Trajanssäule in Rom zu ihrer formvollendeten Ausgestaltung. ${ }^{387}$ Aber auch Inschriften kleineren Formats, wie etwa auf Statuenbasen und Altären oder an repräsentativen Grabdenkmälern, zeigten in der Regel wohl proportionierte Großbuchstaben. Für die Anfertigung staatlicher Dokumente, Gesetzestexte, Urkunden und Militärdiplome, für lange Ehreninschriften, aber auch für publikumswirksame Dipinti wie Wahlaufrufe wählte man hingegen die sog. scriptura actuaria. Diese war im Vergleich zur capitalis quadrata eine zwanglosere Schriftart mit weniger formstreng ausgeführten Buchstaben und einem einfachen Wechselspiel von Haar- und Schattenstrichen. ${ }^{388}$ Ihre Lettern sind wesentlich schmaler, akzentuieren die vertikalen Hasten stärker als die horizontalen und weisen recht kurze, leicht geschwungene oder geschweifte Deckstriche sowie ausgeprägte Serifen auf. Durch ihren ,lockeren‘ Charakter und den eleganten, zur Ornamentik neigenden Duktus erinnert die actuaria an handschriftliche Gebrauchs- und Kursivschriften und war wohl auch dazu gedacht, deren Stil zu imitieren. Bis in die späte Kaiserzeit hinein war das optische Erscheinungsbild öffentlich dargebrachter Inschriften durch diese beiden Schriftarten geprägt, die sich im Laufe der Zeit zwar weiterentwickelten und regional unterschiedliche Ausprägungen annahmen, die ihren grundsätzlichen formalen Merkmalen und ihrem stilistischen Charakter aber treu blieben. ${ }^{389}$ Insbe-

\section{Riegl 1901.}

387 Zur Inschrift der Trajanssäule s. Ohlsen 1981.

388 S. zum Beispiel Gordon/Gordon 1958-65, Bd. II, plate 99. no. 217.

389 Zur lateinischen Paläographie im Allgemeinen s. Bischoff 1979; zu den verschiedenen Schrifttypen der lateinischen Epigraphik und ihrer Entwicklung s. Hübner 1885 mit einer Sammlung von Abklatschen auf der Grundlage des CIL sowie einer Übersicht der chronologischen Entwicklungsstufen 
sondere im Fall öffentlicher Inschriften des Kaiserhauses kamen deutlich sichtbare Abweichungen von dem gewohnten ,typographischen Schema' selten vor. Dementsprechend waren sich zeitgenössische Stücke formal und stilistisch oft sehr ähnlich, zumal dann, wenn sie in derselben Werkstatt gefertigt wurden.

Dieses Bild eines in sich homogenen Schriftspektrums änderte sich jedoch im späten 3. und frühen 4. Jh. Von nun an ließen immer mehr Inschriften die standardisierten Buchstabenformen und kanonisierten Schriftbilder der Kaiserzeit vermissen und präsentierten sich stattdessen in einer zunehmend freien, individuellen Gestalt jenseits der bis dahin geltenden Konventionen. Ein vergleichender Blick auf einige kaiserliche Inschriften Roms aus der Zeit des Hadrian, ${ }^{390}$ der ersten Tetrarchie ${ }^{391}$ und des Konstantin I. ${ }^{392}$ führt dies besonders deutlich vor Augen. Während die hadrianischen Stücke rein optisch nur geringfügig voneinander abweichen, sich sowohl in ihrem Duktus als auch in ihrer handwerklichen Ausführung wenig unterscheiden, präsentieren sich die spätantiken Stücke disparater. Sie zeigen verschiedene Schrifttypen und Stile sowie unterschiedliche Buchstabenformen, die nicht nur je nach Schrifttyp, sondern auch innerhalb derselben Inschrift variieren. Wie sehr sich der schriftbildliche Gesamteindruck öffentlicher Inschriften gleicher Zeitstellung und Herkunft nunmehr unterscheiden konnte, zeigt auch die Gegenüberstellung dreier Basen- bzw. Altarinschriften aus Rom (Abb. 34, 35, 36). Sie sind von handwerklich ähnlicher Qualität und wurden alle um die Wende des 4. zum 5. Jh. zur Aufstellung gebracht.

Die für den Konsul und Prätorianerpräfekten Sextus Petronius Probus im Jahr 395 errichtete Ehreninschrift (Abb. 34) 393 $^{39}$ hnelt in ihrem Charakter noch am ehesten der kaiserzeitlichen capitalis quadrata und zeigt neben einem annähernd quadratischen Modulus, wohl proportionierten Buchstaben und feinen Serifen auch ein ebenes Schriftbild und regelmäßige Zeilen- und Buchstabenabstände. Die nur wenige Jahre später um 404 entstandene Basis für den Stadtpräfekten Flavius Peregrinus Saturni-

der scriptura capitalis quadrata und der scriptura actuaria; s. außerdem Mallon 1952 und Gordon/Gordon 1957. Zuweilen begegnet in der Literatur auch die Bezeichnung scriptura cursiva oder rustica für eine dritte Form der Majuskelschrift, die mit ihren schmalen bogigen Buchstaben und ihrem flüchtigen Charakter noch stärker als die actuaria an Buchschriften erinnert und hier ihre Entsprechung am ehesten in der scriptura libraria findet. Für die Klassifizierung eines eigenständigen epigraphischen Schrifttypus eignet sie sich allerdings nur bedingt, da sie nahezu ausschließlich für Kleininschriften, Graffiti sowie für auf Holz oder Wachs eingeschriebene Texte, nicht aber für öffentliche Monumente verwendet wurde. Es handelte sich also um eine ganz auf den Bereich des privaten Schriftwesens konzentrierte Form, die sich Regelhaftigkeiten weitgehend entzog; zu diesem Problemkreis s. Del Corso 2010, 208f.

390 S. hierzu die Abbildungen bei Gordon/Gordon 1958-65, Bd. II, zum Beispiel Pl. 85a No. 191; Pl. 90a No. 198; Pl. 90b No. 200; Pl. 91a No. 199.

391 Gordon/Gordon 1958-65, Bd. III, zum Beispiel Pl. 146b No. 307; Pl. 147a No. 310; Pl. 147b No. 312; Pl. 147d No. 313.

392 Gordon/Gordon 1958-65, Bd. III, zum Beispiel Pl. 154a No. 324; Pl. 154b No. 325; LSA 1386.

393 CIL VI 1753. 


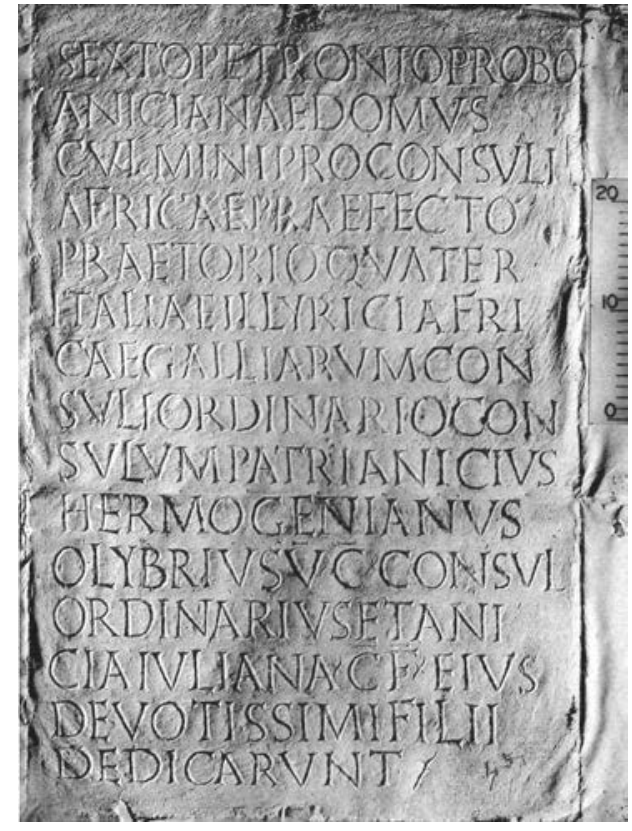

Abb. 34: Ehreninschrift für Sextus Petronius Probus, Rom (Abklatsch).

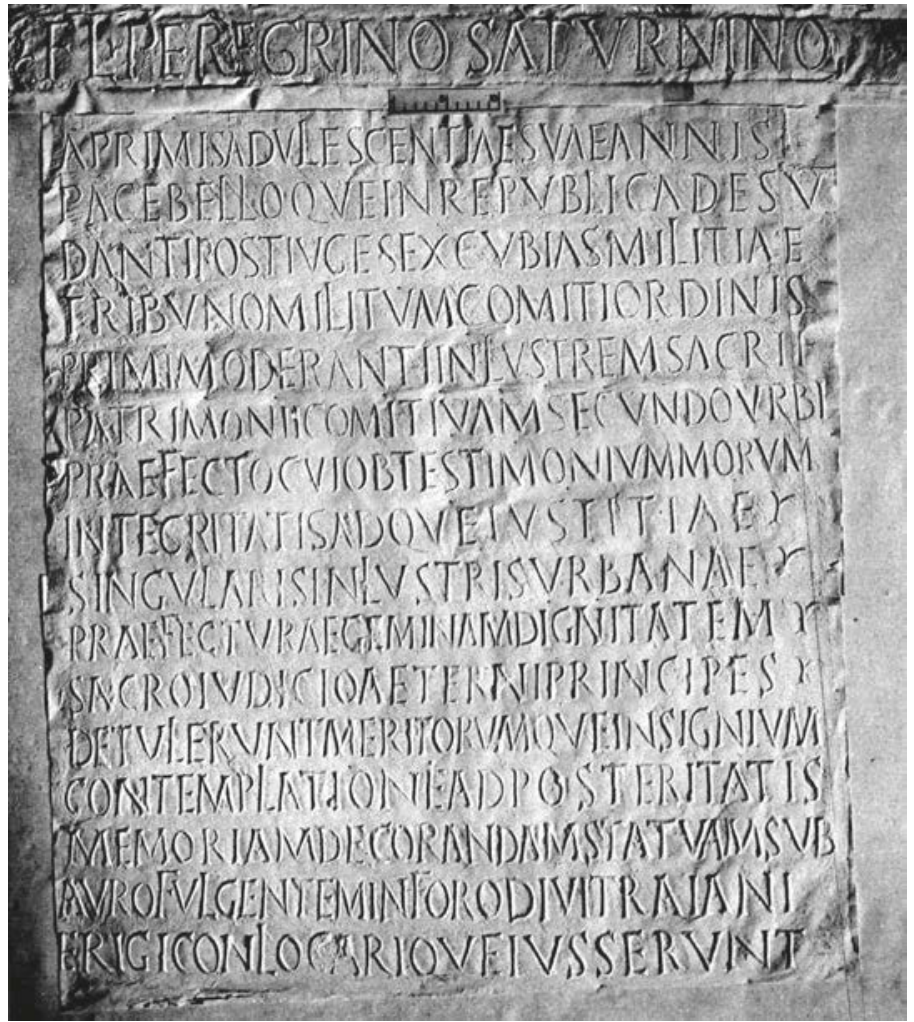

Abb. 35: Ehreninschrift für Flavius Peregrinus Saturninus, Rom (Abklatsch). 


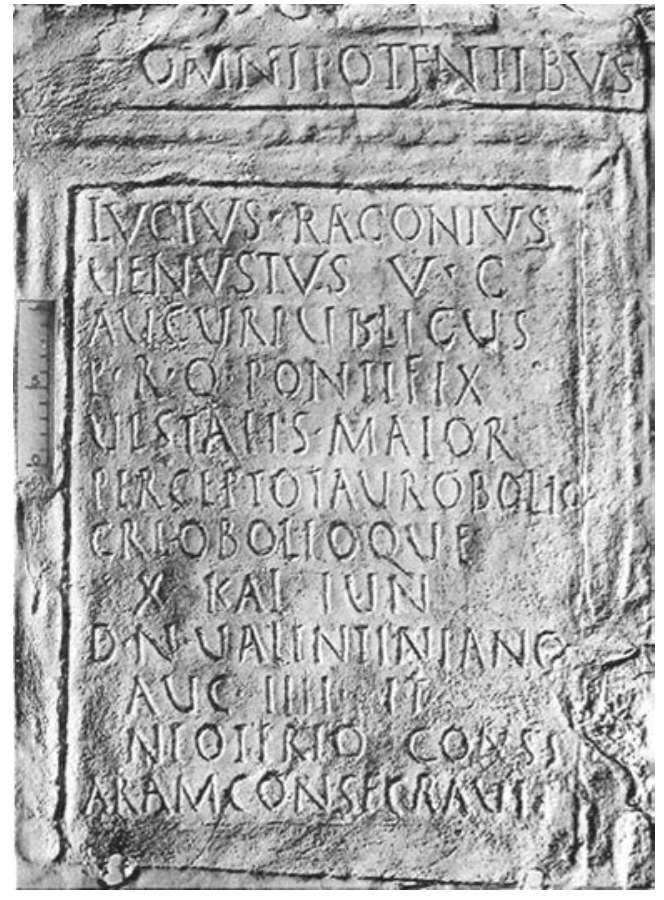

Abb. 36: Weihinschrift des Ragonius Venustus, Rom (Abklatsch).

nus (Abb. 35) ${ }^{394}$ weist bei genauem Hinsehen deutliche Unterschiede in der Gestaltung einzelner Buchstaben auf, die sich am auffälligsten im gebrochenen Querstrich des A und der nach innen gerollten Haste des G im Schriftzug des signum auf dem Basisaufsatz niederschlagen - im Übrigen zwei Gestaltungselemente, die sich erst in der Spätantike auf breiter Linie durchsetzten und sich danach zu einem typischen Merkmal frühmittelalterlicher Inschriftenkunst entwickelten. Ein anderes Charakteristikum der Spätantike zeigt auch das dritte Beispiel einer Altarinschrift des Jahrs 390 mit einer Weihung des Auguren Lucius Ragonius Venustus an die Dii omnipotentes (Abb. 36). ${ }^{395}$ Das U bzw. V wurde hier in verschiedenen Varianten ausgeführt, begegnet einmal mit gleichmäßig aufeinander zulaufenden Diagonalen, ein anderes Mal mit einem vertikalen rechten und einem gebogenen linken Schenkel.

Was sich bei den Inschriften des öffentlichen Raums - das heißt Ehreninschriften, Dedikationsinschriften und Bauinschriften - seit dem 4. Jh. noch vergleichsweise schwach abzeichnete, manifestierte sich bei den Inschriften des sepulkralen Raums offenkundiger. Es sind vor allem diese, dem persönlichen Gedenken zugehörigen Zeugnisse, die eine reiche Quelle für die verschiedenen Spielformen spätantiker Schriftgestaltung bieten. Gleichzeitig illustrieren sie den Wandel von einer tendenziell konformistischen hin zu einer stärker individualistischen Inschriftenkultur in der 

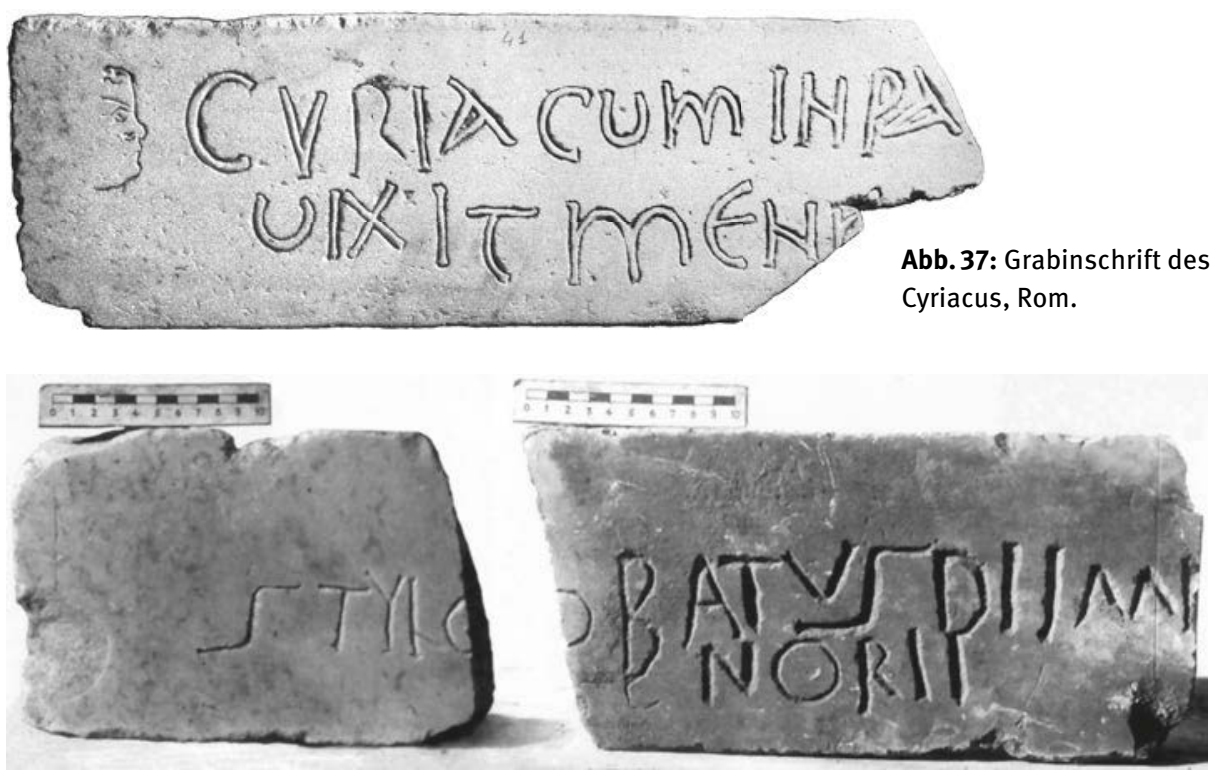

Abb. 38: Grabinschrift des Stylobatus, Rom.

Spätantike. Was dies konkret bedeutete, veranschaulichen einige Exemplare römischer Loculusplatten und Grabtafeln: die beiden in Kontur gearbeiteten Grabinschriften des Cyriacus (Abb. 37) ${ }^{396}$ und der Aurelia; ${ }^{397}$ diejenige des Stylobatus mit ihrem sonderbar anmutendem rechtwinkligen S (Abb. 38); ${ }^{398}$ die Grabtafel des Fl. Marianus Iunior, auf welcher neben den üblichen Kapitalen auch die Unzialen $\mathfrak{M}$ und $\mathbf{U}$ sowie die Minuskel a begegnen (Abb. 39); ${ }^{399}$ oder die Inschrift der Pulla und des Scolasticus, bei der das A gleich in mehreren Varianten vorkommt, unter anderem auf dem Kopf stehend (Abb. 40). ${ }^{400}$

Wie es diese wenigen aus einer Fülle ähnlicher Stücke ausgesuchten Beispiele andeuten, warteten die Inschriften der Spätantike seit dem 4. Jh. nicht nur mit den sonst üblichen indistinkten Versalschriften auf. Sie zeigten nunmehr verstärkt auch andere Schrift- und Buchstabenformen, darunter individuell geformte, mitunter verspielte Majuskeln, Unzialen mit abgerundeten Schäften und zunehmend häufiger auch Minuskeln, also Kleinbuchstaben, wie sie bis dahin eigentlich nur für Buchschriften verwendet worden waren. Beispiele dieser Art sind häufig unter denjenigen Inschriften $\mathrm{zu}$ finden, die nicht in den Stein eingemeißelt, sondern darin eingeritzt

396 ICUR I 1577 = Ehler 2012, II.1.10.

397 ICUR V 14059 = Ehler 2012, II.10.40 mit Abbildung.

398 SII Roma II 3276.

399 AE 1999, 391; Illuminati 1999, 685f.

400 ICUR I 741 = II 4519 = EDB 18950 = Ehler 2012, VIII.2.21. 


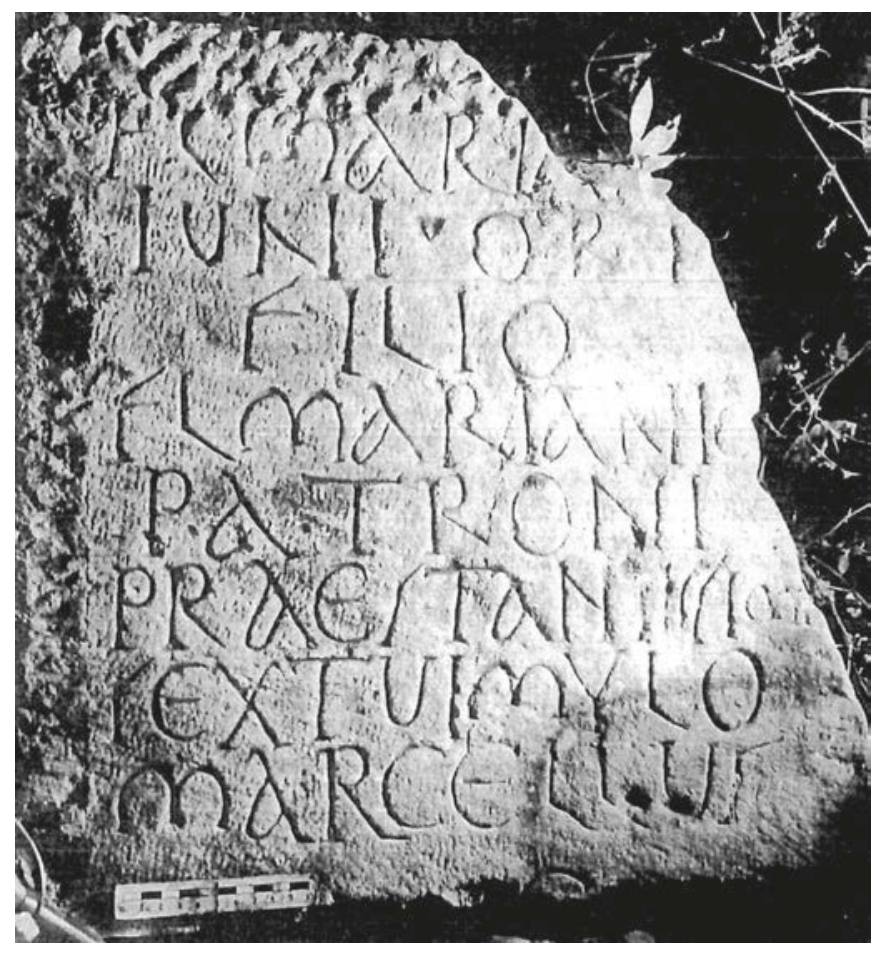

Abb. 39: Grabinschrift des Fl. Marianus, Rom.

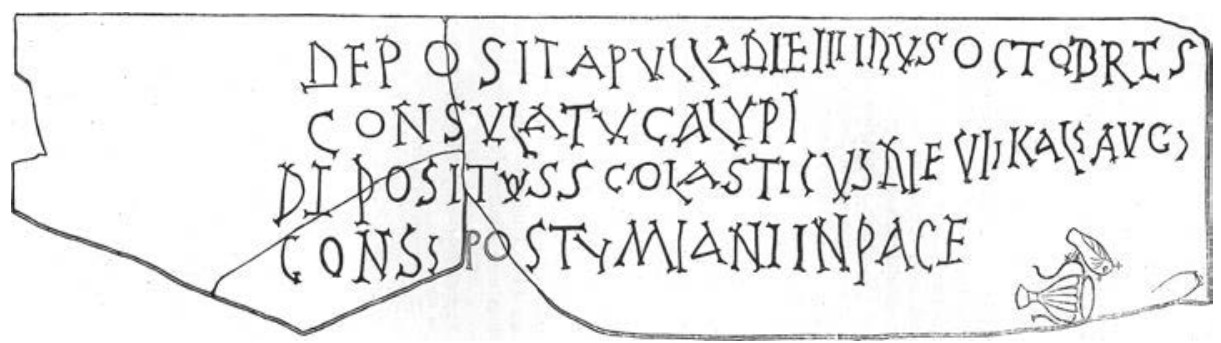

Abb. 40: Grabinschrift der Pulla und des Scolasticus, Pontianus-Katakombe in Rom.

wurden, wie es zum Beispiel in der Katakombe S. Theodora in Rom des Öfteren der Fall war. ${ }^{401}$ Dass ausgerechnet Graffiti vielfach handschriftlichen Charakter annahmen, liegt nahe, wurden solche Texte doch ohne zeichnerische Vorlage, wahrscheinlich erst vor Ort am Grab und unter Verwendung eines einfachen spitzen Griffels umgesetzt, mit dem man die Schrift wie mit einem Pinsel oder einer Feder gestalten konnte. Doch auch unter den mit Hammer und Meißel in einer Werkstatt gefertigten Inschriften sind Mischformen keine seltenen Ausnahmen. So tauchen einzelne Unzialen seit

401 S. zum Beispiel ICUR I 55, 75, 81, 86. 


\section{ÇENTIANUSFIdEIIININACEIUIUIX ITANNISXXIMENSSVIIIDIES XVIETINOA EXROSRATIONISTUIS ROSESPRONOBISTUIASCIMUSTENR}

Abb. 41: Grabinschrift des Gentianus, Rom.

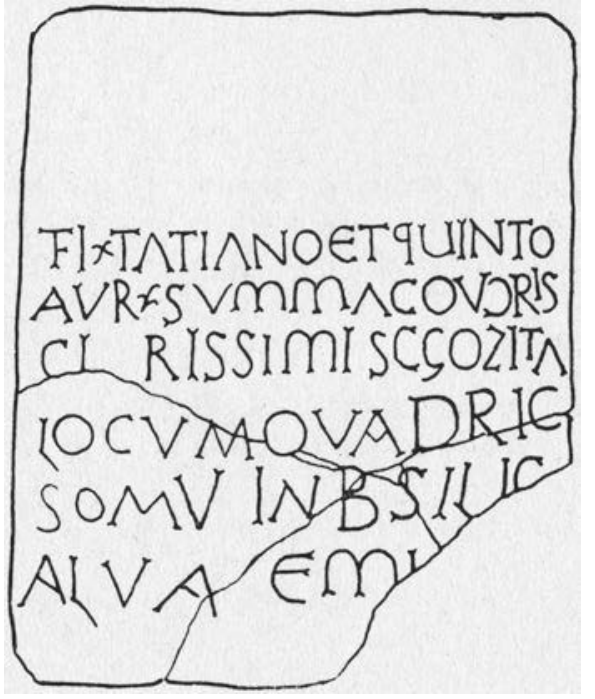

Abb. 42: Grabinschrift der Zita, Rom.

dem mittleren 4. Jh. immer wieder zwischen den in ihrer Formgebung vertrauten Kapitalen auf, beispielsweise in der Grabinschrift des Gentianus ${ }^{402}$ (Abb.41), derjenigen der Zita (Abb. 42), ${ }^{403}$ oder des kleinen, im Alter von fünf Jahren verstorbenen Mercurius. $^{404}$

Während bei diesen Beispielen der Text einem Konglomerat aus Buchstabenformen verschiedener Schriftarten gleicht, Majuskeln, Unzialen und Minuskeln also nebeneinander im selben Wort vorkommen, zeigen andere Stücke eine weitere Variante für die Vermischung unterschiedlicher Schrifttypen innerhalb eines Texts. Bei dieser mischte man allerdings nicht die Buchstabenformen untereinander, sondern wählte für bestimmte Textpassagen jeweils andere Schriftarten.

402 ICUR VIII 22480 = ILCV 2350 = ICaRoma 94; Dresken-Weiland 2012, 109f. Nr. I.11.

403 ICUR III 8428 = ILCV 3821.

404 ICUR IX 24061 = EDB 13013 = Ehler 2012, VI.4.6 mit Abbildung. 


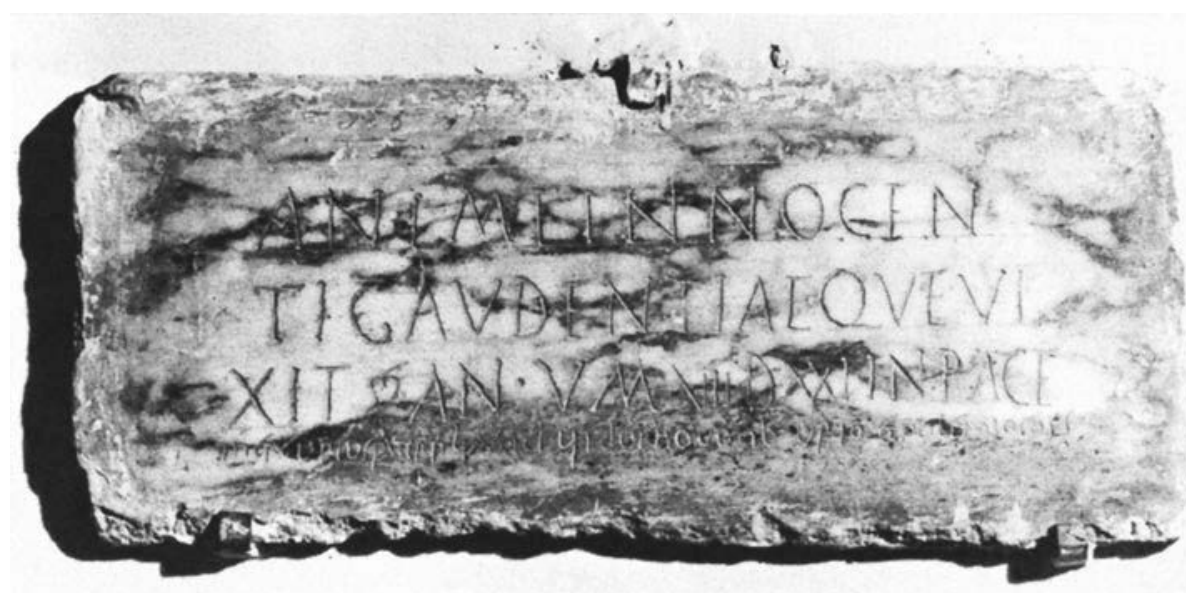

\section{Linnininine}

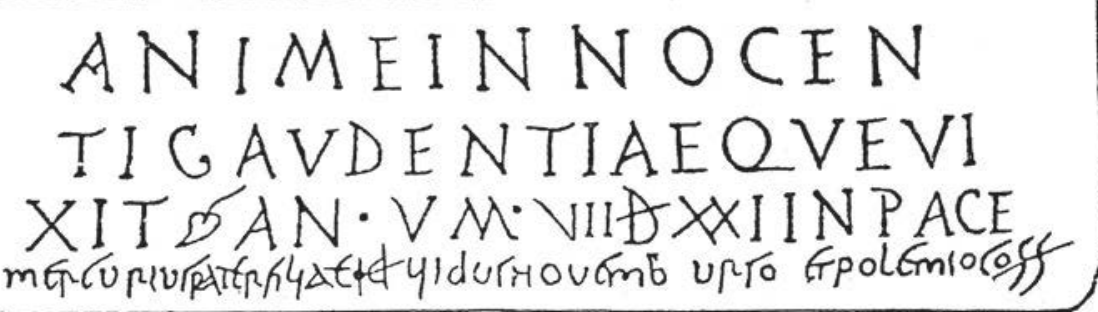

Abb. 43: Grabinschrift der Gaudentia, Rom.

Auf der Grabplatte der kleinen Gaudentia etwa (Abb.43) erscheinen die ersten drei Zeilen der Inschrift mit den Worten Anime innocen/ti Gaudentiae que vi/xit an(nos) $V m$ (enses) VII d(ies) XXI in pace in den für die Zeit geläufigen Großbuchstaben. Die letzte Zeile mit der Nennung des für ihre Bestattung verantwortlichen Vaters Mercurius und der Angabe des Beisetzungsdatums wurde hingegen in einer kleineren Kursivschrift unter Verwendung von Unzialen und Minuskeln ausgeführt. ${ }^{405}$ Platzmangel allein wird dabei wohl kaum ausschlaggebend gewesen sein, wie es andere Exemplare gleicher Machart nahelegen, bei denen der letzte Teil der Inschrift mit der Datumsangabe und der Nennung der amtierenden Konsuln ebenfalls in einer Kursive ausgeführt wurde, und das, obgleich genügend Raum für großformatige Majuskeln gewesen wäre. ${ }^{406}$ Offenbar wurden die verschiedenen Passagen der Inschriften - persönliche

405 ICUR VII 17426

406 S. zum Beispiel ICUR II 4898 mit Abbildung. 
Angaben der Verstorben auf der einen Seite und quasi ,amtliche Informationen ex officio' auf der anderen Seite - in ihrem inhaltlichen Charakter als so unterschiedlich empfunden, dass man sie auch visuell voneinander zu scheiden suchte und ihnen jeweils andere Schriftbilder verlieh: Die Großbuchstaben für den Namen und das Lebensalter der Verstorbenen verschafften durch ihre starke optische Präsenz dem Wunsch nach dauerhafter Erinnerung an deren Person Ausdruck. Die flüchtigen, einer Handschrift ähnelnden kursiven Kleinbuchstaben für die Nennung des Datums und der amtierenden Beamten hingegen griffen den dokumentarischen Charakter dieses formelhaften Standardelements spätantiker Grabtituli auf. ${ }^{407}$ Inschriften wie diejenige der Gaudentia lassen daran denken, dass die Vorstellung von verschiedenen Schriftarten im Sinne zusammengehöriger Schriftzeichen mit einer gemeinsamen Struktur und gleichen Formprinzipien anscheinend auch auf dem Feld der Inschriftenkunst von Bedeutung war. Demnach waren die diversen Schriftarten nicht nur verschiedenen Zwecken und Kontexten zugeordnet, sondern konnten diese in einer wechselseitigen Beziehung auch repräsentieren.

Jenseits des Schriftbilds nahm auch die Anordnung des Texts auf dem Untergrund, die mise en page ${ }^{408}$ freiere, mitunter eigentümliche Formen an. Waren die Inschriften des öffentlichen Stadtraums wie auch diejenigen an den Gräbern und Grabdenkmälern der Kaiserzeit zumeist um ein möglichst symmetrisches, jedenfalls gleichförmiges Arrangement des Texts bemüht, scheint man in der Spätantike auch auf diesem Gebiet neuartige Wege fernab konventioneller visueller Schemata gegangen zu sein. ${ }^{409}$ Einen Extremfall vom äußeren Ende einer gedachten Skala zwischen einer strukturierten und einer willkürlichen mise en page hält ein Fundstück in den Vatikanischen Museen in Rom bereit. Es ist die Verschlussplatte vom Grab des in jugendlichem Alter verstor-

407 In gesteigerter Form lässt sich eine solche Konvergenz von Schriftinhalt und Schriftgestaltung an einer Inschrift des Jahrs 533 aus Didyma nachvollziehen. Dabei handelt es sich um ein Reskript Justinians. Es legte fest, dass die bisher von Milet eingezogenen Grundsteuern der kürzlich unabhängig gewordenen Stadt Ioustinianopolis/Didyma künftig von Milet zu erbringen seien. Für die Inschrift wurden drei verschiedene Schrifttypen und unterschiedliche Alphabete verwendet: griechische Kapitalen für den konkreten Inhalt, lateinische Halbunzialen und lateinische kursive Majuskeln für die Datierung mit dem Namen und der Titulatur Kaiser Justinians. Die Anordnung des Texts auf der Stele ist dem Textarrangement eines juristischen Papyrus nachempfunden; zu dem Stück s. ausführlich Feissel 2004. Beispiele eines solchen ,epigraphischen Dossiers' sind im lateinischen Westen unseres Untersuchungsgebiets nicht bekannt. Die Provinz Africa Proconsularis hält indes ein ähnliches Beispiel eines weiteren justinianischen Dekrets bereit, bei dem die aus der offiziellen Rechtsterminologie stammenden Begriffe sancimus und firmamus in Minuskeln, der Rest des Texts aber in Majuskeln geschrieben steht: CIL VIII 23127 = ILTun 268 = ILCV 1642 = CICBardo 12 = AE 1996, 1703.

408 Der Begriff mise en page stammt aus der Buchdruckerkunst und wird vor allem für Handschriften und Drucke angewendet. In seiner Bedeutung als ,Layout‘ ist er aber auch für epigraphische Texte geeignet und soll daher auch in diesem Zusammenhang Verwendung finden.

409 Generell zum Aspekt der graphischen Textanordnung auf dem Inschriftenfeld s. Sartori 1995. 


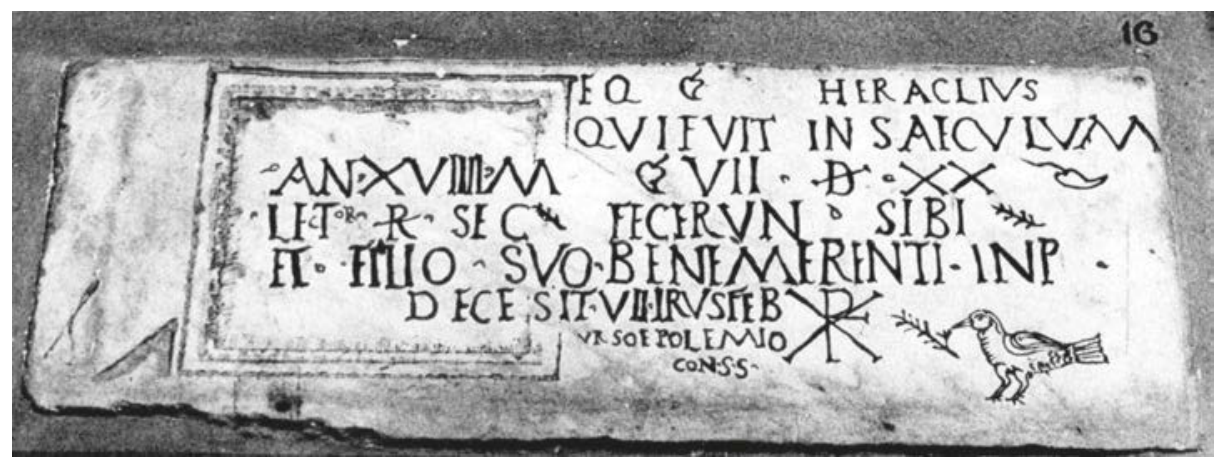

Abb. 44: Grabinschrift des Heraclius, Rom.

benen Heraclius, auf welcher die Inschrift auf den ersten Blick unstrukturiert, jedenfalls sehr ungewöhnlich angeordnet wurde (Abb. 44). ${ }^{410}$

Bevor die Eltern des Heraclius die Platte für die Grablege ihres Sohnes in Gebrauch nahmen, diente das Stück offenbar als Front eines Sarkophags, wie es die auf der linken Seite noch deutlich sichtbare tabula ansata nahelegt. Sie sollte wohl als Rahmung für die Namensinschrift des Beigesetzten dienen. Als der mit der Inschrift des Heraclius beauftragte Steinmetz mit seiner Arbeit begann, nahm er auf das alte Überbleibsel offenbar noch Rücksicht und ließ den Text direkt rechts daneben beginnen. Doch schon in der dritten Zeile gab er das Vorhaben, die Tafel auszusparen, auf und ließ die restliche Inschrift schlichtweg darüber laufen. Ein einheitliches Zeilenmaß vermisst man ebenso wie regelmäßige Abstände zwischen den einzelnen Buchstaben und Wörtern. Die Höhe der Zeilen variiert zwischen fünf und acht Zentimetern. Zwischen einigen Wörtern herrschen große, zwischen anderen sehr kleine Abstände. Unregelmäßig und ohne erkennbaren Plan wurden Interpunktionszeichen gesetzt, welche die Form von Punkten, hederae oder Palmzweigen annehmen. Rechts unterhalb des Texts fügte der Steinmetz ein Christogramm ein, das in ungewöhnlicher Art und Weise eine zusätzliche horizontale Linie unter dem Bogen des P zeigt. Daneben erscheint die Abbildung eines kleinen Vogels mit einem Zweig im Schnabel. Was das Schriftbild angeht, so wirkt dieses sehr unruhig, und das nicht nur aufgrund der uneinheitlich gestalteten Buchstaben mit verschiedenen Moduli und unterschiedlichen Strichstärken. Dazu tragen auch die Einfügung kleiner Lettern am oberen Zeilenrand (Superpositionen) bei dem Wort $\mathrm{LE}^{\mathbf{C}} \mathrm{T}^{\mathbf{0 R}}$ und die Durchstreichungen einzelner Buchstaben bei,

410 ICUR III 8719 = ILCV 1266: Eq(uitius?) Heraclius / qui fuit in saeculum(!) / an(nos) XVIIII m(enses) VII d(ies) XX / lector $r$ (egionis) sec(undae) fecerun(t) sibi / et filio suo bene merenti in $p$ (ace) / deces(s) it VII Irus(!) Feb(ruarias) / Urso e(t) Polemio / cons(ulibus). Zu dem Stück s. Gordon/Gordon 1958-65, Bd. III, 113f. Nr. 316; di Stefano Manzella 1997, 3.3.6; Ehler 2012, V.3. 8. Der ursprüngliche Aufstellungsort ist nicht mehr eindeutig zu rekonstruieren, vgl. Gordon/Gordon 1958-56, Bd. III, 113. Die Ausmaße betragen 44,3 $\times 106,1 \times 1,6-4,8 \mathrm{~cm}$, die Buchstabenhöhe schwankt zwischen 5,2 und $8 \mathrm{~cm}$. 


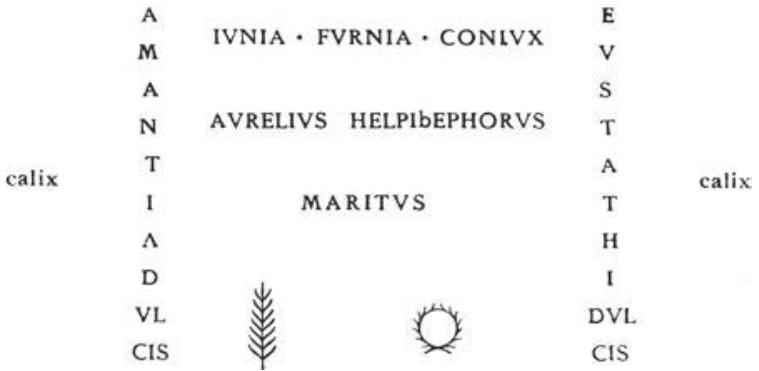

\author{
Abb. 45: Grabinschrift des Paares \\ Amantia und Eusthatus, Calixtus- \\ Katakombe in Rom.
}

mit denen Abkürzungen deutlich gemacht wurden. Ganz offenbar hatte kein ordinator Hand an das Stück gelegt, bevor der Steinmetz den Text in den Stein einmeißelte, denn sonst wäre ihm sicherlich eine ansehnlichere, das heißt strukturiertere mise en page gelungen. Womöglich war der Steinmetz auch wenig geschult darin, Inschriften dieses Formats anzufertigen. In Anbetracht des spontanen, intuitiven Charakters des Arrangements auf der Tafel war er vielleicht als Maler ausgebildet worden und hatte versucht, die ihm bekannte Technik des Farbauftrags auf das fremde Material des Marmors zu übertragen..$^{411}$ Doch selbst wenn seine handwerklichen Fähigkeiten in dieser Hinsicht vergleichsweise gering waren, so ist ihm ein gewisser künstlerischer Gestaltungswille doch nicht abzusprechen - die bewusste Formgebung des A mit gebrochenem Querstrich, die leicht geschwungene Horizontale des L, die feinen Serifen auch am Durchstrich des D und nicht zuletzt die Abbildung der kleinen Vogelfigur sprechen jedenfalls dafür. Und ganz offensichtlich waren ja auch die Auftraggeber mit dem Stück zufrieden, sodass sie es für die Erinnerung an ihren Sohn zur Aufstellung bringen ließen.

Nun ist die Inschrift des Heraclius sicherlich nicht repräsentativ. Sie führt aber allemal vor Augen, welche Entwicklung die visuelle Gestaltung von Inschriften in der Spätantike nehmen konnte. Andere, weniger extreme Beispiele weisen in die gleiche Richtung und zeugen von einer zwanglosen Textgestaltung, die weniger von der Idee einer allgemeingültigen Ästhetik als vielmehr von den persönlichen Stilen und Vorlieben des Einzelnen getragen war. Am deutlichsten zeigt sich dies in der vielfältigen Kombination von Schrift und Bild, der wir uns später noch genauer zuwenden wollen, ferner aber auch in der Anordnung des Texts innerhalb des Inschriftenfelds. Um dieses einzurahmen, waren (wie auch schon in der Kaiserzeit) tabulae ansatae sehr beliebt, insbesondere im Fall von Loculusplatten und Sarkophagen. ${ }^{412}$ Es finden sich aber auch andere Formen wie einfache Rechtecke ${ }^{413}$ oder Trapeze, so etwa auf der Loculusplatte vom Grab der Amantia und des Eusthatus (Abb. 45).414

411 So die Idee bei Illuminati 1999, 684.

412 Für Beispiele für tabulae ansatae auf Loculusplatten s. Ehler 2012, II.7.16; V.4.11; VI.1.16; für Sarkophage s. Dresken-Weiland 2003.

413 S. zum Beispiel Ehler 2002, V.5.2; VII.2.12.

414 ICUR III 8969 = Ehler 2012, VIII.1.23. 


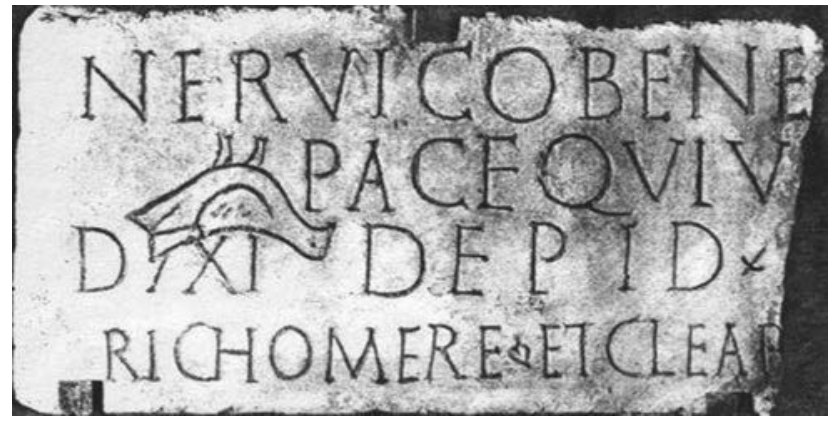

Abb. 46: Grabinschrift des Nervicus, Coemetrium subdiale ad Catacumbas in Rom.

Die Inschrift aus der Calixtus-Katakombe bietet ferner ein anschauliches Zeugnis für ein bewusstes, auf optische Attraktivität hin ausgerichtetes und vor allem individuell gestaltetes Textarrangement. Die Namen der Verstorbenen wurden senkrecht und gleichsam als Rahmung für die Nennung der beiden zurückgebliebenen Ehepartner Iunia Furnia und Aurelius Helpidephorus eingeschrieben. Vertikal ausgerichtete Schrift gab es auch anderswo, wobei ihre spezifische Anordnung von oben nach unten allerdings nicht nur im Hinblick auf eine reizvolle mise en page eine Rolle spielte, sondern auch von der textlich-inhaltlichen Gestaltung der Inschrift herrühren konnte. Die Rede ist hier von Akrosticha, also von Texten, bei denen die Anfangsbuchstaben der einzelnen Zeilen ein Wort oder einen Satz ergeben. Unter spätantiken Grabinschriften und -epigrammen sind sie häufiger zu finden. ${ }^{415}$ Vielfach begegnen auch auf dem Kopf stehende Schriftzüge bzw. Inschriften, bei denen der Text und die zugehörige figürliche Abbildung einander entgegenstehen, wie bei einem Stück aus der Priscilla-Katakombe, ${ }^{416}$ einem zweiten aus dem Friedhof von S. Paolo fuori le mura ${ }^{417}$ oder einem dritten aus dem Coemetrium subdiale ad Catacumbas (Abb. 46).418

Wie es zu dieser, für uns befremdlichen Anordnung kommen konnte, ob dem Steinmetzen schlichtweg ein Fehler unterlaufen ist oder er Text und Bild absichtlich gegensätzlich ausrichtete, zum Beispiel weil der Stein als Bodenplatte Verwendung finden und als solche von mehreren Richtungen aus ,lesbar' sein sollte, ist schwer $\mathrm{zu}$ entscheiden. Fest steht, dass es der Funktion der Inschrift als Erinnerungsmal offenkundig keinen Abbruch getan hat, und dass sich die Käufer von dem eigentümlichen visuellen Eindruck nicht dazu veranlasst sahen, das Stück nicht zu erwerben. Ohnehin scheinen kleinere optische Unstimmigkeiten (oder was wir als solche empfinden), namentlich spiegelverkehrt eingemeißelte Buchstaben ${ }^{419}$ oder Korrekturen ${ }^{420}$

415 S. hierzu das auf S. 71f. besprochene Akrostichon oder das Damasus-Epigramm aus der Crypta Hippolyti: Damas. Epigr. 35¹. Zu spätantiken Akrosticha s. Sanders 1991, 183-205.

416 ICUR IX 24964 = Ehler 2012, V.1.24 mit Abbildung.

417 Ehler 2012, V.2.31 mit Abbildung.

418 ICUR V 13347 = Ehler 2012, V.1.61.

419 S. zum Beispiel ICI III 45; ICI VIII 58, 69; ICI XIII 16, jeweils mit Abbildung.

420 Zum Beispiel: Ehler I.7. 5; ICI XIV 21, jeweils mit Abbildung. 


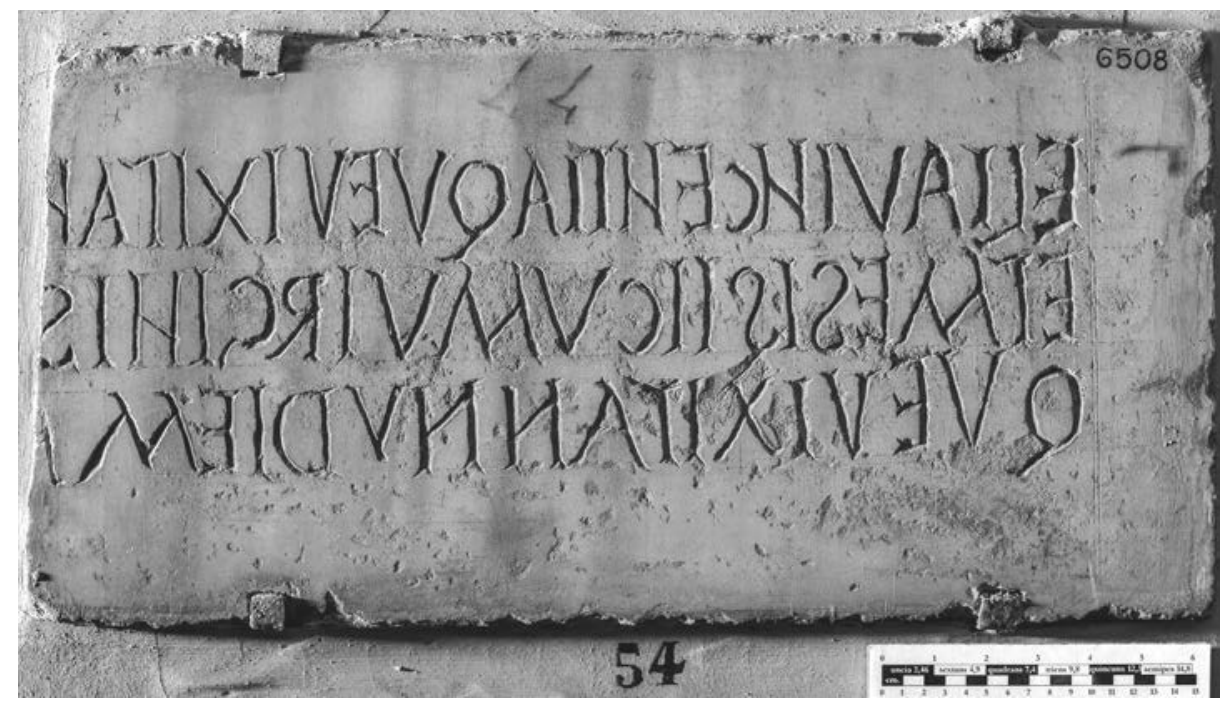

Abb.47: Grabinschrift der Elia Vincentia, geschrieben in Spiegelschrift, Rom.

auch bei technisch hochwertigeren Stücken ebenso wenig gestört zu haben wie die so häufig vorkommenden grammatischen Fehler. ${ }^{421}$

In dieser Hinsicht rätselhaft ist die Grabinschrift der Elia Vincentia aus Rom, deren kompletter Text in Spiegelschrift eingemeißelt wurde (Abb.47). ${ }^{422}$ Die Inschrift ist so außergewöhnlich und geradezu kurios, dass überzeugende Erklärungen nicht einfach zu finden sind. Um das Resultat einer Unachtsamkeit wird es sich jedenfalls kaum handeln, denn es ist nur schwer vorstellbar, dass der Steinmetz eine komplette Inschrift ,aus Versehen' spiegelverkehrt eingemeißelt haben soll. Und selbst wenn man annimmt, dass der Fehler bereits bei der ordinatio passiert war, dass die auf Papyrus oder Pergament vorliegende Vorlage also falsch herum auf den Stein gelegt und folglich spiegelverkehrt durchgepaust worden war, so ist es mehr als unwahrscheinlich, dass der Steinmetz diesen Lapsus nicht bemerkt haben sollte. Angesichts der handwerklichen Qualität des Stücks war dieser außerdem kein Anfänger und hätte den

421 Zwei Beispiele unter vielen: die Grabinschrift eines gewissen Liber aus Rom: Liber qui vixi(t) qum(!) quo(m)/pare(!) iua(!) an(n)oi(!) V et an(n)oru/m plui(!) minui(!) XXXI pace[m consecutus est] (ICUR II 4636); die Bauinschrift des Amphitheaters aus Veletriae: $D D$ (ominis) nn(ostris) Valentiniano et Valente senper(!) Augg(ustis) / Lol(ius?) Cyrius princ(ipalis) cur(iae) et eritor(!) duodena de prop(r)io suo / vetustate $\{m\}$ conlapsum at(!) statum pristinum red[u]cit)(!) / amphiteatrum cum portis posticiis et omnem fabric[am] / aren(a)e nepus(!) Lol(li?) Cyri princ(ipalis) cur(iae) et ante eretoris(!) filius Lol(li?) / Claudi princ(ipalis) et patroni curiae pronepos Messi Gorgotis / princ(ipalis) filiciter(!) (CIL X 6565). Zu diesem Phänomen s. Wachter 1992 mit einer Klassifizierung verschiedener Fehlertypen in griechischen und lateinischen Inschriften; Solin 1995 mit einer Studie zu den Ursachen von Schreibfehlern in lateinischen Inschriften.

422 ICUR IV 12551 = ILCV 4250 = di Stefano Manzella 1997, 264f. Nr.3.4c.7. 
misslungenen Entwurf sicher nicht ausgeführt. Die Inschrift muss also absichtlich verkehrt herum eingemeißelt worden sein, und zwar auf Verlangen des Auftraggebers. Was mochte ihn dazu bewogen haben? War es eine besondere Form der Trauerbewältigung, in der sich die Klage über eine unbegreifliche, ,verkehrte' Welt niederschlägt, in der nach dem Tod eines geliebten Menschen nichts mehr so ist, wie man es kennt? Steckte der Glaube an magische Kräfte dahinter und war die spiegelverkehrte Schrift Sinnbild eines rituellen Zaubers? Ist die Inschrift Ausdruck des Wunschs nach unverwechselbarer Einzigartigkeit und das Resultat eines extravaganten Selbstdarstellungsbedürfnisses? Oder am Ende doch das Ergebnis einer ,verrückten Idee“ eines kreativen Steinmetzes? Eine eindeutige Antwort wird man wohl schuldig bleiben müssen, zumal wir den genauen Fundkontext des Stücks nicht kennen. Wir müssen daher auch damit rechnen, dass die Inschrift niemals zu sehen gewesen und die Tafel womöglich mit der Schriftseite nach innen am Grab angebracht war - obgleich die Vorstellung einer absichtsvollen Präsentation der Inschrift wesentlich reizvoller ist.

In welchem Kontext die Inschrift der Elia Vincentia auch immer Verwendung fand, in jedem Fall wirft sie ein bezeichnendes Schlaglicht auf den Fertigungsprozess sowie die Fähigkeiten und Kompetenzen der beteiligten Handwerker und lenkt unseren Blick damit auf einen für das Verständnis der (spät)antiken Inschriftenkultur zentralen Aspekt, nämlich denjenigen des Herstellungsprozesses inschriftlicher Monumente, auf ihre Auftraggeber, Käufer und ausführenden Werkstätten. Die Rahmenbedingungen für die Produktion inschriftlicher Monumente veränderten sich in der Spätantike ebenso wie es Angebot und Nachfrage, Kundschaft und Produzenten, Sehgewohnheiten und ästhetisches Empfinden taten. Sucht man nach den Gründen für den so deutlich spürbaren Wandel in der Gestaltung des Schriftbilds spätantiker Inschriften, so muss man mithin auch danach fragen, wer diese zu welchem Zweck in Auftrag gegeben hat, wer sie ausführte und an welchen ästhetischen Leitbildern man sich bei der Anfertigung orientierte.

Dabei sollte allerdings nicht vergessen werden, dass unser Bild von der qualitativen, stilistischen und ästhetischen Erscheinung spätantiker Inschriften maßgeblich von einem ganz bestimmten Inschriftentypus geprägt ist, und zwar von jenem der Grabinschriften, die in einigen Regionen des Römischen Reichs gut drei Viertel des erhaltenen Gesamtbestands stellen und aus deren Gruppe wir die meisten der soeben angeführten Beispiele entnommen haben. Doch obgleich der übergroße Anteil der Grabinschriften kein bloßer Zufall der Überlieferung ist, sondern der Kontext der Bestattung tatsächlich die meisten Inschriften hervorgebracht hat, birgt die Fokussierung auf eben jene sepulkralen Inschriften forschungspraktische Gefahren im Hinblick auf die Frage, wie es zu dieser tendenziell ,ent-formalisierten', ,ent-konformisierten' Inschriftengestaltung in der Spätantike kommen konnte. Mehr als die im öffentlichen Stadtraum zur Aufstellung gebrachten civic inscriptions boten die Grabinschriften durch ihren privateren Charakter größere Freiräume was die Umsetzung persönlicher Vorlieben und eigener Gestaltungsvorstellungen anging - weshalb sie als Gradmesser für das Ausleben individueller Stile und Ausdrucksformen also nicht 
ganz unproblematisch sind. Sie dennoch als Belege für den Wandel des materialen Erscheinungsbilds spätantiker Inschriftlichkeit anzuführen, ist aber durchaus zulässig, bündeln sie doch wie in einem Brennglas viele verschiedene Phänomene, die sich auch anderswo bemerkbar machten. Wie wir gesehen haben, sind Einzelphänomene der Schriftgestaltung auch bei anderen Inschriftentypen zu beobachten. Erinnert sei etwa an die zunehmend häufiger vorkommende Verwendung von an Handschriften erinnernde Buchstabenformen bei civic inscriptions. ${ }^{423}$ Und bezeichnenderweise machen auch in anderen Techniken und Materialen ausgeführte Inschriften hier keine Ausnahme: Die Schriftbilder musivischer Stifterinschriften aus dem 5. und 6. Jh. sind denjenigen spätantiker Steininschriften in vielen Fällen auffallend ähnlich, wie es ein Blick auf einige Beispiele aus Grado und Tergeste verdeutlicht (Taf. 7 Abb. 107-112, Taf. 16 Abb.128, Taf. 40 Abb.172). Wie auch bei den Steininschriften begegnet das A mit gebrochener Querhaste, das E, F und L mit schräg geführten Horizontalen, das $\mathrm{U}$ bzw. V in gerundeter Form, das $\mathrm{G}$ mit geschwungenem, abfallendem Schaft, und allenthalben sind akzentuiert ausgearbeitete Serifen zu finden. Die Veränderungen im äußeren Erscheinungsbild, welche sich besonders deutlich in der Übernahme einzelner Formelemente aus dem Bereich der Handschriften niederschlugen, betrafen also Inschriften sämtlicher Macharten und Aufstellungskontexte gleichermaßen.

Dass ausgerechnet die Buchschrift einen so starken Einfluss auf die Inschriftenpraxis der Spätantike ausübte, ist angesichts des großen politischen und gesellschaftlichen Stellenwerts des Schrift- und Buchwesens in jener Zeit nicht verwunderlich. Die Kultur der Spätantike war eine Kultur des Buches. ${ }^{424}$ Wie sehr dies der Fall war, zeigt sich bereits an der Vielzahl von öffentlichen Bibliotheken, die es nicht nur in den großen Metropolen, sondern auch in kleineren Provinzstädten gegeben hat. So verzeichnet die Regionenbeschreibung Roms aus konstantinischer Zeit nicht weniger als 28 Bibliotheken, ${ }^{425}$ von denen einige - wie etwa die Bibliothek am Trajansforum ihren Betrieb bis ins 5. Jh. aufrecht erhielten. ${ }^{426}$ Berühmt war die unter Constantius II. in Konstantinopel gegründete Bibliothek mit rund 120.000 Büchern, die auch als

423 S. hierzu o. S. 151 Abb. 36. Weitere Beispiele: AE 2007, 354 = LSA 2570 mit Abbildung (Privernum, Dat.: 325/36); AE 1972, 143 = LSA 1934 mit Abbildung (Beneventum, Dat.: 409); AE 1956, 259 = LSA 2057 mit Abbildung (Catina, Dat.: spätes 5./frühes 6. Jh.).

424 Zum spätantiken Buch- und Schriftwesen s. die Beiträge im 18. Band der Zeitschrift Antiquité tardive von 2010 zum Thema Lecture, livres, bibliothèques dans l'antiquité tardive; außerdem Schipke 2013; Wallraff 2013.

425 Vgl. Nordh 1949, 97f. Viele dieser Bibliotheken gingen auf kaiserliche Gründungen des 1. und 2. Jhs. zurück; belegt sind solche zum Beispiel unter Augustus, Tiberius, Vespasian und Trajan; s. hierzu Blanck 1992, 160-165; Balensiefen 2002 zur Bibliothek des Augustus auf dem Palatin; Meneghini 2002 zur Bibliotheca Ulpia am Trajansforum. - Mit Überlegungen zur baulichen Gestalt, zum Angebot und zur Funktion der stadtrömischen Bibliotheken s. Balensiefen 2011.

426 Belegt wird dies durch eine Passage bei Sidonius Apollinaris, dem um 450 eine Statue in der Bibliothek oder deren unmittelbarer Umgebung errichtet wurde: Sidon. epist. 9,16,3, 25-28. (ed. Anderson 1963, S. 601); vgl. hierzu auch den Eintrag bei LSA 2675. 
Skriptorium diente. ${ }^{427}$ Wie wir durch den am kaiserlichen Hof Konstantinopels tätigen Rhetor Themistios wissen, sorgte Constantius II. mit Staatsmitteln dafür, dass ausgebildete Kalligraphen dort Werke der griechischen Literatur abschrieben und auf diese Weise für die Nachwelt erhielten ${ }^{428}$ - wahrscheinlich, indem sie die auf Papyrusrollen abgefassten Texte auf neue Pergamentkodizes übertrugen, die zu dieser Zeit die gebräuchlichste Form des Buchs darstellten. ${ }^{429}$ Ähnliches geht aus einem Erlass Kaiser Valens, aus dem Jahr 372 hervor, der den Personalbestand des Skriptoriums auf vier Kalligraphen für das Griechische und drei für das Lateinische festsetzte. ${ }^{430}$ Kaiserliche Bibliotheksgründungen sind auch für Julian bekannt, unter anderem in Antiochia, wo er die umfangreiche Büchersammlung Bischofs Georgios nach dessen Tod in den Trajanstempel bringen ließ, um sie vor dem Verschwinden zu bewahren. ${ }^{431}$ In den Provinzstädten waren es hingegen vor allem Privatpersonen, die sich als Stifter öffentlicher Bibliotheken und Besitzer privater Büchersammlungen hervortaten. Gut bekannt ist etwa diejenige des Paulinus von Nola, die dieser innerhalb des Kirchenkomplexes in Primuliacum einrichten ließ, um - wie er selbst in einem Brief darlegt ${ }^{432}$ - jedem Gläubigen die Möglichkeit zu bieten, in den Heiligen Schriften zu lesen. Dass Paulinus als Angehöriger des Klerus in erster Linie religiöse Texte sammelte und bereitstellte, liegt nahe. Damit befand er sich in guter Gesellschaft: ,Christliche Bibliotheken', das heißt von Klerikern gegründete und vornehmlich mit Texten christlicher Autoren ausgestattete Bibliotheken, waren in der Spätantike häufig. Große Sammlungen dieser Art gab es zum Beispiel in Caesarea Maritima, Alexandria und in Rom. ${ }^{433}$

427 Von dieser Bibliothek ist ausführlicher in dem Panegyrikus des Themistios die Rede, die dieser anlässlich des Konsulatsantritts des Constantius II. am 1. Januar 357 hielt (Or. 4,59b-61d (ed. Leppin/ Portmann 1998, S. 95-99)). Sie wurde 473 durch einen großen Brand zerstört (Zon. epit. hist. 14,2). Der daraufhin errichtete Neubau beherbergte erheblich weniger Bücher, rund 36.500 (Michael Glycas, ann. 4 p. 281c-d (PG 158, 524d-525a)). Ihr Ende fand die Bibliothek nach Ausweis der Quellen unter Kaiser Leo III. (717-741), der die dort aufbewahrten Schriften angeblich im Zuge ikonoklastischer Politik verbrennen ließ (Zon. epit. hist. 15,3, 13-22); s. hierzu auch Rohmann 2016 zu Bücherverbrennungen in der Spätantike; zu der Bibliothek und ihrem Angebot s. Schlange-Schöningen 1995, 103-107.

428 Or. 4,59b-61d (ed. Leppin/Portmann, S. 95-99).

429 Hieronymus (ep. 34,1, ed. Labourt 1951, Bd. II, S. 44f.) überliefert, dass die Bestände der Bibliothek in Alexandria in der 2. Hälfte des 4. Jhs. von Papyrusrollen auf Pergamentkodizes umgeschrieben wurden. Gleiches geschah auch in anderen großen Bibliotheken. Diese Praxis blieb nicht ohne Folgen: Weil man beim Umschreiben auf die Kodizes oft nicht den gesamten Bestand berücksichtigte, sondern eine Auswahl an bestimmten Schriften traf, wurden einige Werke der antiken Literatur nicht tradiert und gingen für die Nachwelt verloren; zu diesen Aspekt der Überlieferungsgeschichte s. Cavallo 1997; ders. 2002; zum Medienwandel von Papyrusrolle auf Pergamentkodex s. Blanck 1992, 95-101; Cavallo 2010; Wallraff 2013, bes. 3-8.

430 Cod. Theod. 14, 9, 2.

431 Iul. epist. 37 (ed. Weis, S.103f.).

432 Paul. Nola, epist. 32, 16.

$433 \mathrm{Zu}$,christlichen Bibliotheken`s. Mratschek 2000; bes. 369f.; Cantino Wataghin 2010, 53-62 (mit archäologischem Fokus); Wallraff 2013, passim. 
Durch die Arbeit der in den Skriptorien tätigen sowie unabhängig arbeitenden Schreiber ${ }^{434}$ verbreiteten sich Text- und Schriftzeugnisse aller Art rasch in viele unterschiedliche Gesellschaftsgruppen hinein, unter denen die gebildeten Oberschichten nur einen - wenn auch bedeutenden - Rezipientenkreis darstellten. ${ }^{435}$ Dass dies möglich war, war zu einem großen Teil dem Medium des Pergamentkodex zu verdanken, der die Papyrusrolle (rotulus) als gängige Buchform in der Spätantike ablöste. ${ }^{436}$ Gegenüber der Rolle bot er mehrere Vorzüge: Er konnte mehr Text aufnehmen, war einfacher und platzsparender aufzubewahren, leichter handhabbar und auch mit nur einer Hand zu benutzen sowie billiger in der Anschaffung. Insbesondere die frühen Christen zeigten große Sympathien für den Kodex und etablierten ihn als allgemein gültiges Medium, das auch für einfachere Leute in Frage kam. ${ }^{437}$ Dass nicht nur die christliche Bildungselite über den Zugang zu Büchern verfügten, belegen Aussagen wie diejenige des Origines, der in seinen Predigten zur häuslichen Bibellektüre aufruft oder die Überlegungen des Paulinus von Nola, wie er seine literarischen Werke einem möglichst breiten Publikum zugänglich machen könnte. ${ }^{438}$ In die gleiche Richtung deutet auch die Tatsache, dass die Mehrzahl der erhaltenen spätantiken Kodizes Werke von eher bescheidenem literarischem Niveau beinhalteten, weshalb Guglielmo Cavallo schlussfolgerte, dass diese Bücher vornehmlich von weniger elitären Schichten konsumiert wurden ${ }^{439}$ - wobei man sich hierunter wohl in erster Linie Beamte aus

434 Frei tätige Schreiber, die sich von ihrem Auftraggeber diktieren ließen oder Texte abschrieben, hat es natürlich weiterhin gegeben. Wie viel ihre Arbeit wert war, ist durch das Preisedikt des Diocletian von 301 bekannt (VII 39-40, ed. Lauffer, S. 238). Demnach bekam ein Schreiber für ein Schriftstück bester Qualität 25 Denare pro 100 Zeilen, für Schriften zweiter Klasse maximal 20 Denare; vgl. hierzu Mratschek 2000.

435 Die Bedeutung des Kodex - und mithin der Text- und Lesekultur - für die oberen Schichten der spätantiken Gesellschaft wird besonders deutlich durch die Prachtkodizes dieser Zeit belegt, von denen einige gewisse Berühmtheit erlangten. Dazu zählen etwa die Büchergeschenke des Verwaltungsbeamten Porfyrius an Konstantin I., der Chronograph des Filocalus von 354 sowie mehrere Prachtbände mit Texten der klassischen Literatur von Homer bis Vergil, die sich einerseits durch aufwendig gestaltete Einbände, andererseits durch anspruchsvolle Illustrationen der Seiten auszeichneten; s. hierzu Zimmermann 1998; Lowden 2007; zum Chronographen des Filocalus vgl. auch unten S.166 mit Anm. 442.

436 S. o. Anm. 429.

437 Die Frage, in welchem Zusammenhang der Aufstieg des Christentums und der Siegeszug des Kodex stehen, wurde oft gestellt, ist aber noch nicht befriedigend beantwortet. Neben den allgemeinen Vorteilen des Kodex gegenüber der Buchrolle könnten auch soziale Kriterien eine Rolle gespielt haben. So vermutet M. Wallraff, „dass Lebensstil und Lebensniveau der Christen die Vorzüge [des Kodex] stärker ins Gewicht fallen ließen“ und spricht ihnen mit Hinweis auf die Studie von W. Kinzig eine größere Aufgeschlossenheit gegenüber Neuerungen zu, ohne dies aber weiter zu begründen; Wallraff 2013, 17. Nicht außer Acht gelassen werden sollte auch die Bedeutung der Kodizes für die Liturgie, in deren Ablauf sie fest eingebunden waren; zur Neigung der Christen zum Kodex s. neben Wallraff 2013 auch Mratschek 2000.

438 Hom. in Gen. 11,3 (ed. Habermehl 2011, 216-221); 12,5 (ed. ders. 228-233); Paul. Nola, epist. 29, 14.

439 Cavallo ${ }^{2} 1977$. 
dem Mittelstand, Rechtsgelehrte oder Ärzte wird vorstellen dürfen, deren Einkommen hoch genug war, um sich die Anschaffung von Büchern leisten zu können. ${ }^{440}$

Bücher waren also ohne Frage selbstverständlicher Teil des gesellschaftlichen Lebens und der Anblick von und der Umgang mit handschriftlichen Texten war nicht nur professionellen Schreibern, Mönchen und Gebildeten, sondern auch einfacheren Leuten vertraut. Angesichts der starken Präsenz von Buch- und Handschriften in der Lebenswirklichkeit der Spätantike scheint es gleichsam unvermeidlich gewesen zu sein, dass deren Schriftbild und Formenrepertoire auch in die Inschriftenpraxis Eingang fand, zumal deren Wesen ja ohnehin gerade im Wandel begriffen und für Einflüsse von außen offen war.

Ein weiterer Faktor für die materiale Wandlung der Inschriften und deren Schriftbilder könnte in dem zunehmenden Verschwinden eines allgemeingütigen ,visuellen Inschriftenparadigmas' liegen: Die Vorstellung von normativen Schriftbildern, musterhaften Textarrangements und leitbildgebenden Erscheinungsformen verblasste angesichts mangelnder Vorbilder, die sich zuvor in den Monumenten des Kaiserhauses und der einflussreichen aristokratischen Elite Ausdruck verschafft hatten, die als Orientierungshilfen nun aber immer öfter fehlten. Vor diesem Hintergrund war es wohl kein Zufall, dass es Bischof Damasus gelang, eine neue ästhetische Ausdrucksform von Inschriftlichkeit zu etablieren, die das visuelle Erscheinungsbild öffentlicher Inschriften über seine Zeit hinaus prägen sollte.

\subsection{Fallbeispiel 1: Die Inschriften des Bischofs Damasus}

Damasus trat das Bischofsamt in Rom im Jahr 366 an. ${ }^{441}$ Damals war er bereits sechzig Jahre alt und konnte auf ein elfjähriges Diakonat unter Papst Liberius zurückblicken. Als der zwischenzeitlich von Kaiser Constantius II. ins Exil geschickte Liberius nach seiner Rückkehr in Rom verstarb, entbrannte ein Streit um die päpstliche Nachfolge, aus dem Damasus mit der Unterstützung einflussreicher Kleriker sowie einfacher Laien aus der Christengemeinde schließlich als Sieger hervorging. Gegen seinen Konkurrenten Ursinus konnte er sich aber erst nach zähem Ringen und mehreren Auseinandersetzungen als Amtsinhaber durchsetzten. Den Anfeindungen seines Widersachers vermochte er sich trotz dessen langjähriger Verbannung nach Gallien aber niemals vollkommen zu entziehen. Während seines Pontifikats sorgte Damasus entschieden dafür, die Vormachtstellung des römischen Bischofs in bisher unbekannter Weise auszubauen und seinen Einflussbereich auch über die Grenzen Roms und Italiens hinaus zu erweitern. Unter ihm wurde der arianische Streit um die Einheit

440 Zum spätantiken Lesepublikum s. Schipke 2013, 29-38.

441 Zur Biographie des Damasus und seinem Wirken als römischer Bischof und Papst s. Ferrua 1942; Carletti/Ferrua/Deckers 1986; Siat 2003; Reutter 2009; Barthold 2011, speziell zur Epigrammdichtung; Diefenbach 2012; Trout 2015. 
des Dogmas zugunsten des Bekenntnisses von Nicäa beigelegt. Historische Bedeutung erlangte er auch als Förderer einer umfassenden Revision und Übersetzung der lateinischen Bibeltexte durch Hieronymus (die sog. Vulgata) und als Verfasser zahlreicher Epigramme, dogmatischer Schriften und Sendschreiben an prominente politische und geistliche Größen seiner Zeit.

Wie kein anderer Papst vor ihm förderte er außerdem den Kult um die während der Christenverfolgungen umgekommenen Märtyrer in Rom. Er bemühte sich um den Erhalt ihrer Gräber in den Katakomben und ließ ihre Kultstätten ausbauen und zum Teil aufwendig ausstatten. Dazu gehörte auch die Ausstellung von großen Inschriftentafeln aus feinem Marmor. Darauf waren panegyrische Gedichte und Grabepigramme zu Ehren der Märtyrer eingeschrieben, die Damasus selbst verfasst hatte. Die künstlerische Ausgestaltung der Inschriften und ihre technische Umsetzung in Stein überantwortete er Furius Dionysius Filocalus, einem seinerzeit berühmten Kalligraphen mit besten Verbindungen zu Mitgliedern der christlichen Aristokratie in Rom. ${ }^{442}$ Als Filocalus um das Jahr 370 in die Dienste des Damasus trat, hatte er sich bereits einen Namen als Verfasser des sog. Chronographen von 354 gemacht, den er im Auftrag eines gewissen Valentius (offenbar ein wohlhabender Christ aus der römischen Oberschicht) angefertigte. ${ }^{443}$ Der Kodex in Form eines Almanachs enthielt vielerlei Listen und Texte chronographischen, astrologischen und historiographischen Inhalts und war reich mit ganzseitigen Illuminationen verziert. Wie es illustrierte Kopien des Kodex aus dem Mittelalter zeigen, hatte Filocalus die Texte des Kalenders in einer außergewöhnlich kunstvollen Majuskelschrift niedergeschrieben, bei der es sich offenbar um eine Neuschöpfung durch ihn selbst handelte. Und es war eben diese spezielle Schönschrift in ihrer visuellen Gestalt ebenso ansprechend wie unverwechselbar -, in welcher er auch die Epigramme im Auftrag des Damasus in Marmor ausführte. Wie viele solcher Inschriftentafeln er genau anfertigte, ist unbekannt. Insgesamt sind etwas mehr als 50 Stück überliefert, die tatsächlich auf Filocalus selbst zurückgehen dürften. ${ }^{444}$ Unklar bleibt auch die konkrete Rolle des Filocalus im Herstellungsprozess. Dass er die textlichen Vorlagen seines bischöflichen Auftraggebers selbst auf die Marmortafeln übertrug, gilt als sicher. Ob er sich aber auch als Steinmetz betätigte und jede einzelne Inschrift persönlich ausmeißelte, ist ungewiss. Die technische Homogenität unter den

442 Zur Person des Filocalus s. Ferrua 1939; Gray 1956; Cameron 1992; Vollkommer 2001, 256 s. v. Filocalus (M. Dennert); Reutter 2009, 12-14.

443 Zum Kalender s. Stern 1953; Salzman 1990; Binder 2002; Divjak 2002; Wischmeyer 2002.

444 Der Jesuitenpater, Archäologe und Epigraphiker Antonio Ferrua hat die erhalten Zeugnisse zusammengetragen und Anfang der 1940er-Jahre in einer umfänglichen Edition vorgelegt. Seine Publikation aus dem Jahre 1942 gilt nach wie vor als maßgeblich: Ferrua 1942. Zu seiner Person und seinen wissenschaftlichen Leistungen s. Personenlexikon zur Christlichen Archäologie, Bd.1, 2012, 489-491 s. v. Antonio Ferrua S. J. (D. Mazzoleni). Von den damasianischen Inschriftentafeln haben sich lediglich vier fast vollständig erhalten, alle anderen sind nur in Fragmenten überliefert. Insgesamt muss Damasus an die 80 Epigramme gedichtet haben, deren Wortlaut in einigen Fällen auch durch mittelalterliche Abschriften von Pilgern bekannt geworden sind. 
EVTYGHIV SMART YR.CRVDELIANVSSAT YRANNI CAR NIFICKMQVIASPARIERTVNCMILIINOENDI VINE REQVODPOAVITMONSTRAITGLORIACIRISII CARERISINIVVIEMSEQVITVRNONAPOENAPERARTVS TESTAKVMFR AGMENTAPARANNESOMNVSADIRET BISSENITRANSIEREDIESALIMENTANEGANT VR MITTIUVRINBARATHRVMSANGVSIALIOMNIASANEIS VVLNERAQNAINT TLERATMORTISMETVENDA.POESTAS NOCTESOPORIFERATVRBANTINSOMNIAMENTEM OSTENDITLATBRAINSONTISQMEMEMBRATENERT QMERITYRINVENVSCHTVRIOVETOMNIAPRESTAT: EXPRESSITDAMASVSMERITVMVENERARESTPVIERVM

Abb. 48: Epigramm des Damasus, Elogium S. Eutychii, Rom.

einzelnen Stücken spricht einerseits für ein und dieselbe Hand ${ }^{445}$ Andererseits fällt es schwer zu glauben, dass ein derart spezialisierter Gelehrter wie Filocalus zugleich Steinmetz gewesen sein soll, weshalb man die Einheitlichkeit der Inschriften auch mit deren Anfertigung in einer Werkstatt erklären könnte, die alle Aufträge des Damasus ausführte.

Das Alphabet des Filocalus orientierte sich in seinem Grundschema am Vorbild der klassischen lateinischen capitalis quadrata, steigerte diese aber ins Ornamentale, beinahe Verspielte (Abb. 48). ${ }^{446}$ Das Wesenhafte der filocalischen Buchstaben war ihre ausgeprägte Kontrastivität einerseits und ihre ornamentale Eleganz andererseits. Die Vertikalen waren stets breit, die Horizontalen stets schmal gestaltet. Haar- und Schattenstriche wechselten sich miteinander ab. Ein extrem prononcierter Keilschnitt ließ ein wirkungsvolles Spiel von Licht und Schatten entstehen, das durch den hellen Untergrund des weißen Marmors noch einmal intensiviert wurde. Die Enden der Hasten und Schrägen waren breit aufgebogen und liefen oben und unten in feinen, sich einander entgegen neigenden Häkchen nach außen hin aus. Die Bögen des B, D, P, und R setzten mit einem leichten Schwung am Schaft an, das O und Q waren exakt kreisrund geformt. Zwischen den einzelnen Buchstaben herrschten gleichmäßige Abstände, ebenso wie zwischen den einzelnen Zeilen. In der Regel fügten sich alle Buchstaben in eine genau gleiche Versalhöhe ein, ab und an ragten aber auch einzelne Lettern über die anderen hinaus oder wurden - nunmehr in sehr viel kleinerer Gestalt - nach oben und unten versetzt oder in die Punzen der vorangegangenen Buchstaben inkludiert. ${ }^{447}$ Ligaturen kamen seltener vor, waren dann aber sehr pro-

445 Vgl. Gray 1956, 6.

446 Die spezifische Gestaltung der filocalischen Buchstaben hat A. Ferrua detailliert beschrieben: Ferrua 1939; ders. 1942, 21-35; s. hierzu außerdem Mallon 1952, 153f.; Gray 1956.

447 S. zum Beispiel Damas. Epigr. 19; 21. 
minent und effektvoll ausgearbeitet. ${ }^{448}$ Als optisch reizvolles Moment und charakteristisches Merkmal der filocalischen Inschriften gleichermaßen zeigten einige Tafeln an ihren Rändern auch senkrecht angebrachte kurze Texte, mit denen Filocalus die Inschriften signierte. ${ }^{449}$ Dass sich der Hersteller einer Inschrift auf diese Art und Weise verewigte, war seinerzeit außergewöhnlich und illustriert nicht nur den großen Stolz des Filocalus auf seine Schöpfung. Es zeigt auch ein ausgeprägtes Bedürfnis, sein Werk als Kunst und sich selbst als Künstler verstanden zu wissen. Wie sehr ihm tatsächlich daran gelegen sein muss, die Inschriften als seine Arbeit zu kennzeichnen, verdeutlicht die Inschriftentafel mit dem Elogium für Papst Eusebius, bei der es in der Randspalte heißt: Damasi papae cultor adque amator Furius Dionysius Filocalus scribsit. ${ }^{450}$ Zwischen Filocalus und Damasus, so sollte es wohl zwischen den Zeilen anklingen, bestanden nicht nur geschäftliche Beziehungen. Die beiden waren sich auch in gegenseitiger Freundschaft und Bewunderung füreinander verbunden.

Angesichts der ungewohnten Signaturen und des auffälligen Schriftbilds waren die filocalischen Inschriften in ihrer visuellen Erscheinung außergewöhnlich - jedoch nicht ohne Vorläufer. So lehnten sich ihre ausgewogenen Proportionen und das harmonische Schriftbild an die monumentalen Versalinschriften des 1. und 2. Jhs. an, mit denen sie ferner den ebenmäßigen, streng homogenen Duktus gemein hatten. Auch die Neigung zu ornamentalen Akzentuierungen hat es bereits zuvor gegeben, wenngleich wesentlich schwächer ausgeprägt und auf Inschriften des sepulkralen Kontexts begrenzt. So zeigt etwa eine in der Nähe von Toulouse gefundene Grabinschrift aus dem endenden 1. oder beginnenden 2. Jh. ebenfalls häkchenartige Serifen im Stil des Filocalus (Abb. 49). ${ }^{451}$ Und unter den römischen Grabinschriften des 3. und früheren 4. Jhs. aus Rom erinnern einige mit ihren gespaltenen Hastenenden an die damasianischen Inschriften, wie zum Beispiel die 366 in der Katakombe S. Sebastiano errichtete Grabtafel einer gewissen Primenia (Abb. 50). ${ }^{452}$ Es ist gut möglich, dass Filocalus sich von Stücken dieser Art hatte inspirieren lassen. Ihr klassisches Gepräge und kaiserzeitliches Erbe konnten die filocalischen Lettern also kaum verbergen - und sollten dies wohl auch nicht. Versucht man die Inschriften in der ihnen eigenen Materialität zu verstehen und sie vor dem politischen und gesellschaftlichen Horizont ihrer Zeit zu betrachten, so wird klar, dass sie weit mehr waren als das Resultat ästhetischer Spielereien. Vielmehr waren sie absichtsvoll kreierte Schöpfungen zwischen Kunstwerk, Erinnerungsmal und Sinnbild, und als solche dazu gedacht, als effektvolle Bedeutungsträger eingesetzt zu werden.

448 S. zum Beispiel Damas. Epigr. 16; 34.

449 S. zum Beispiel Damas. Epigr. $18^{1} ; 18^{2} ; 27$.

450 Damas. Epigr. $18^{1}$.

451 CIL XIII 5 = CAG IX, S. 159 .

452 ICUR V 13321. Womöglich machte sich hier der Einfluss der griechischen Inschriftenkunst bemerkbar, denn unter christlichen Grabinschriften des Ostens waren ornamentale Verzierungen und Serifen dieser Art durchaus üblich. N. Gray vermutete hinter den gebogenen Hastenenden symbolische Bedeutung und schlug vor, sie als stilisierte Fischschwänze zu deuten: Gray 1956, 8 f. 

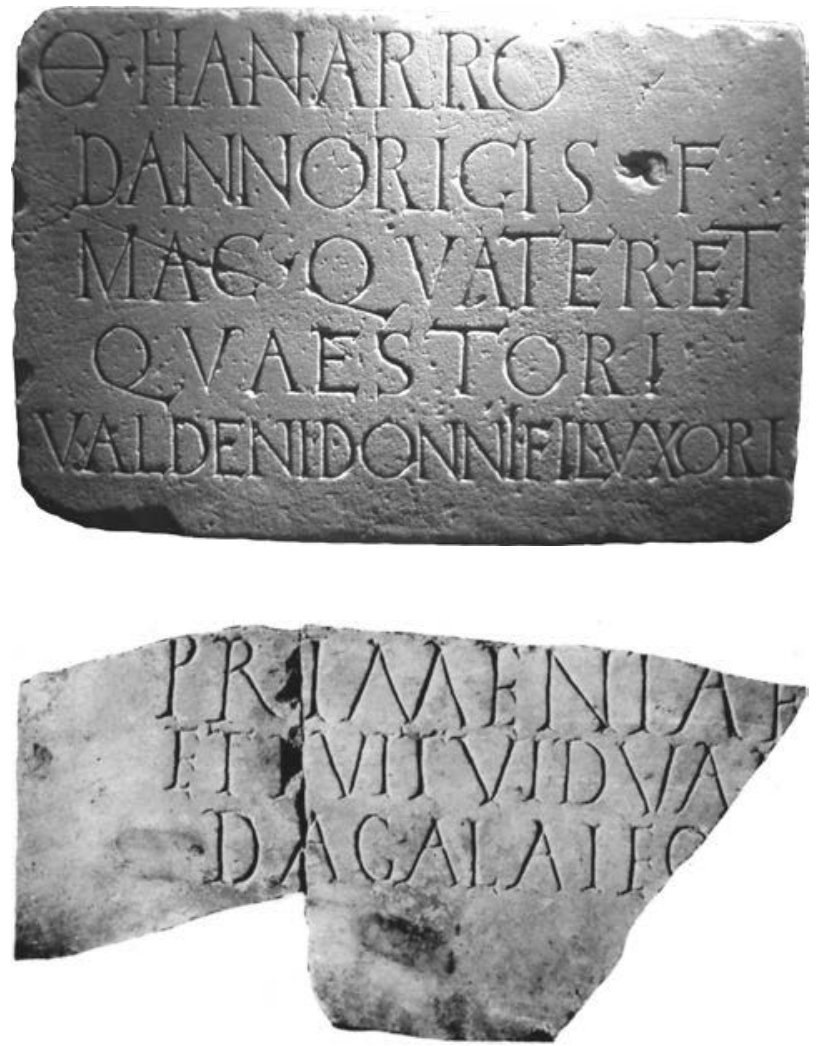

Abb. 49: Grabinschrift des späten 1. oder frühen 2. Jhs. aus der Nähe von Toulouse.
Abb.50: Grabinschrift der Primenia, Rom.

Das visuelle Potential der Inschriften war beachtlich. Die meisten Tafeln nahmen große Dimensionen an und erreichten gut zwei Meter in der Breite und einen Meter in der Höhe, die Inschriftentafel mit dem Elogium der Heiligen Agnes war sogar mehr als drei Meter lang. ${ }^{453}$ Entsprechend waren die Buchstaben solcher Inschriften zwischen fünf und sechs, zuweilen sogar fast acht Zentimeter hoch. Als Werkstoff war lediglich heller, fast weißer Marmor benutzt worden, auf dem die tief eingeschnitten Buchstaben besonders gut zur Geltung kamen, insbesondere dann, wenn man sie sich noch in roter oder dunkler Farbe ausgemalt vorstellt.

Aufgestellt waren die Tafeln in den Katakomben von Rom, wo die Märtyrer ihre letzte Ruhe gefunden und von der christlichen Gemeinde verehrt wurden. Damasus bemühte sich seit Beginn seiner Amtszeit intensiv darum, die alten unterirdischen Kultstätten wieder aufzuwerten, die zum Teil verfallenen Anlagen wieder herzurichten, auszuschmücken und für eine größere Besuchermenge zugänglich zu machen. Dazu ließ er die unterirdischen Gänge verbreitern, Zugangswege schaffen, Treppen anlegen, Luft- und Lichtschächte einbauen und künstliche Lichtquellen installieren.

453 Damas. Epigr. 37. 
Die meisten Gedenkstätten wurden in Form eines flachen Scheinbaldachins errichtet. Über zwei marmornen Säulen erhob sich ein Bogen oder Giebel, am Boden dazwischen saßen gitterförmige Schranken oder reliefverzierte Schrankenplatten. Wenn möglich, wurden auch kapellenartige Räume oder kleine Basiliken angelegt, wo Kultund Gedenkfeiern zu Ehren der Märtyrer gefeiert werden konnten. Die Inschriftentafeln befanden sich für alle Besucher der Katakomben gut sichtbar an den Wänden der Gänge, an der jeweiligen Grabstätte und an prominenten Stellen innerhalb der kleinen unterirdischen Kirchen. Vermutlich waren sie durch Fackel- oder Kerzenlicht effektvoll in Szene gesetzt. In den dunklen, unwirtlichen Katakomben müssen die weiß strahlenden Marmortafeln im wahrsten Sinne des Worts wie ,Lichtblicke gewirkt haben, vermochten sie die verehrten Märtyrer am Ort ihrer Bestattung doch gleichsam zu vergegenwärtigen und den Gläubigen Hoffnung und Trost zu schenken.

So nachdrücklich, wie Damasus den Kult um die wegen ihres christlichen Glaubens gestorbenen Männer und Frauen förderte, kultivierte und nachgerade bewarb, muss auch den Epigrammen großes Interesse und Beachtung zuteil geworden sein. Obgleich in Versen abgefasst, waren sie auch für weniger gebildete Leser verständlich und wurden größeren Gruppen von Pilgern womöglich sogar von eigens geschulten Führern vorgelesen und erläutert. ${ }^{454}$ Das belesenere Publikum hingegen mochte sich ebenfalls angesprochen und in seinen literarischen Bedürfnissen befriedigt gefühlt haben. Denn einige Epigramme erinnerten an Werke der klassischen römischen Literatur, allen voran an die Schriften des augusteischen Dichters Vergil, dessen Sprache und Stil sich Damasus immer wieder zu bedienen versuchte und dessen Aeneis er stellenweise sogar wörtlich zitierte. ${ }^{455}$ Dabei verstand er es, das literarische Erbe der römischen Kultur mit den religiösen Vorstellungen des Christentums zu verbinden und es christologisch umzudeuten, wie es etwa das Grabepigramm des Nereus und des Achilles aus der Domitilla-Katakombe vor Augen führt. Es erzählt die Geschichte der beiden Märtyrer im Stile eines antiken Heldenepos und macht zahlreiche Anspielungen auf die vergilsche Dichtung. ${ }^{456}$

Die Inschriften des Damasus ließen sich also sowohl auf der sprachlichen Ebene des Texts als auch auf der materialen Ebene des filocalischen Schriftbilds durchaus auf ihre,paganen“ Wurzeln zurückführen und präsentierten sich (vielleicht nicht ganz ohne Stolz) als Erben des klassisch-römischen Kulturguts. Gleichzeitig ließen sie aber keinen Zweifel daran, dass ihr Wesen christlicher Natur war und dass sie von Christen zum Gedenken an die im Glauben an Gott gestorbenen Märtyrer geschaffen wurden.

454 Insbesondere im Fall von sehr bekannten und beliebten Märtyrern sind geführte Besuche zu ihren Grab- und Kultstätten in den Katakomben gut vorstellbar, zumal einige dieser Anlagen wahrscheinlich nicht immer zugänglich waren, sondern nur während spezieller Gedenktage und anlässlich bestimmter Gedächtnisfeiern für ein breites Publikum geöffnet wurden.

455 Anspielungen auf und Zitate aus der Aeneis-Dichtung des Vergil finden sich zum Beispiel in Damas. Epigr. 11, 21, 25, 46, 47², 51 und 59; vgl. hierzu Reutter 2009, 137-147.

456 Damas. Epigr. 8. 
So wenig sie ihre Prägung durch pagane Traditionen auf der einen Seite verschleierten, so sehr propagierten sie auf der anderen Seite ihre grundsätzliche Andersartigkeit und Originalität als aus dem christlichen Glauben hervorgegangene Schöpfungen und dies nicht nur im Hinblick auf ihre inhaltliche Thematik, sondern auch angesichts ihres Schriftbilds, welches sich jeglicher Anlehnungen an kaiserzeitliche Vorläufer zum Trotz doch sehr deutlich von allem zuvor Gesehenen und in Rom Bekannten unterschied. Ins beinahe Opulente gesteigert, geprägt von einer reichen Fülle an ornamentalen Verzierungen und optisch reizvollen Spielereien, hätten sie den übrigen offiziellen Inschriften ihrer Zeit kaum eindeutiger entgegenstehen können. Und es fällt schwer zu glauben, dass es Damasus nicht um eben diesen scharfen Kontrast zwischen seinen eigenen Inschriften und denjenigen des öffentlichen Raums - insbesondere solchen des Kaiserhauses - gegangen war. Die offensichtliche Gegensätzlichkeit setzte er als absichtsvolles Stilmittel und als Bedeutungsträger ein.

Vor dem historischen Hintergrund der noch nicht allzu lange zurückliegenden Christenverfolgungen unter Diocletian (284-305) und der kurzen, aber emphatischen Herrschaft des christenfeindlichen Kaisers Julian (360-363) gelesen, symbolisierte das andersartige Schriftbild der damasianischen Epigramme den Anbeginn eines neuen Zeitalters, und zwar eines Zeitalters des Christentums, welches das , heidnische Kaisertum' und seine Feindseligkeit gegenüber den in den Epigrammen besungenen Märtyrern und ihre Glaubensbrüdern beendet hatte. Die christliche Thematik sowie die sprachliche und ästhetische Eleganz der Inschriften negierten gleichsam all das, wofür das dem alten polytheistischen Kult anhängige römische Kaisertum in christlichen Augen eingetreten war. Das neue Zeitalter sollte aber nicht nur eines des christlichen, sondern auch des kirchlichen Triumphs sein, in dem nicht länger allein der Kaiser, sondern nunmehr der Papst das Wort führen sollte. Seit der Anerkennung und Förderung des Christentums durch Konstantin I. war in Rom vieles anders geworden: Christen konnten ihren Glauben jetzt ungehindert ausüben, und frei von staatlichen Repressionen, wuchs auch ihr gesellschaftlicher und kultureller Einfluss. Kirchenbauten, Märtyrerschreine und Baptisterien wurden zahlreicher, christliche Feiertage und Feste erhielten einen festen Platz in der römischen Kultlandschaft. Der Machtbereich des Bischofs von Rom endete nicht mehr an den Grenzen seiner Kirche. Mit der wachsenden Bedeutung des Christentums als identitäts- und sinnstiftende Religion kam ihm auch in der staatlichen Politik eine führende Rolle zu. Als Damasus das römische Bischofsamt übernahm, war der Inhaber des Heiligen Stuhls zu einem gewichtigen Akteur im machtpolitischen Geschehen Roms und nicht selten zum Gegenspieler des regierenden Kaisers geworden. ${ }^{457}$ Sich gegenüber diesem zu profilieren und den eigenen Status und Herrschaftsanspruch auch öffentlich zu proklamieren, war für römische Bischöfe also nichts grundsätzlich Neues. Die Art und Weise, wie es Damasus tat, allerdings schon. Denn um seine eigene Stellung zu stärken und Rom

$457 \mathrm{Zu}$ den Konflikten zwischen Bischöfen und Kaisern in der Spätantike s. Barceló 2013. 
mit den Werten und Normen des christlichen Glaubens zu durchdringen, erdachte er ein umfängliches Programm, in welchem nicht zuletzt die Märtyrerinschriften eine maßgebliche Rolle spielten. Auf der einen Seite vermochten sie in ihrer Rolle als Texte ein breites Publikum anzusprechen, darunter nicht nur gläubige Christen und einfache Leute, sondern auch die am paganen Glauben festhaltenden Aristokraten der einflussreichen römischen Oberschicht. Indem er die dem christlichen Kult zugehörigen Inschriften in das sprachliche Gewand der altrömischen Dichtkunst kleidete, gelang es ihm ferner, sie auch für Anhänger paganer Traditionen attraktiv zu machen und diesen einen leicht gangbaren Zugang zum Christentum zu eröffnen, und dies, ohne dabei zum Glaubensübertritt aufzufordern und so Unmut und Konflikte heraufzubeschwören. ${ }^{458}$ Auf der anderen Seite entfalteten die Inschriften in ihrer Rolle als Kunstwerke eine nicht zu unterschätzende Wirkung als repräsentative Denkmäler. Angesichts ihres unverwechselbaren Erscheinungsbilds waren die Inschriftentafeln untrennbar mit dem Namen und dem Wirken des Damasus verbunden, zumal er es nicht versäumt hatte, stets auf seine Leistung als Verfasser der Texte und Verehrer der besungenen Märtyrer ausdrücklich hinzuweisen. ${ }^{459}$ Angebracht in den von Damasus wiedererrichteten Grabanlagen der Katakomben, im Fall von Bau- und Weihinschriften aber zuweilen auch in großen Kirchenbauten wie S. Lorenzo, ${ }^{460}$ besetzten sie einige der wichtigsten Kultstätten des damaligen christlichen Roms und prägten deren Atmosphäre als heilige, würdevolle Orte des christlichen Glaubens. Bedenkt man die große Anzahl der erhaltenen Tafeln und Tafelfragmente von knapp 50 Stück und erwägt, dass es wahrscheinlich weitere, heute verlorene Exemplare gab, fällt es nicht schwer sich vorzustellen, wie präsent die Inschriften des Damasus im Rom des späteren 4. Jhs. gewesen sein müssen. In einer Zeit, als die Kaiser anderen Städten den Vorzug gaben, sich immer häufiger und länger in Konstantinopel, Mediolanum (Mailand) und Augusta Treverorum (Trier) aufhielten, war nicht nur ein politisches, sondern in mancher Hinsicht auch ein kulturelles Vakuum entstanden. Repräsentative Denkmäler des Kaiserhauses, derer es zuvor in Rom viele gegeben hatte, wurden nun jedenfalls an anderen Orten errichtet. ${ }^{461}$ Dazu zählten auch - und vor allem Inschriften: monumentale Bauinschriften an Staatsgebäuden, Weihinschriften an Tempeln, Ehreninschriften auf Tafeln und Statuenbasen. Autoritative, vom Herrscherhaus ausgegebene und durch den kaiserlichen Stil geprägte Vorbilder, die das Erschei-

458 Vgl. Reutter 2009, $151 \mathrm{f}$.

459 So zum Beispiel in Damas. Epigr. 18: Damasus episcopus fecit; 20: Haec Damasus vestras referat nova sidera laudes; Damas. Epigr. 39: His Damasus supplex voluit sua reddere vota; Damas. Epigr. 42: Ornavit Damasus tumulum, cognoscite, rector, pro reditu cleri Christo presante triumphans.

460 Damas. Epigr. 57, 58.

461 Die Vorstellung, dass Rom mit der Verlagerung des politischen Geschehens nach Konstantinopel im Niedergang begriffen gewesen wäre und dass hier ein kausaler Zusammenhang bestanden hätte, greift zu kurz und ist mittlerweile widerlegt. $\mathrm{Zu}$ der politischen und kulturellen Entwicklung Roms und Konstantinopels in vergleichender Perspektive s. den Sammelband Grig 2012. 
nungsbild repräsentativer Inschriften hätten bestimmen können, fehlten nunmehr in Rom - eine Situation, die Damasus offenbar als äußerst vorteilhaft für die Durchsetzung seiner Politik von einem starken, christlich geprägten Rom erkannte und zu nutzen wusste, indem er die Stadt zur repräsentativen Bühne für die Ausstellung seiner Inschriften machte und diese dort als Sinnbilder eines neuen Zeitalters christlicher Dominanz etablierte. Wie nachhaltig der Eindruck der damasianischen Inschriften tatsächlich gewesen sein muss, zeigt nicht zuletzt die große Zahl an Imitationen und Reminiszenzen, die in den darauf folgenden Jahrzehnten entstanden. ${ }^{462} \mathrm{Zu}$ den bekanntesten Zeugnissen dieser Art zählt die musivische Stiftungsinschrift Bischofs Coelestin (422-432) aus dem früheren 5. Jh. (Abb.16, 17), die sich offensichtlich am Schriftbild der filocalischen Lettern orientierte und diese sogar in der Technik des Mosaiks umzusetzen wusste. ${ }^{463}$

\subsection{Inschriften und Bilder: Kombination und Zusammenwirken}

Wenn von der Materialität spätantiker Inschriftlichkeit die Rede ist, so verdient ein Aspekt besondere Aufmerksamkeit: das Zusammenspiel von Texten und Bildern. Mit Bildern sind an dieser Stelle allerdings keine Werke der Rundplastik gemeint, etwa Porträtstatuen oder andere Standbilder, wie sie in der Kombination mit Ehren-, Weihund Stiftungsinschriften auf Basen vorkommen. Zwar handelt es sich auch hier um Bilder, und natürlich sind auch hier Inschrift und Bild auf das Engste miteinander verbunden und gleichsam voneinander abhängig. Doch wollen wir uns in diesem Zusammenhang vornehmlich mit der Interaktion von Inschriften und Bildern der Flächenkunst beschäftigen, also mit jener Spielart des intermedialen Zusammenwirkens, bei der sich Texte und Bilder auf einem gemeinsamen Untergrund bzw. Träger, in einem gemeinsamen Medium zu einer zweidimensionalen Komposition vereinigen. Dabei wollen wir uns im Übrigen auch darauf beschränken, das Neben- und Miteinander dieser beiden Kompositionselemente innerhalb der Grenzen des jeweiligen Artefakts $\mathrm{zu}$ beleuchten, ohne dieses in seinem größeren räumlichen Kontext in den Blick zu nehmen. Die Wirkung einer Inschrift bzw. eines inschriftlichen Bildwerks im Raum und in der Zusammenschau mit anderen Monumenten und Objekten ist ein Thema der ,Präsenz' und soll uns erst im folgenden Kapitel ausführlicher beschäftigen.

Texte und Bilder sind in ihrer Wirkung verschieden. Bilder wirken direkter und unmittelbarer auf den Betrachter. Sie rufen schon beim ersten Anblick bestimmte Assoziationen und Stimmungen hervor, lösen vielleicht sogar gewisse Emotionen und spontane Handlungen bei ihm aus. Dafür ist kein großer Wissens- und Erfahrungs-

462 Ferrua 1942, 219-263; Gray 1956, 9f.

463 Weitere Beispiele von Grabinschriften im filocalischen Stil: ICUR VI 18450 mit teilweise auf dem Kopf stehenden A; ICUR VIII 22588. 
schatz des Betrachters notwendig. Er braucht keine speziellen Kenntnisse, um ein Bild wahrzunehmen und es sinnlich als das zu erfassen, was es ist, nämlich eine Darstellung mit künstlerischen Mitteln. Auch wenn die meisten Bilder mehr sind als reine ,Ab-bilder', häufig mit zeichenhafter und symbolischer Bedeutung aufgeladen sind, komplexe Botschaften transportieren und zuweilen mit einer subtilen Bildsprache arbeiten, muss der Betrachter sie nicht in diesem Sinn ,lesen“ können. Er muss die kulturellen Codes eines Bilds nicht unbedingt verstehen, um sich von ihm angesprochen und berührt zu fühlen. Texte hingegen wirken nicht so unmittelbar wie Bilder. Denn sie sind in ein bestimmtes Zeichensystem übertragene und materiell verdinglichte Sprache, die verstanden werden muss. Wer nicht lesen kann, für den ist Geschriebenes ohne tiefere Bedeutung. Er wird darin in der Regel jedenfalls nicht mehr sehen als eine Aneinanderreihung von Zeichen, die er in ihrer formhaften Ausgestaltung vielleicht (und bestimmt) auffällig, ansprechend oder schön finden kann. Es wird in ihm aber sicherlich keine nennenswerten mentalen und emotionalen Reaktionen hervorrufen wie es ein Bild tun würde. Dafür nämlich müsste er das Geschriebene nicht nur sinnlich als Schrift, sondern auch kognitiv als Text verarbeiten können. Er müsste es nicht nur sehen, sondern tatsächlich lesen und seinen Inhalt verstehen können.

Wenn Texte und Bilder in einer gemeinsamen Komposition miteinander verschmelzen, werden solche medialen Grenzen überschritten und neue Möglichkeiten der Wirksamkeit eröffnet. Bild-Text-Arrangements erreichen ein breites Publikum, denn sie wenden sich sowohl an illiterate wie an literate Betrachter. Sie schaffen eindeutige Fakten und versenden gleichermaßen subtile Botschaften. Sie sind zweckmäßige Informationsträger wie ästhetische Kunstwerke. Wir wollen uns derlei Zeugnissen nun aus drei verschiedenen Blickwinkeln nähern und dabei das Zusammenwirken des geschriebenen Worts und gemalten Bilds unter den Überschriften ,Text und Bild‘, ,Text im Bild‘ und ,Text als Bild‘ näher beleuchten.

\subsubsection{Text und Bild: Beispiele spätantiker Grabinschriften aus Rom und Aquileia}

Texte und Bilder im Kontext des Grabs miteinander in Beziehung zu setzen, war in der römischen Welt nichts Ungewöhnliches. Man denke nur an die zahlreichen republikanischen und kaiserzeitlichen Grabstelen, auf denen sich Porträtdarstellungen der Verstorbenen mit den entsprechenden Inschriften auf einem Monument vereinten oder an die seit dem 2. Jh. häufig vorkommenden Sarkophage mit ihren teils sehr komplexen Bildprogrammen aus der mythischen Sagenwelt oder der vita humana. In der Spätantike, als sich das Bestattungswesen und die Praxis des Totengedenkens änderte, wandelte sich auch die Gestalt der Grabinschriften. Anteil daran hatten nicht zuletzt die jetzt intensiv genutzten Katakomben, die durch ihre spezifischen Gegebenheiten besondere Anforderungen an die Gestaltung von Grabinschriften stellten. An die Stelle von reliefverzierten Stelen und Grabaltären traten schlichtere Marmortafeln zur Markierung des Bestattungsplatzes und zur Anbringung der Grabinschrift durch die 
Hinterbliebenen. In einigen Regionen Italiens - aber längst nicht überall - setzte sich im Verlauf des 3. und frühen 4. Jhs. die Praxis durch, neben den Texten auch bildliche Darstellungen auf den Tafeln unterzubringen, darunter sowohl kleine einfache Motive von eher dekorativem Charakter wie auch größere Symbole und Sinnbilder der christlichen Bildsprache. Einmal mehr liefert Rom den in dieser Hinsicht umfangreichsten und vielfältigsten Befund. In den unterirdischen Grabstätten der Katakomben haben sich unzählige Loculusplatten des mittleren 3. bis 6. Jh. mit den verschiedensten Spielarten solcher Text-Bild-Arrangements erhalten, die in ihrer Masse und Formenvielfalt einzigartig sind. Elisabeth Ehler hat die betreffenden Stücke (knapp 4000) zusammengestellt und katalogartig vorgelegt. ${ }^{464}$ Außerhalb der Hauptstadt scheint die Sitte, Texte und Bilder auf Grabtafeln zu vereinen, vor allem in der norditalischen Bischofsstadt Aquileia von Bedeutung gewesen sein. Zwar haben sich hier nicht annähernd so viele figürliche Grabinschriften erhalten wie in Rom. Die rund 120 bekannten Exemplare sind aber als Zeugnisse des frühchristlichen Bestattungswesens einerseits und der spätantiken Inschriftenkultur andererseits nicht weniger wertvoll. ${ }^{465}$

Was das Repertoire der verwendeten Bildthemen und -motive angeht, so lassen sich diese auf der einen Seite dem Bereich des Menschenlebens und der Alltagswelt zuordnen, häufiger aber entstammen sie - namentlich bei den Stücken aus Aquileia der Sphäre des religiösen Lebens und des christlichen Glaubens. Zu erster Gruppe gehören solche Motive, welche die Persönlichkeit des Toten wiederaufgreifen und auf dessen Charakter oder Beruf Bezug nehmen. Darunter fallen vor allem Porträtdarstellungen. Sie zeigen die in den Inschriften erinnerten Männer, Frauen und Kinder zum Teil recht stilisiert und ohne großen künstlerischen Anspruch, ${ }^{466}$ waren mitunter aber auch um eine individualistische Darstellung und Betonung persönlicher Merkmale bemüht, wie etwa im Fall eines im Profil dargestellten Mannes mit markanter Nase und gewelltem Nackenhaar oder eines kleinen Jungen mit Lockenkopf und bubenhaften Pausbacken. ${ }^{467}$ Insbesondere bei Grabtafeln von Kindern und Jugendlichen wirken manche dieser Bildnisse fast anrührend. Da ist zum Beispiel das Bildnis eines in eine Tunica gekleideten Jungen mit ins Gesicht fallenden Haaren und traurigem Blick, dasjenige der im Alter von sieben Jahren verstorbenen Melitia beim Reifenspiel oder das-

464 Ehler 2012. Einige der bei Ehler zusammengetragenen Stücke zeigen allerdings lediglich Bilder und keine Texte, sei es, weil diese auf der Platte von Anbeginn an fehlten oder nachträglich verloren gegangen sind.

465 Die meisten Stücke sind in Band III der Inscriptiones Aquileiae (IAq III, 1993) und bei Vergone 2007 ediert. Anderswo im italischen Raum waren Inschriften dieser Art offenbar Ausnahmen. Zwar finden sich hier und da immer wieder einzelne Stücke, bei welchen den Texten kleine Bildmotive zugefügt wurden, wie etwa in Dertona und Mediolanum in Norditalien oder in einigen mittelitalischen Gemeinden Tuscia et Umbrias. Mit den Exemplaren aus Rom und Aquileia sind sie aber kaum zu vergleichen. Zu den betreffenden Stücken s. die jeweiligen Einträge in: ICI VI 7, 33, 107, 125; ICI VII 8, 14, 21; ICI XII 18, 19, 27, 57, 82.

466 Zum Beispiel Ehler 2012, II.1.5, 9, 10, 25.

467 Ehler 2012, II.1.1; II.1.20, jeweils mit Abbildung. 
jenige der kleinen Severina, welches das Mädchen mit einem Vogel, offenbar ihrem Spielkameraden, im Arm zeigt. ${ }^{468}$ Gerade bei Inschriften von Kindern waren Motive dieser Art sehr beliebt und so begegnen im Kontext ihrer Gräber immer wieder Bilder von Jungen und Mädchen beim Spielen oder zusammen mit ihren Haustieren. ${ }^{469}$

Bei Erwachsenen wurde hingegen häufig deren Beruf aufgegriffen. In den römischen Katakomben haben sich zahlreiche Stücke mit den Darstellungen von Bauern, Tierzüchtern, Schmieden, Gerbern oder Ärzten erhalten, ${ }^{470}$ und auch aus Aquileia sind solche Beispiele bekannt: das Bildnis eines aus Dardania in Moesia stammenden Soldaten, das ihn in voller Rüstung mit Helm und Schild auf seinen Speer gestützt zeigt (Abb. 51), ${ }^{471}$ ein anderes des Schmieds Flavius Saturninus, der in Handwerkskluft bei der Arbeit mit Amboss und Hammer zu sehen ist (Abb. 52), ${ }^{472}$ und ein weiteres des Weinhändlers Vincentius, den man im Laufschritt mit einer großen Amphora in den Händen porträtiert hat (Abb.53). ${ }^{473}$

In bescheidenerer Arte und Weise wiesen zuweilen auch kleine Abbildungen von Werkzeugen und Gerätschaften auf die berufliche Tätigkeit des Toten hin, ohne dass dieser dabei selbst zu sehen war. Darunter waren zum Beispiel Hämmer, Äxte, Messer und Meißel oder, wie im Fall des in einer römischen Inschrift als Architekten ausgewiesen Constantius, eine Schaufel und ein Lineal. ${ }^{474}$ Neben dem Beruf bot ferner der Name des Grabherrn Spielraum, den Inschriftentext mit Illustrationen zu bereichern. So zeigt etwa die Inschrift des Capreolus ein Böckchen. Bei Leontius ist es ein Löwe, bei Dracontius eine drachenähnliche Schlange und bei Porcella ein Schwein ${ }^{475}$ - eine ebenso originelle wie interessante Form der Text-Bild-Kombination, bei der der Name des/der Verstorbenen sowohl als Schrift gelesen wie auch als Bild gesehen werden konnte. Das Bild, so scheint es hier, sollte den Text nicht nur illustrieren, sondern paraphrasieren. Dessen ungeachtet sind es aber vor allem kleine motivische Abbildungen von Gerätschaften des Alltags wie Pflegeutensilien, Kleidung und Accessoires, Schreibgeräten und Musikinstrumenten, Gefäßen und Geschirr sowie kleinere szenische Darstellungen von Menschen bei der Verrichtung alltäglicher Arbeiten, in denen sich der lebensweltliche Erfahrungsschatz der Verstorbenen und ihrer Hinterbliebenen bildlichen Ausdruck verschaffte.

Ungleich zahlreicher als die Bilder aus der Alltagswelt und des persönlichen Lebens sind diejenigen aus dem Bereich der christlichen Symbolsprache. Auch hier

468 Ehler 2012, II.2.5; II.5.5; II.6.3, jeweils mit Abbildung.

469 Für Beispiele s. Ehler 2012, II.5. und II.2.

470 Für Beispiele s. Ehler 2012, II.7; Bisconti 2000, 101-143 unter Einbeziehung von Katakombenmalereien und die im Katalog aufgeführten Stücke S. 161-258.

471 IAq 2913 = Vergone 2007, 139.

472 IAq 2933 = Vergone 2007, 36.

473 IAq 2934 = Vergone 2007, 112.

474 Ehler 2012, III.3.13; zu Werkzeugdarstellungen s. ebd. III.

475 Capreolus: Ehler 2012, IV.3.14; Leontius: ebd. IV.6.4., ähnlich: IV.6.3; Dracontius: ebd. IV.11.1; Procella: ebd. IV.11.5. 


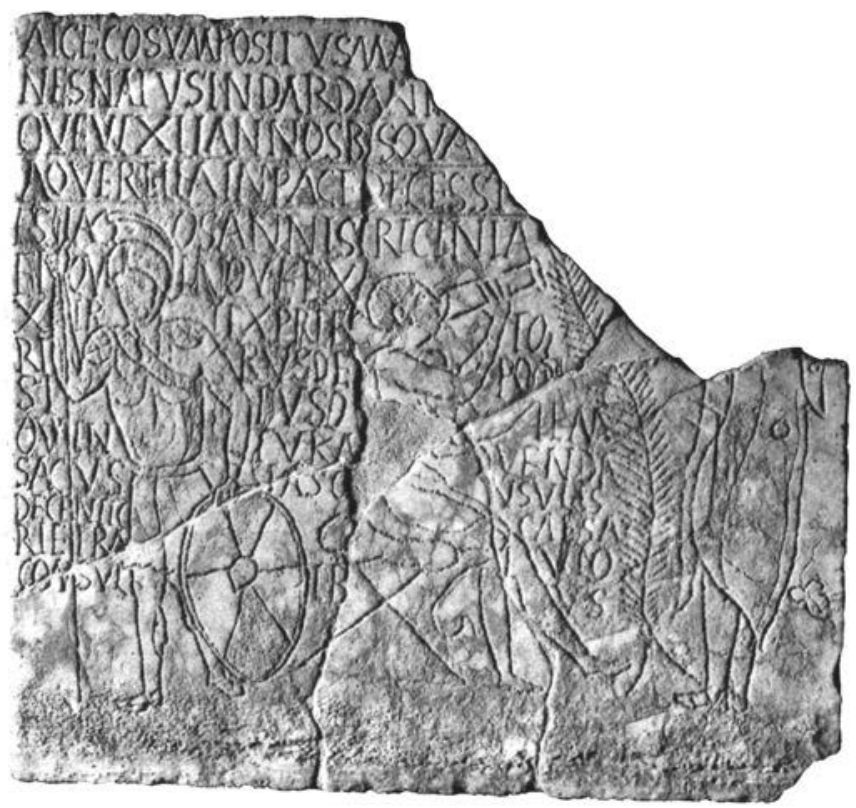

Abb. 51: Grabinschrift mit der Darstellung eines Soldaten, Aquileia.

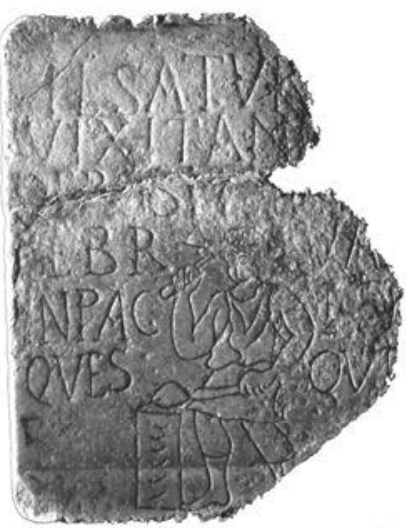

Abb. 52: Grabinschrift des Schmieds Fl. Saturninus, Aquileia.

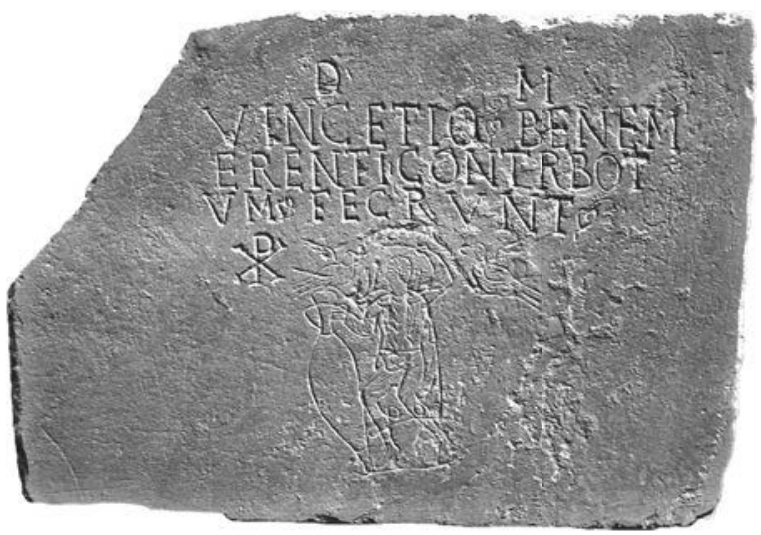

Abb. 53: Grabinschrift des Weinhändlers Vincentius, Aquileia.

herrschen wieder vornehmlich Einzelmotive vor, gelegentlich begegnen aber auch szenische oder narrative Darstellungen. Bei den Loculusplatten der römischen Katakomben wie auch bei den Grabtafeln aus Aquileia zählen Vögel zu den beliebtesten Symbolen. Sie begegnen entweder einzeln oder als Paar, das eine Mal mit Palmzweig oder Trauben im Schnabel, das andere Mal in Kombination mit einem Chrismon. ${ }^{476}$

476 Für Beispiele römischer Loculusplattens. s. ebd. V; Exemplare aus Aquileia sind zum Beispiel: IAq 2960, 3000, 3006, 3018, 3076, 3133, 3152, 3195, 3244. 
In der frühchristlichen Vorstellungswelt galt der Vogel - wohl in Anknüpfung an den antiken Seelenvogel - als ein Symbol der unsterblichen Seele, die nach dem Tode in das Himmelreich zu Gott emporsteigt. Als solches verkörperte er auch die Hoffnung auf die Auferstehung des Leibs und auf das ewige Leben nach dem Tod. Neben Vögeln gab es auch andere Tiersymbole: den als Sinnbild der Auferstehung geltenden Pfau, das Lamm, seinerseits ein Symbol des Opfers und in diesem Sinne auch als Präfigurationen Christi verstanden ${ }^{477}$ sowie Fische. Der Fisch war eines der frühesten Christussymbole überhaupt. Er war Erkennungszeichen der ersten Christen und wurde zuweilen auch als Sinnbild für den Getauften an sich aufgefasst, weshalb er gerne im Zusammenhang mit Grabinschriften von neophytoi, also von Neugetauften auftaucht. ${ }^{478}$ Einen weiteren wichtigen Kreis der christlichen Symbolsprache bilden Motive aus der Nautik, darunter Anker, Leuchttürme und Schiffe, mit denen auf die letzte Reise des Toten in den sicheren Hafen des göttlichen Paradieses und die unter der Führung Christi stehende Kirche der Gläubigen verwiesen wurde. ${ }^{479}$

Beliebte Sinnbilder für Jesus Christus waren neben dem Lamm auch der Schafträger und der gute Hirte, der, wie im Gleichnis des verlorenen Schafs erzählt, seine Herde verlässt, um das Leben eines einzigen in Gefahr geratenen Tiers zu retten (Mt 18,12-14 und Lk15,3-7). Ein besonders schönes Beispiel dieser Art ist in der Domitilla-Katakombe überliefert (Abb.54). ${ }^{480}$ Die Loculusplatte aus dem späteren 4. Jh. zeigt den Hirten auf einem Stein unter einem Baum sitzend. In der Linken hält er seinen Hirtenstab, in der Rechten eine Flöte. Zu seinen Füßen liegt ein Lamm, das ihm seinem Kopf zustreckt, als wolle es der Musik lauschen. Über der Szene ist die kurze Glücksformel Geronti vibas in Deo zu lesen. Darstellungen von Hirten und Lammträgern kommen auf den Loculusplatten der römischen Katakomben recht häufig vor. ${ }^{481}$ In die Bilderwelt der Grabinschriften Aquileias fanden sie hingegen keinen Eingang. Hier dominierte (neben der Darstellung von Vögeln) das Motiv des Oranten, einer mit erhobenen Händen betenden Gestalt in langem Gewand. Nicht nur auf Grabtafeln und Loculusplatten, auch in der frühchristlichen Katakombenmalerei und in der Sarkophagplastik gehörte der Orans seit dem beginnenden 3. Jh. zu den beliebtesten Bildthemen der Sepulkralkunst. Er galt als Symbol für die Seele des Toten, in ihm verkörperte sich gleichsam die Gewissheit über das Seelenheil und die Hoffnung auf ein ewiges Leben

477 Beispiele für Pfaue bei Ehler 2012, IV.1; Beispiele für Lämmer bei ebd. IV.3; IAq 3034 zusammen mit einem Vogel, 3099 und 3224 offenbar in Zusammenhang einer größeren Bildszene und nicht als Einzelmotiv.

478 Für Rom s. Ehler 2012, IV.7; für Aquileia s. IAq 3074 = Vergone 2007, 82 zusammen mit einer Taube; Vergone 2007, 95; für Fische bei Grabinschriften von Neugetauften s. Ehler 2012, IV.7. 30, 76, 74. 479 Beispiele aus Rom bei Ehler 2012, XI. Nautik; s. außerdem Feraudi-Gruénais 2017b zu Schiffsdarstellungen am Grab.

480 ICUR III 6727 = Ehler 2012, II.8.11.

481 Ehler 2012, XI Nautik. 


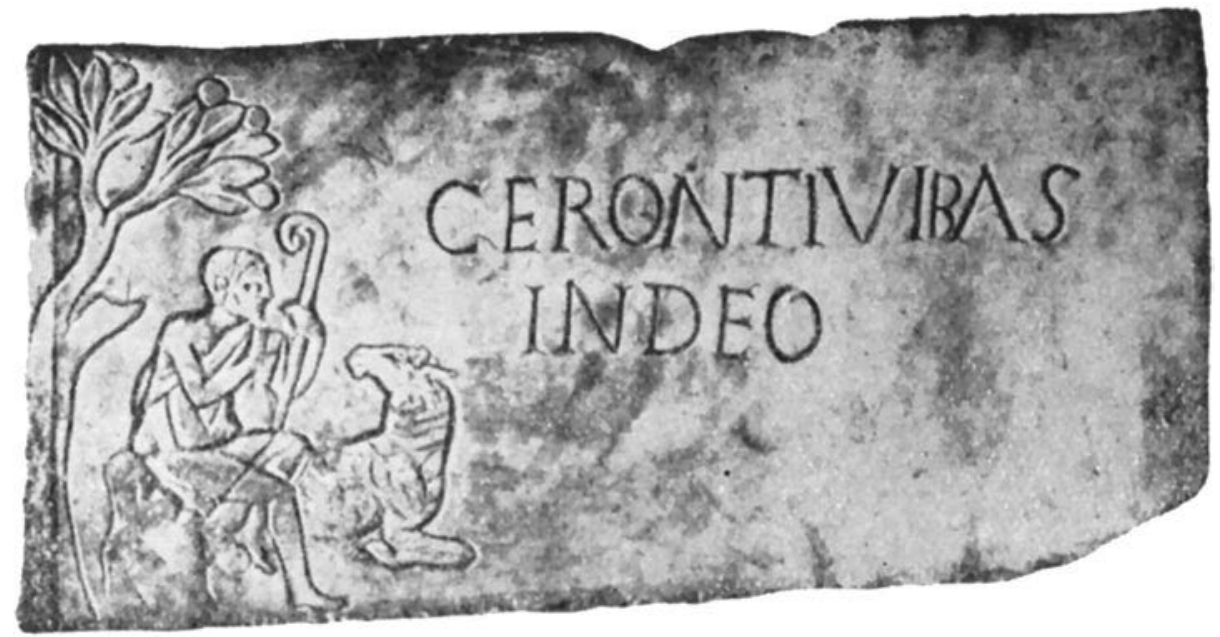

Abb. 54: Grabinschrift des Gerontius, Domitilla-Katakombe in Rom.

nach dem Tod im Reich Gottes. ${ }^{482}$ Die Grabtafeln aus Rom und Aquileia zeigen sowohl Oranten als auch Orantinnen, bilden diese mal alleine, mal als Paar oder zusammen mit den Verstorbenen und anderen symbolhaften Motiven und Figuren, wie Tauben und Lämmern, Schafträgern oder Hirten ab. ${ }^{483}$ Gelegentlich sind die Figuren auch in eine Gartenlandschaft eingebettet oder stehen unter einer Art Ädikula oder einem Vorhang, wie etwa im Fall der aquileianischen Grabtafel für den kleinen Iohannes. Dort sind unterhalb des Inschriftentexts drei Oranten - wohl der kleine Junge selbst und seine Eltern - zwischen Bäumen und Kandelabern zu sehen (Abb.55). ${ }^{484}$ Auf einer anderen Tafel eines im Alter von 18 Jahren verstorbenen Knaben steht ein junger Mann - auch hier handelt es sich offenbar wieder um den Toten selbst - gemeinsam mit einer Betenden unter einem von zwei Säulen getragenen Bogen. Über ihnen öffnet es sich ein Vorhang, aus dem eine Taube als Symbol der unsterblichen Seele hervorfliegt (Abb. 56). ${ }^{485}$ Beide Male sollte wohl auf den Aufenthaltsort der Verstorbenen im Jenseits verwiesen werden, das man sich seinerzeit sowohl als eine paradiesische Landschaft wie auch als Himmelsstadt vorstellen konnte. ${ }^{486}$

482 Zur Genese und Bedeutung der Orans als christliches Symbol s. Baudry 2010, 17f.; Dresken-Weiland 2010, 38-76.

483 Für Rom s. Ehler 2012, II.10 (Oranten); 11 (Oranten mit Vögeln); 12 (Oranten mit anderen Tieren). Für Beispiele aus Aquileia s. IAq 2988, 3021, 3022, 3024, 3059, 3068, 3134, 3162, 3207, 3209 (Oranten alleine); 2943, 3019, 3092, 3104, 3144, 3147, 3212 (zwei oder mehr Oranten gemeinsam); 3006, 3011, 3095, 3096, 3109, 3168, 3237, 3251 (Oranten von Tieren flankiert).

484 IAq 3092.

485 IAq 2989.

$486 \mathrm{Zu}$ den Aufenthaltsorten von Oranten im Kontext der Katakombenmalerei und der Sarkophagplastik und deren Bedeutung für frühchristliche Jenseitsvorstellungen s. Dresken-Weiland 2010, 40-76. 


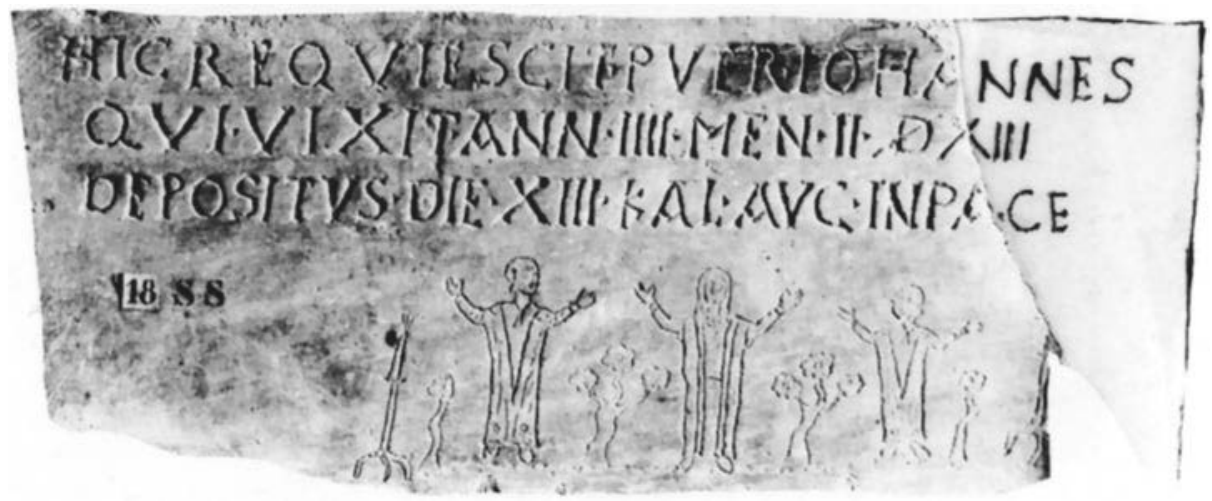

Abb. 55: Grabinschrift des Kinds lohannes, Aquileia.

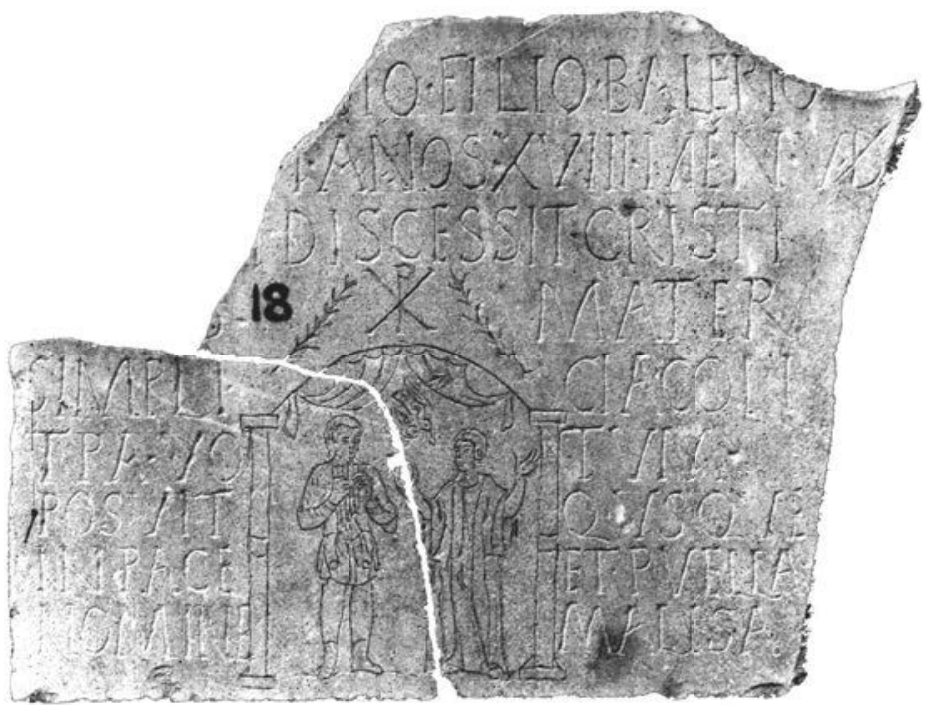

Abb.56: Grabinschrift eines jungen Manns, Aquileia.

Als ein letztes bedeutendes Bildmotiv sind Szenen aus dem Alten und Neuen Testament zu nennen. Sie spielen allerdings lediglich in der Bestattungskultur der römischen Katakomben eine Rolle, während Zeugnisse dieser Art anderswo weitgehend fehlen. In ihrer Zusammenstellung der figürlichen Loculusplatten aus Rom führt Ehler zehn verschiedene Geschichten und narrative Motive aus der Bibel an, darunter das Quellwunder, die Erzählungen des Noah und des Jonas, Moses mit den Gesetzestafeln oder die Erweckung des Lazarus. ${ }^{487}$ Eines der eindrucksvollsten Exemplare dieser Art ist die Platte vom Grab der Pontiana, die Darstellungen aus dem Alten Testament, Szenen des Alltags und symbolische Motive der christlichen Bildsprache miteinander

487 Ehler 2012, II.1-7. 


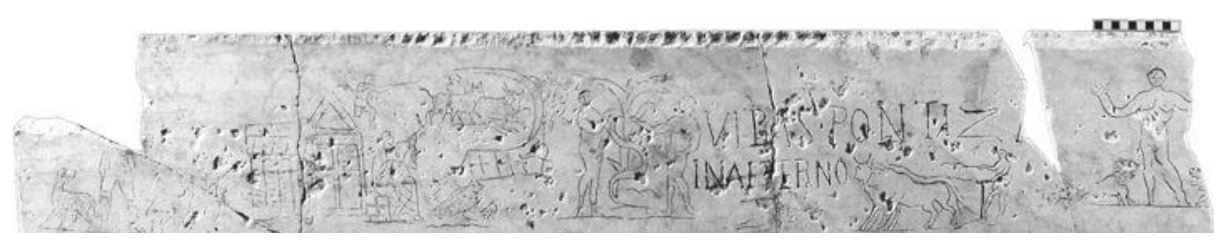

Abb.57: Loculusplatte mit der Grabinschrift der Pontiana, Rom.

kombiniert (Abb. 57). ${ }^{488}$ Die Tafel zeigt ganz links einen Schafträger im Beisein zweier seiner Tiere. Danach folgt ein Bild aus der Lebenswelt: eine Frau beim Spinnen vor ihrem Haus und einen Bauer beim Zusammentreiben seiner Rinder. Die kurze Inschrift Vibas Pontiana in aeterno ${ }^{489}$ in der Mitte der Tafel wird gerahmt von zwei biblischen Szenen: links Adam und Eva, wie sie gerade vom Baum der Erkenntnis essen, rechts der nackte Daniel, seinerseits umringt von zwei Löwen. Unterhalb der Inschrift sind noch ein kleiner springender Hund sowie ein Bauer mit seinem Ochsengespann zu sehen.

Nicht der Bilderwelt der Bibel entstammend, sondern der Symbolik der liturgischen Riten zuzuordnen, ist eine andere interessante Darstellung aus Aquileia. Es handelt sich um eine Grabinschrift mit der Eingangswidmung Innocenti sp(irit)o, deren Text mit der Darstellung einer Taufe illustriert wurde (Abb. 28, s. o. S. 137). ${ }^{490}$ Die Szene wird von zwei Bäumen an den Seiten und einer Reihe von Zweigen und Blumen am unteren Bildrand gerahmt, zwischen denen sich ein Lamm niedergelassen hat. Im Zentrum steht in einem runden Becken der nackte Täufling, ein Junge oder Mädchen im Kindesalter. Aus einem mit Sonne, Mondsichel und Sternen angedeuteten Himmelsgewölbe ergießt sich ein breiter Strahl Wasser über seinen Kopf in das Becken. Zur Rechten des Kinds steht ein Mann in Tunica und geschnürten Schuhen, der gerade die impositio manus vollführt, also das rituelle Handauflegen, mit dem der Täufling während der Zeremonie den Heiligen Geist empfängt und in die Gemeinschaft der Gläubigen aufgenommen wird. Zur Linken sieht man einen in ein Himation gekleideten Mann mit Nimbus, der das Kind mit der erhobenen Rechten gerade zu segnen oder zu salben scheint. Gleichsam als symbolische Bekräftigung des Ritus und als Sinnbild für den Empfang des Heiligen Geists fliegt eine Taube aus dem Himmelsgewölbe auf die Szene herab. Die Grabtafel ist in ihrer Art ohne Vergleich und ragt auch in qualitativer Hinsicht unter den meisten anderen Stücken aus Aquileia hervor. Interessant ist sie im Übrigen auch deshalb, weil sie den Namen des Verstorbenen verschweigt und seine Person offenbar lediglich in der bildlichen Darstellung des Täuflings sichtbar werden lässt. Mitten im Zentrum der Inschriftentafel platziert, beherrscht sein Bildnis

488 ICUR I 1723 = Ehler 2012, I.1.1. Die Herkunft des Stücks ist unbekannt. Es befindet sich heute in den Vatikanischen Museen, Inv. 32458.

489 Die Schreibweise und Ausformung der Buchstaben ist interessant: Das zweite N im Namen liegt auf der Seite.

490 IAq 3204 = Vergone 2007, 16. 
den visuellen Gesamteindruck des Stücks und lässt den um die Szene herumgruppierten Text beinahe wie Beiwerk erscheinen.

Das Bild in den Mittelpunkt zu rücken und vom Text gleichsam umfließen zu lassen, war indes nur eine von mehreren Möglichkeiten, Bild und Text auf dem Inschriftenfeld zu arrangieren und miteinander in Beziehung zu setzen. Daneben finden wir ebenso andere Formen des visuellen Miteinanders. Insbesondere bei den hochrechteckigen Tafeln aus Aquileia sind Beispiele häufig, bei denen Text und Bild übereinander angeordnet sind. So etwa im Fall der Grabtafel zweier in hohem Alter und eines als Kleinkind Verstorbenen mit der Inschrift in der oberen Hälfte und der Darstellungen der Verstorbenen oder ihrer Hinterbliebenen im Beisein von zwei Oranten vor einer arkadenähnlichen Architektur darunter. ${ }^{491}$ Bei den langrechteckigen Loculusplatten aus Rom hingegen wurden Bild und Text nicht selten nebeneinander platziert, gerne auch so, dass die Bildmotive die Inschrift zu beiden Seiten wie in einem Rahmen einfassten. Auf einer Platte in der Calixtus-Katakombe wurde dafür eine besonders elegante Lösung mit zwei sich gegenüberstehenden Vögeln gefunden. ${ }^{492}$ In ihren Schnäbeln halten sie eine Girlande, in deren Halbrund die griechische Namensaufschrift

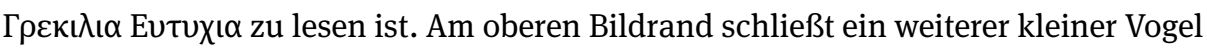
mit einem Zweig im Schnabel das Ensemble ab. Gelegentlich tauchen auf den römischen Loculusplatten auch Kränze als bildliche Rahmungen des Texts auf, wie bei der Grabinschrift der kleinen Victoria, bei der die komplette Inschrift mit einem recht stilisiert wirkenden Kranz mit einfachen gestrichelten Blättern eingefasst wird, derjenigen des kleinen Felix, bei welcher der Kranz von zwei Vögeln gehalten wird, oder bei derjenigen des Herculius, wo lediglich der letzte Teil mit der Angabe des Beisetzungsdatums in einen kleinen Kranz links neben dem in großen Lettern geschriebenen Namen steht, so als sei der Steinmetz aus Platzgründen dorthin ausgewichen. ${ }^{493}$

Wie kreativ man war, wenn es darum ging, die beiden Elemente Text und Bild visuell miteinander zu vereinigen, illustrieren abschließend drei Beispiele aus Rom: Um der kleinen Iuliana zu gedenken, ließen ihre Eltern eine große tabula ansata auf der Loculusplatte ihres Grabs anbringen, in deren Mitte die Darstellung eines großen Volutenkraters prangte. ${ }^{494}$ Der Text mit den Worten $m(e) m$ (oriae) a(ternae) $V$ kal(endas) Iun(ias) pater et mater Iulia nice dolens fecerunt wiederum wurde in die dreieckförmigen ansae einschrieben, jeweils eingeleitet durch ein Christogramm und auf der rechten Seite abgeschlossen durch die kleine Abbildung einer Traubenrispe. Eine andere Spielart zeigt eine Platte in den Vatikanischen Museen. ${ }^{495}$ Sie gehörte

491 IAq 2943. Ein ähnliches Beispiel liefert die Inschriftentafel des Largius, unter deren Text ein von einem Vogel und einem Lamm flankierter Orant zu sehen ist: IAq 3109.

492 ICUR IV 11036 mit Abbildung = Ehler 2012, V.5.10 mit Abbildung.

493 Ehler 2012, VII.1.37; VII.3.4; VII.1.24. S. hierzu auch die Studie zu Inschriften in Siegerkränzen auf delischen Stelen von P. A. Butz: Butz 2007.

494 Ehler 2012, VIII.1.42.

495 Ehler 2012, IX.1.3. 


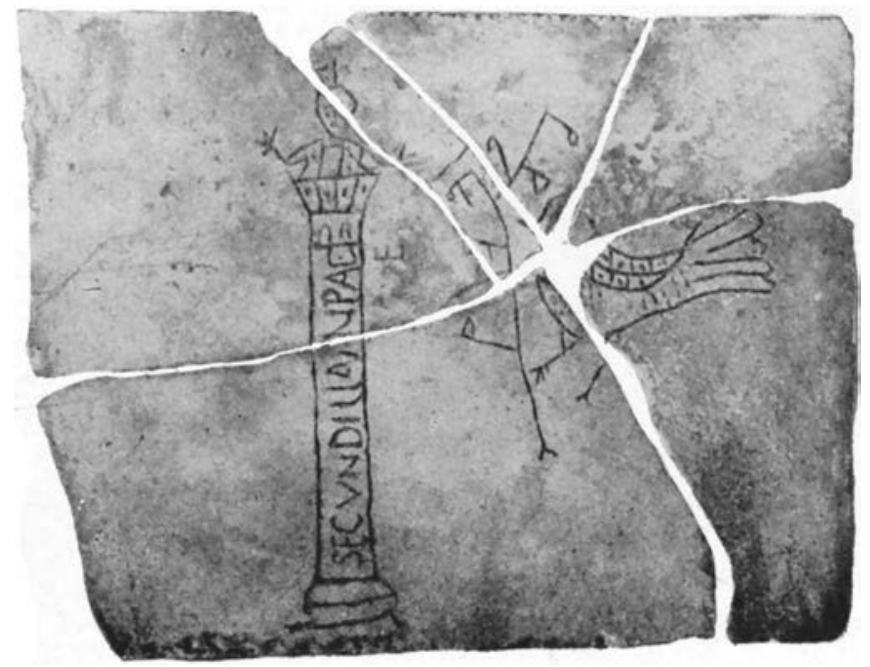

Abb.58: Loculusplatte vom Grab der Secundilla, Rom.

ursprünglich zum Grabmal des mit 18 Jahren verstorbenen Leopardus, der seinen Lebensunterhalt wohl als Friseur verdiente, wie es die Abbildungen eines Rasiermessers, eines Kamms, eines Spiegels und einer Schere rechts neben dem Text verraten. Als die Tafel ein weiteres Mal für einen gewissen Florentius in Anspruch genommen wurde, setzte man seinen Namen kurzerhand in das Rund des Spiegels und die Altersangabe auf den Griff des Kamms. Bei dem letzten Beispiel aus der DomitillaKatakombe sieht man rechts einen großen Vogel mit einem Zweig im Schnabel und daneben eine Stylitendarstellung: eine Säule, auf deren Kapitell sich das Brustbild eines Betenden mit Kreuz auf dem Kopf erhebt. Der Segenswunsch an die Grabherrin Secundilla wiederum ist auf eben dieser Säule von unten nach oben zu lesen: Secundilla in pace (Abb. 58). ${ }^{496}$

Ganz ähnlich wie es sich auch schon anhand des ungemein großen Formenschatzes der verschiedenen Schriftarten und Schriftbilder spätantiker Inschriften abzeichnete, war auch das breite Spektrum der verwendeten Bildmotive sowie der Variantenreichtum des visuellen Zusammenspiels von Texten und Bildern Symptom eines Wandlungsprozesses der Inschriftenkultur in der Spätantike, in dessen Zug Direktive, Prinzipien und allgemeingültige Standards verwässerten. Das Erscheinungsbild inschriftlicher Artefakte war nun weniger Ausdruck konventionalisierter Normen als vielmehr persönlicher Stile und eines individuellen ästhetischen Empfindens. 


\subsubsection{Text im Bild: Beispiele spätantiker Mosaikbilder aus frühchristlichen Kirchen Roms und Ravennas}

Wenn sich Bild und Text innerhalb einer größeren Komposition wie Mosaiken miteinander vereinten, so geschah dies auf unterschiedliche Weise und mit anderen Absichten als bei den Grabtafeln. Bei letzteren wurden Bild und Text in der Regel nacheinander gefertigt, die Anbringung des Bilds ging derjenigen der Inschrift oftmals voraus. Im Fall von Mosaiken wurden Bild und Text von vornherein als sich gegenseitig bedingende Elemente konzipiert und in ein und demselben Arbeitsschritt umgesetzt. Anders als bei den Grabtafeln, bei denen Bild und Text nicht notwendigerweise inhaltliche Bezüge zueinander aufweisen mussten, erstere auch schlichtweg als mehr oder minder beliebige Illustrationen für letztere gedient haben mochten, war das BildText-Verhältnis bei Mosaiken enger. Es war stärker von einem Miteinander statt von einem Nebeneinander geprägt. Inschriften in Mosaikbildern waren für sich alleine nicht vorstellbar und machten ohne die dazugehörige Abbildung keinen Sinn, denn in der Regel handelte es sich hierbei um benennende oder erklärende Beischriften der dargestellten Figuren oder um Texte, die ihrerseits wieder Abbildungen waren, wie in aufgeschlagenen Büchern oder Schriftrollen. Mireille Corbier hat sich eingehender mit der Kombination von Bild und Text innerhalb der römischen Inschriftenkultur beschäftigte und auf der Grundlage zahlreicher Zeugnisse aus der Relief-, Malund Mosaikkunst eine Typologie des intermedialen Zusammenspiels entworfen. ${ }^{497}$ Sie unterscheidet im Wesentlichen zwei Typen von Inschriftlichkeit im Zusammenhang mit Bildwerken. Bei dem ersten Typus, in ihren Worten: „l'èpigraphie au second degré“, ist die Inschrift Bestandteil der im Bild dargestellten Realität. Zu dieser Gruppe zählen etwa Bauinschriften an Gebäuden, Weihinschriften auf Altären, auf beweglichen Objekten wie Schilden, Tafeln und Vexilla angebrachte Aufschriften sowie handschriftliche Texte in Büchern, Kodizes, Rotuli oder Wachstafeln. Bei dem zweiten Typus ist die Inschrift keine Abbildung von Geschriebenem, sondern ein selbständiges Element der Gesamtkomposition, welches - nunmehr ohne einen konkreten Träger oder Untergrund zu haben - in das Bild einfügt wurde. Hierzu gehören Namensbeschriften, Bezeichnungen oder wörtliche Rede im Freiraum zwischen oder unmittelbar bei den betreffenden Figuren sowie erklärende Legenden im Randbereich.

Dass Schrift und Text im Zusammenhang mit Bildwerken sowohl konkreter Bestandteil des Bildinhalts wie auch abstrakter Informationsträger sein konnten, lässt sich auch in der Inschriftenkultur des spätantiken Italien, namentlich im Kontext des frühchristlichen Kirchenraums beobachten. Gemeint sind die Mosaikbilder der Apsiden, Triumphbögen und Wände, die mitunter eine ganze Vielzahl verschiedener Inschriften unterschiedlichen Charakters bargen. Ein besonders anschauliches Beispiel bietet das Mosaik des Triumphbogens in der Kirche S. Lorenzo fuori le mura in

497 Corbier 2006, 91-128; zuvor bereits veröffentlicht unter Corbier 1995. 
Rom. Der Bau geht auf eine Stiftung Papsts Pelagius II. (579-590) zurück, der die Basilika Ende des 6. Jhs. über der Grabstätte des Diakons und Märtyrers Laurentius an der Via Tiburtina errichten und in ihrem Inneren aufwendig ausstatten ließ. ${ }^{498}$ Das Mosaik zeigt Jesus Christus als Pantokrator auf einer Weltkugel sitzend, umgeben von Petrus und Paulus, den Heiligen Stephanus, Laurentius und Hippolytus sowie dem bischöflichen Stifter Pelagius mit einem Modell der Kirche in den Händen (Abb.9, s. o. S. 81).${ }^{499}$ Bis auf Christus in der Mitte sind alle Figuren durch Namensbeischriften benannt, die sich in großen Majuskeln direkt über oder neben ihren Köpfen abzeichnen. Die beiden Apostel und drei Märtyrer tragen außerdem das Epitheton $s(a n) c(t u) s$. Dem Namen des Pelagius folgt sein Titel episc(opus). Jedes einzelne Wort wird zu beiden Seiten von einem Punkt oder einem kleinen Efeublatt gerahmt, die Abkürzungen wurden durch Überstreichungen als solche gekennzeichnet. Aus dunklen tesserae zusammengesetzt, heben sich die einzelnen Buchstaben sehr deutlich von dem golden glänzenden Untergrund ab. In ihrer quadratischen Grundform, dem Spiel von breiten und schmalen Hasten und ihrem ornamentalem Duktus erinnern sie stark an die filocalischen Lettern und scheinen wie diese um eine besonders elegante Formgebung bemüht gewesen zu sein. In den Zwickeln des Bogens unterhalb der Szene sind ferner die Ansichten zweier Städte mit hohen geschmückten Stadtmauern und sich darauf erhebenden Häusern zu sehen. Dass es sich hierbei um die Geburts- und die Grabstätte Jesu handelt, verraten wiederum zwei weitere Inschriften, die ihrerseits auf dem dunklen Hintergrund der Stadttore mit hellen Buchstaben und in ähnlichem Schriftduktus wie die Namensbeischriften eingeschrieben wurden: Hierusalem und Bethleem. Neben diesen legendenartigen Benennungen der Städte und den Bezeichnungen der im Hauptfeld dargestellten Personen bietet das Mosaik noch zwei andere Inschriften. Bei diesen handelt es ich - wie Corbier sagen würde - um „Inschriften zweiten Grads“, da sie selbst konkreter Gegenstand des Bilds sind: zwei kurze Psalmzitate, welche Laurentius und Stephanus dem Betrachter in ihren geöffneten Büchern gleichsam zur Lektüre präsentieren. Diese waren wohl ausgewählt worden, weil sie auf eine Episode in der Vita des jeweiligen Heiligen verwiesen. Im Fall des Laurentius spielt die Wendung dispersit dedit pauperibus (Psalm 111,9) auf seine Wohltätigkeit gegenüber den Armen seiner Gemeinde als Diakon an. Im Fall des Stephanus sind dessen letzte Worte wiedergegeben, die er angesichts des nahenden Tods gen Himmel gerufen haben soll: adesit anima mea (Psalm 62). Ob Namensbeischriften, Betitelungen, Benennungen oder Schriftzitate - das Mosaik vom Triumphbogen in S. Lorenzo zeigt eine ganze Reihe verschiedener Texte im Bild auf, die ihrerseits wieder unterschiedliche Funktionen übernahmen. In ihrer Rolle als Beischriften gaben sie Personen zu erkennen, identifizierten diese als Heilige oder Amtsträger und benannten

$498 \mathrm{Zu}$ dem Bau s. Brandenburg 2004, 236-240.

499 DACL VIII 1931-1952. 
einzelne Bildmotive. In ihrer Rolle als Schriftzitate griffen sie das Bildthema wieder auf und schufen feine Sinnbezüge zu den dargestellten Figuren.

Während sich diese Sinnbezüge hier auf recht subtile Art und Weise Ausdruck verschafften, sprachen andere Beispiele solcher „Inschriften zweiten Grads“ eine deutlichere Sprache, indem sie das Bildthema direkt benannten. So zeigt etwa das Gewölbemosaik im Mausoleum von S. Constanza in Rom aus der zweiten Hälfte des 4. Jhs., wie der auf dem Paradiesberg stehende Christus im Beisein des Paulus Petrus eine große Schriftrolle mit den Worten Dominus legem dat überreicht (Abb.18, s. o. S. 86) ${ }^{500}$ Auch hier ist der Text als Abbildung von Schrift einerseits ikonographischer Bestandteil des Bilds. Er gibt dessen Thema andererseits aber auch einen konkreten Namen und betitelt die Darstellung als traditio leges, also als Gesetzesübergabe an Petrus, mit welcher dessen Einsetzung als erster Bischof von Rom symbolisiert wurde. ${ }^{501}$ Ähnlich verhält es sich mit dem Apsismosaik der Basilika S. Pudenziana aus dem beginnenden 5. Jh. mit der Darstellung Chrisi im Kreis der zwölf Apostel und der beiden Personifikationen der Juden- und der Heidenkirche. ${ }^{502}$ Auf einem Thron sitzend und in ein goldenes pallium gekleidet, erscheint Christus als lehrender didaskalos mit erhobener Rechten und einem großen Kodex in der Linken, der die Worte Dominus Conservator Ecclesiae Pudentianae preisgibt. Wie schon zuvor ist der ins Bild integrierte Text Element der abgebildeten Wirklichkeit und hatte die Aufgabe, diese mit konkreten Worten zu benennen. Dessen ungeachtet ,sprach“ er aber auch aus, was das Bild dem Betrachter ikonographisch verschlüsselt zu verstehen geben wollte: Das Christentum hat über den Glauben an die alten Götter und den römischen Staatskult gesiegt. Nicht länger Iuppiter Conservator, sondern Dominus Conservator sollte von nun an in Rom thronen und das Wort führen, so lautete wohl die Botschaft, die Bild und Text im intermedialen Zusammenspiel von verbaler und visueller Kommunikation vermittelten. ${ }^{503}$

Doch nicht immer lässt sich die Sinnhaftigkeit eines Texts im Bild so deutlich nachvollziehen wie im Fall von S. Pudenziana. Insbesondere wenn es um Namensbeischriften geht, erscheint ihre Existenz bzw. ihre konkrete Funktion auf den ersten

$500 \mathrm{Zu}$ dem Bau s. Brandenburg 2004, 69-86. Die heute auf der Schriftrolle zu lesende Inschrift Dominus pacem dat ist das Resultat einer fehlerhaften Restaurierung des 17. Jhs.; vgl. hierzu auch Kap. 2.2.7, S. 77f. mit Anm. 230.

501 Ein weiteres Beispiel dieser Art hält das frühchristliche Baptisterium in Neapel bereit. Auch hier zeigt das sehr frühe, bereits um 400 entstandene Mosaik des Gewölbes eine traditio-leges-Szene und wieder stehen auf der Schriftrolle die Worte Dominus legem dat geschrieben. Ein interessantes Detail: Unterhalb dieses in Majuskeln abgefassten Texts erscheint eine weitere ,Schrift‘, allerdings nicht Form tatsächlicher Buchstaben, sondern durch schwarze tesserae lediglich angedeutet; s. hierzu Poeschke 2009, 27 Abb. 24.

502 Zur Kirchenanlage s. Brandenburg 2004, 137-142; speziell zum Mosaik und dessen Deutung s. Schlatter 1992; ders. 1995; Wisskirchen 1998; Letsch-Brunner 2000.

503 Zur Bedeutung der Inschrift und speziell der Wendung Dominus Conservator als Hinweis auf das Ende des traditionellen römischen Staatskultes und auf die Dominanz des christlichen Glaubens s. Schlatter 1989. 
Blick rätselhaft. Denn sie tauchen gelegentlich auch bei solchen Figuren auf, die anhand ihrer spezifischen Ikonographie sehr einfach zu erkennen waren und einer identifizierenden Beischrift in dieser Hinsicht nicht bedurft hätten. So wären etwa um nunmehr ein Beispiel aus Ravenna anzuführen - die Namensbeischriften für den heiligen Vitalis und den Bischof Ecclesius in der Kirche S. Vitale nicht unbedingt notwendig, um die beiden im Gewölbe abgebildeten Figuren als den Stadtheiligen und bischöflichen Stifter des Baus zu erkennen. Das Mosaik zeigt in der Mitte den jugendlichen Christus auf der Weltenkugel sitzend, neben ihm zwei Engel, die ihm Vitalis auf der einen, Ecclesius auf der anderen Seite zuführen (Abb.10, s. o. S. 82). Für den spätantiken Betrachter, der mit solchen Bildthemen gut vertraut war, konnte kein Zweifel daran bestehen, dass die Figur am linken Bildrand niemand anderer als der Titelheilige Vitalis sein konnte: Der Nimbus über dem Kopf des Mannes und der Empfang der Märtyrerkrone aus den Händen Christi wiesen ihn unverkennbar als Sanctus aus, die militärisch anmutende Tracht mit Tunica und Chlamys unterstrichen seine Herkunft aus dem Soldatenstand. Die Figur am rechten Rand wiederum war als Mann der Kirche und ehrwürdiger Amtsträger auszumachen: ohne Nimbus, aber dafür in bischöflichem Ornat, mit der für Kleriker üblichen Tonsur und mit einem Modell der Kirche der Hand, war er eindeutig als Ecclesius zu erkennen, eben als derjenige, der den Bau in Auftrag gegeben hatte.

Kaum anders ergeht es dem Betrachter beim Blick auf Südwand des Presbyteriums, wo der bärtige Melchisedek beim Opfer von Brot und Wein und der jugendliche Abel beim Opfern eines Lamms zu sehen sind (Abb.59, s. o. S. 86). Wieder stehen ihre Namen in großen Buchstaben und gut lesbar oberhalb ihrer Köpfe geschrieben und wieder hätten sich die Figuren auch ohne die Beschriftungen identifizieren lassen. Die Reihe solcher Beispiele ließe sich noch leicht fortführen, zumal wenn wir auch etwas später entstandene Werke des 7.Jhs. in die Betrachtung miteinbeziehen. Auch im Baptisterium der Orthodoxen und den Basiliken Sant'Apollinare Nuovo und Sant'Apollinare in Classe in Ravenna, in der Eufrasius-Basilika in Parentium sowie den stadtrömischen Kirchen S. Agnese und S. Stefano Rotondo lassen sich Inschriften entdecken, die uns auf den ersten Blick entbehrlich erscheinen - jedenfalls wenn wir sie als der Identifizierung bestimmter Personen angedachte Beischriften lesen. Dass dies jedoch nicht ihre einzige (und womöglich nicht ihre erste) Bestimmung war, legt schon die Überlegung nahe, dass viele der zeitgenössischen Betrachter die Inschriften gar nicht haben lesen können, sei es, weil sie des Lesens nicht mächtig waren oder weil die Texte angesichts ihrer Anbringung in großen Höhen gar nicht erst zu entziffern waren. Es musste hier also weniger um die tatsächliche Präsenz als viel mehr um die potentielle Präsenz der Inschriften bzw. deren Lesbarkeit sowie um die Emphatisierung der Szene gegangen sein. Ob vom Kirchenbesucher wahrgenommen oder nicht erst mit der Anbringung der jeweiligen Namensinschrift, erst wenn die Figur eindeutig benannt wurde und sie sich dem Betrachter in Bild und Wort vergegenwärtige, wurde die Abbildung als vollständig und authentisch empfunden. 


\subsubsection{Text als Bild: Zum ikonischen Potential von Inschriften}

Bevor Texte gelesen werden, werden sie gesehen. Das gilt auch für Inschriften, umso mehr, weil diese nicht bloß Texte, sondern immer auch Monumente waren und als solche über eine besonders stark ausgeprägte Visualität verfügten. Zumal wenn Inschriften eine außergewöhnliche Gestaltung erfahren hatten, zum Beispiel durch die Wahl einer bestimmten Schrifttype, die Verwendung eines ausgefallenen Materials oder eine auffällige Farbgebung, ging von ihnen eine Wirkung aus, die derjenigen von Bildern durchaus vergleichbar war. Nicht nur wie Texte zum Lesen, sondern auch wie Bilder zum Sehen gedacht, konnten Inschriften ebenfalls Funktionen jenseits des Informierens, Kommemorierens und Repräsentierens übernehmen. Ausgestattet mit einem ikonischen Potential, vermochten sie auch zu dekorieren, zu ornamentieren und zu ästhetisieren.

Es ist dies zwar kein alleiniges Merkmal spätantiker Inschriften und lässt sich auch in anderen Perioden beobachten. Doch scheint die Inschriftenkultur der Spätantike offenbar besonders günstige Rahmenbedingungen dafür geschaffen $\mathrm{zu}$ haben, Inschriften nicht nur mit Bildern zu kombinieren, sondern sie auch zu einem Bild selbst werden zu lassen. Einmal mehr bildet der christliche Glaube den kulturellen und der christliche Kultbau den räumlichen Hintergrund solcher ,ikonischer Inschriften'. Denn insbesondere hier wurde intensiv mit verschiedenen Materialen, Techniken und Farben gespielt und natürliche und künstliche Lichteffekte gezielt genutzt, um den Blick des Betrachters zu gewinnen und in bestimmte Richtungen zu lenken. Vor allem im Kontext des Kirchenraums versuchte man, Inschriften die Wesenszüge von Bildern zu eigen zu machen und sie in ihrer äußeren Gestaltung der Form eines Dekors oder Ornaments anzunähern. Auf diese Weise sollten sie die gleiche Effektivität und Wirkung wie Bilder entfalten. Sucht man nach Zeugnissen dieser Art, so wird man im Wesentlichen in dreierlei Hinsicht fündig: zuerst bei den Monogrammen, bei denen einzelne Buchstaben zu einem zeichenhaften Emblem verschmelzen. Ferner bei den musivischen Stifterinschriften der Fußböden, welche durch ihre auffällige Gestaltung und visuelle Einbettung in originelle Dekorprogramme selbst wie Ornamente anmuten. Und schließlich bei den monumentalen Bau- und Weihinschriften in den Apsiden und Stirnwänden, denen man einen ikonischen Charakter ebenso wenig absprechen kann, waren sie doch angesichts ihrer kunstvollen Ausführung sowie des optischen Zusammenspiels mit den sie umgebenden Bildwerken für das menschliche Auge kaum weniger ansprechend und anziehend als diese selbst.

Was die bildhafte Wirkung von Monogrammen angeht, so entsteht diese dadurch, dass sie nicht linear wie Texte gelesen werden können, sondern in ihrer Form einem einzigen, zuweilen recht komplexen Zeichen gleichen. Unter Auflösung ihrer eigentlichen Reihenfolge werden die einzelnen Buchtstaben eines Worts - zumeist eines Namens - ineinander gestellt oder durch Ligaturen, Involutionen und Superpositio- 
nen miteinander verwoben, sodass ein aus Majuskeln geformtes Emblem entsteht. ${ }^{504}$ Als ein solches verbietet es das Monogramm dem Betrachter, diskursiv wie ein niedergeschriebenes Wort wahrgenommen zu werden, zumal der Anfangsbuchstabe in der Regel nicht besonders hervorgehoben wird und mehrfach vorkommende Buchstaben nur einmal abgebildet werden. So sieht man beim ersten Blick auf ein Monogramm nicht tatsächlich ein Wort, sondern ein aus unterschiedlich großen, mitunter ungewöhnlich positionierten und miteinander verschmolzenen Buchstaben geformtes Ge,bild'e, dessen Aussprache zunächst ebenso rätselhaft bleibt wie seine Bedeutung. Erst wenn es dem Betrachter gelingt, die einzelnen Buchstaben voneinander $\mathrm{zu}$ lösen und in der richtigen Abfolge anzuordnen, lässt sich das Monogramm entziffern und als Wort lesen und verstehen. In der Spätantike waren Monogramme als ausdrucksstarke Repräsentationsmedien vor allem unter Herrschern und Bischöfen beliebt, die sich mitunter äußerst kunstvolle Kreationen erschaffen und diese an von ihnen errichteten Bauwerken anbringen ließen. Die berühmtesten Beispiele dieser Art sind die Monogramme des Kaiserpaares Justinian und Theodora in der Hagia Sofia in Konstantinopel, welche die Kapitelle im Inneren des ehemals als Kirche errichteten Baus zieren. ${ }^{505}$ Ein besonders anschauliches Beispiel aus unserem Untersuchungsgebiet überliefert die Basilika S. Clemente in Rom, wo Papst Johannes II. (533-553) sein Monogramm auf einer der von ihm gestifteten Chorschranken setzen ließ (Abb.19, s. o. S. 88) ${ }^{506}$ Rechts und links daneben sind außerdem zwei große Kreuze und darunter je eine stilisierte Efeuranke zu sehen. Ein kreisrunder Rahmen umfasst das Monogramm und verstärkt dessen bildhaften Charakter so noch einmal zusätzlich.

Mehr wie dekoratives Ornament als wie tatsächliche Schriftzeichen wirken auch die Monogramme des Bischofs Eufrasius in der nach ihm benannten Basilika in Parentium aus dem 6. Jh. (Abb. 60a-c) ${ }^{507}$ Auch sie sitzen in einer runden Rahmung, prangen hier aber an den Innenseiten der Kämpfer im Mittelschiff. Im optischen Zusammenspiel mit der künstlerischen Ausgestaltung der Kapitelle (darunter gerahmte Kämpfer-, Komposit- und sog. Adlerkapitelle byzantinischen Stils) scheinen die Monogramme in der Einheitlichkeit ihres visuellen Eindrucks und ihrer motivartigen Silhouette selbst ornamentales Element des Dekors zu sein.

Während das Monogramm des Johannes II. als Hochrelief aus dem Marmor der Schrankenplatten herausgearbeitet und die Monogramme des Eufrasius mit feinen Linien in die Kämpferblöcke eingraviert wurden, hat Bischof Elias von Grado (571-587) eine andere materiale Spielart gewählt. Er ließ sein Monogramm in den Mosaikboden der von ihm erbauten Basilika Sant'Eufemia legen. Dort erschien es (wahrscheinlich) gleich drei Mal: in einem kleinen Nebenraum der Apsis (Taf.21 Abb. 141) im Salutatorium (Taf. 20 Abb. 140) sowie mit großer Wahrscheinlichkeit noch einmal im zu großen

$504 \mathrm{Zu}$ Monogrammen s. o. Kap.2.2.8.

505 S. hierzu demnächst Stroth (in Vorbereitung).

506 Brandenburg 2004, 147; s. hierzu auch o. Kap. 2.2.8.

507 Russo 1991; Terry/Maguire 2007. 

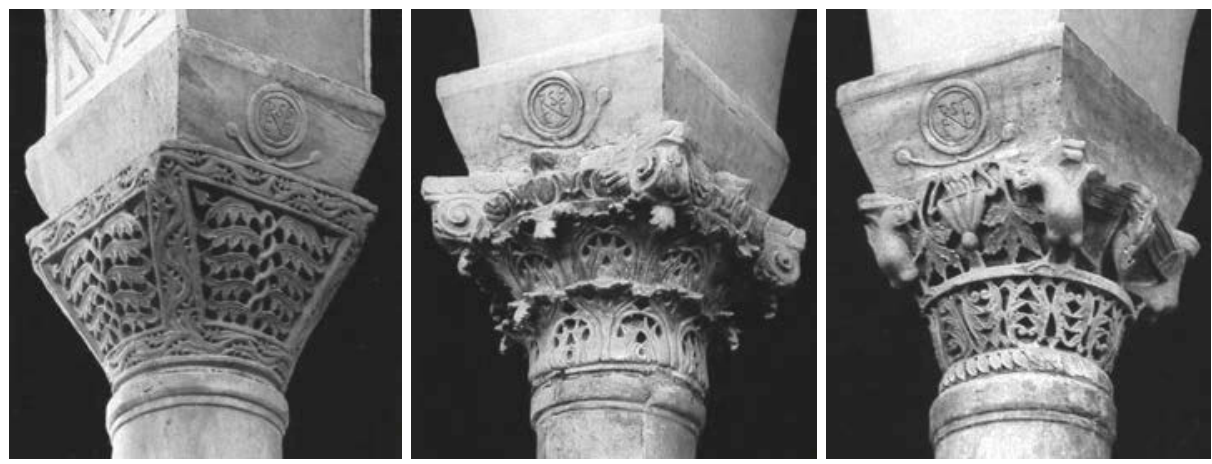

Abb.60a-c: Kapitelle der Säulenstellung im Naos der sog. Eufrasius-Basilika (,Basilika Eufrasiana') in Poreč, an den Kämpfern jeweils das Monogramm des Bischofs Eufrasius in einem Medaillon.

Teilen verlorenen Bereich des Mittelgangs, zusammen mit einer Stifterinschrift des Bischofs (Taf.17 Abb.131). ${ }^{508}$ Das heute noch vollständig erhaltene Monogramm des Apsisraums sitzt inmitten eines Mosaikteppichs aus quadratischen und runden Zierfeldern mit geometrischen Motiven. Gerahmt von einem großen Kreis und in schwarzen tesserae ausgeführt, hebt es sich deutlich von seiner Umgebung ab, fügt sich angesichts seiner emblematischen Gestalt aber harmonisch in das dekorative Schema aus gerahmten Schmuckmotiven ein und erweist sich mithin wie diese von bildhaftem Charakter. In seiner Farbgebung vielfältiger als das in Beige- und Rottönen gehaltene Mosaik des kleinen Apsisraums, präsentiert sich das Monogramm im Salutatorium. Es beherrscht das Zentrum eines aus einem raffinierten Schlingband geformten Ensembles mehrerer Kreise, die in sechs Fällen als Rahmungen für Stifterinschriften dienen, zwei Mal einen Flechtknoten und ein weiteres Mal das Bild eines von Ranken umspielten Vogels zeigen. Aus der Mitte sticht vor blauem Hintergrund das golden glänzende Monogramm des Elias hervor. Seine Bildhaftigkeit wird nicht zuletzt durch diese auffällige Farbgebung in Gold und Blau intensiviert - zwei Farben, die auf der einen Seite einen deutlichen Kontrast zu der Schrift der übrigen, in schwarz gehaltenen Inschriften bilden, auf der anderen Seite in den bildlichen Motiven der Flechtknoten und des kleinen Vogels wieder aufgegriffen wurden. In seiner spezifischen Form und Farbe stand also auch dieses Monogramm einem Bild näher als einem Text und wurde vom Betrachter wohl eher wie ein Emblem gesehen denn als Schrift gelesen.

Das Mosaik des Salutatoriums legt auch in anderer Hinsicht ein eindrückliches Zeugnis ikonischer Inschriftlichkeit ab. Dabei spielt allerdings nicht das Monogramm im Zentrum die Hauptrolle, sondern die dieses in einem breiten Band umlaufende

508 Carlini 1980; Trovabene 2010. Das betreffende Mosaik des Mittelgangs ist an dieser Stelle stark zerstört. Insbesondere mit dem Vergleich des ähnlich gestalteten Mosaikfelds im Salutatorium, wo das Kreisrund in der Mitte ebenfalls das Monogramm des Elias zeigt, ist es sehr wahrscheinlich, dass ein solches auch auf dem Mittelgang zu sehen war. 
Stifterinschrift des Elias mit den Worten Servus Ie(s)u Chr(ist)i Helias ep(i)s(copus) $s\left(\right.$ an) $c(t)$ ae Aquil(eiensis) eccl(esiae) tibi serviens fec(it). ${ }^{509}$ Anders als bei dem Monogramm, bei dem das Bildhafte von der Konzentration aller beteiligten Buchstaben in einem einzigen Zeichen herrührt, äußert sich die Ikonizität dieser Inschrift in ihrer ornamentalen, beinahe dekorativen Erscheinung. In das Kreisband eintragen, wirken die eng aneinander gereihten Buchstaben in ihrem Gesamtbild wie ein ornamental gestalteter Zierstreifen, zumal es dem Betrachter auf den ersten Blick nicht leicht fällt, die einzelnen Wörter in dem Rund auszumachen und sie als Text zu lesen. Ähnlich verhält es sich mit der Mosaikkomposition im Mittelschiff, bei der das Monogramm des Elias zwar verloren ging, die ebenfalls ringförmig angeordnete Inschrift Servus Ie(s)u Christi Helias ep(iscopu)s Aquil(eiensis) dei gratia auxilioque fundator eccl(esiae) s(an)c(t)ae Eufemiae votum solvit aber wenigstens in Teilen erhalten geblieben ist. ${ }^{510}$ Sie steht hier im äußeren von insgesamt drei Kreisbändern eingeschrieben und erweckt - nicht zuletzt aufgrund der ähnlichen Farbgestaltung wie das anschließende Rankenmotiv des mittleren Bands - den Eindruck, das Ensemble als Ornament abschließen zu wollen.

Zuletzt seien noch die großformatigen Mosaikinschriften an den Kirchenwänden und Apsiden angesprochen, die bereits aufgrund ihrer Monumentalität und ihrer aufwendigen Gestaltung mit goldglänzenden tesserae auffallen. Ohne sich sogleich dem Text und seinem Inhalt zu widmen, konnte man den Anblick zunächst auf sich wirken lassen. Die imposante Inschrift der Basilika S. Sabina in Rom mit ihren goldenen, an die ornamentalen Zierbuchstaben des Filocalus erinnernden Buchstaben, dem tiefblauen Hintergrund und den beiden Figurendarstellungen an ihren Seiten vermag diesen Eindruck vielleicht am besten wiederzugeben (Abb. 16, 17, s. o. S. 85). ${ }^{511}$ Nicht anders als es den figürlichen Bildwerken zu eigen war, trugen auch Inschriften dieser Art zur dekorativen Ausstattung von Kirchenanlagen bei und übernahmen als solche nicht nur die Aufgabe, die Errichtung oder die Weihung eines Baus in Worten festzuhalten und die Nachwelt an den jeweiligen Stifter zu erinnern. In ihrer Rolle als visuell absichtsvoll gestaltete Kunstschöpfungen von ästhetischem Wert waren sie immer auch Bildwerke und als solche dazu bestimmt, den sie umgebenden Raum optisch aufzuwerten.

509 IAq 3365.

510 IAq 3338.

511 Zu dem Bau s. Brandenburg 2004, 167-176; Inschrift: CLE 312 = ILCV 1778a. 
